Uma abordagem distribuída e bio-inspirada para mapeamento de ambientes internos utilizando múltiplos robôs móveis 



\title{
Uma abordagem distribuída e bio-inspirada para mapeamento de ambientes internos utilizando múltiplos robôs móveis
}

\author{
Janderson Rodrigo de Oliveira
}

Orientadora: Profa. Dra. Roseli Aparecida Francelin Romero

Tese apresentada ao Instituto de Ciências Matemáticas e de Computação - ICMC-USP, como parte dos requisitos para obtenção do título de Doutor em Ciências - Ciências de Computação e Matemática Computacional. VERSÃO REVISADA.

USP - São Carlos

Abril de 2014 
Ficha catalográfica elaborada pela Biblioteca Prof. Achille Bassi e Seção Técnica de Informática, ICMC/USP, com dados fornecidos pelo(a) autor(a)

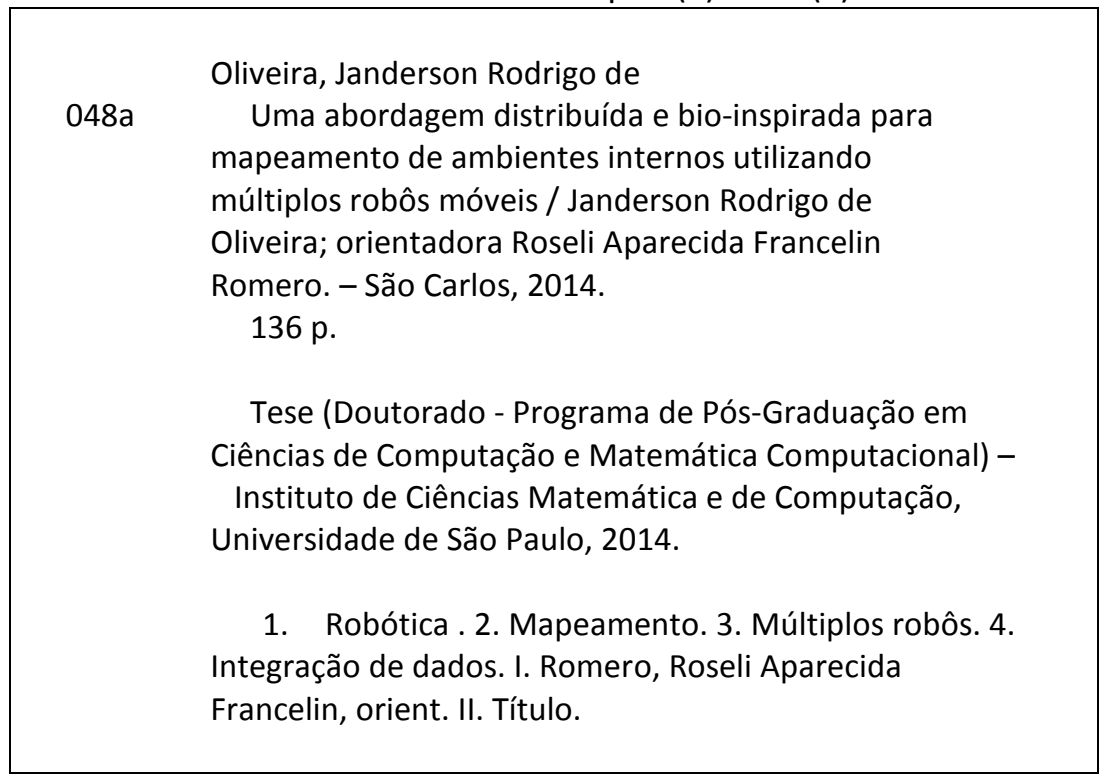


À Universidade de São Paulo, pela oportunidade de realização do curso de doutorado.

Ao Conselho Nacional de Desenvolvimento Científico e Tecnológico, à Coordenação de Aperfeiçoamento de Pessoal de Nível Superior e à Fundação de Amparo à Pesquisa do Estado de São Paulo, pelo apoio financeiro para a realização desta pesquisa. Número do processo FAPESP: 2010/07955-8.

Ao Instituto de Ciências Matemáticas e de Computação, por colocar à disposição o Laboratório de Aprendizado de Robôs.

À Prof ${ }^{\mathrm{a}}$. Dr ${ }^{\mathrm{a}}$. Roseli Aparecida Francelin Romero, pela orientação ao longo desse projeto de doutorado.

À minha família e amigos, pelo apoio sempre presente. 



\section{OLIVEIRA, J. R. Uma abordagem distribuída e bio-inspirada para mapeamento de} ambientes internos utilizando múltiplos robôs móveis. 2014. 136 f. Tese de Doutorado Instituto de Ciências Matemáticas e de Computação, Universidade de São Paulo, São Carlos, 2014.

As estratégias de mapeamento utilizando múltiplos robôs móveis possuem uma série de vantagens quando comparadas àquelas estratégias baseadas em um único robô. As principais vantagens que podem ser elucidadas são: flexibilidade, ganho de informação e redução do tempo de construção do mapa do ambiente. No presente trabalho, um método de integração de mapas locais é proposto baseado em observações inter-robôs, considerando uma nova abordagem para a exploração do ambiente. Tal abordagem é conhecida como Sistema de Vigilância baseado na Modificação do Sistema Colônias de Formigas, ou IAS-SS. A estratégia IAS-SS é inspirada em mecanismos biológicos que definem a organização social de sistemas de enxames. Especificamente, esta estratégia é baseada em uma modificação do tradicional algoritmo de otimização por colônias de formiga. A principal contribuição do presente trabalho é a adaptação de um modelo de compartilhamento de informações utilizado em redes de sensores móveis, adaptando o mesmo para tarefas de mapeamento. Outra importante contribuição é a colaboração entre o método proposto de integração de mapas e a estratégia de coordenação de múltiplos robôs baseada na teoria de colônias de formigas. Tal colaboração permite o desenvolvimento de uma abordagem de exploração que emprega um mecanismo não físico para depósito e detecção de feromônios em ambientes reais por meio da elaboração do conceito de feromônios virtuais integrados. Resultados obtidos em simulação demonstram que o método de integração de mapas é eficiente, de modo que os ensaios experimentais foram realizados considerando-se um número variável de robôs móveis durante o processo de exploração de ambientes internos com diferentes formas e estruturas. Os resultados obtidos com os diversos experimentos realizados confirmam que o processo de integração é efetivo e adequado para executar o mapeamento do ambiente durante tarefas de exploração e vigilância do mesmo.

Palavras-chave: Múltiplos robôs, integração de mapas locais, sistema de colônias de formigas. 



\section{OLIVEIRA, J. R. A distributed and bioinspired approach for mapping of indoor} environments using multiple mobile robots. 2014. 136 s. PhD Thesis - Instituto de Ciências Matemáticas e de Computação, Universidade de São Paulo, São Carlos, 2014.

The multiple robot map building strategies have several advantages when compared to strategies based on a single robot, in terms of flexibility, gain of information and reduction of map building time. In this work, a local map integration method is proposed based on the inter-robot observations, considering a recent approach for the environment exploration. This approach is based on the Inverse Ant System-Based Surveillance System strategy, called IASSS. The IAS-SS strategy is inspired on biological mechanisms that define the social organization of swarm systems. Specifically, it is based on a modified version of the known ant colony algorithm. The main contribution of this work is the fit of an information sharing model used in an mobile sensor network, adapting the method for mapping tasks. Another important contribution is the collaboration between the local map integration method and the multiple robot coordination strategy based on ant colony theory. Through this collaboration it is possible to develop an approach that uses a mechanism for controlling the access to pheromones in real environments. Such mechanism is based on the integrated virtual pheromones concept. Simulation results show that the map integration method is efficient, the trials are performed considering a variable number of robots and environments with different structures. Results obtained from several experiments confirm that the integration process is effective and suitable to execute mapping during the exploration task.

Keywords: Multiple robot, local map integration, ant colony system. 

Figura 1.1 Exemplo de integração: (a) Mapa gerado pelo robô $R_{l}$; (b) Mapa gerado pelo robô $R_{2}$; (c) Integração dos mapas de $R_{l}$ e $R_{2}$

Figura 2.1 Exemplo de estratégias de mapeamento: (a) Ambiente não mapeado; (b) Mapeamento métrico; (c) Mapeamento topológico

Figura 2.2 Grade de ocupação discretizada

Figura 2.3 Conceito de esqueletização de imagens: (a) Imagem original; (b) Imagem resultante... 39

Figura 2.4 Conjunto de nove células

Figura 2.5 Exemplo do método de esqueletização: (a) Estado de $C_{l}$ não alterado; (b) Estado de $C_{l}$ alterado

Figura 2.6 Linhas topológicas: (a) Baseadas em GVG; (b) Baseadas em esqueletização de imagens

Figura 2.7 Atualização incremental do mapa topológico

Figura 3.1 Sistemas de coordenadas locais

Figura 4.1 Grade de inferência.

Figura 4.2 Parâmetros do método de integração

Figura 4.3 Exemplo do método de integração

Figura 4.4 Dados para a integração.

Figura 4.5 Rastreamento do ponto $P^{*}$.......

Figura 4.6 Diagrama de blocos do IAS-SS...

Figura 4.7 Modelo sensorial do robô.

Figura 4.8 Nível hierárquico dos robôs em formação................................................................ 80

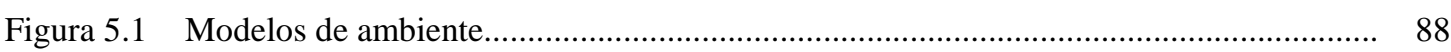

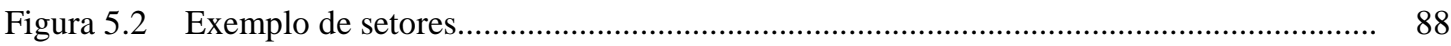

Figura 5.3 Exemplo de mapeamento: (a), (b), (c) Mapas métricos locais dos robôs $R_{1}, R_{2}$ e $R_{3}$, respectivamente; (d), (e) e (f) Mapas métricos integrados dos robôs $R_{l}, R_{2}$ e $R_{3}$, respectivamente.

Figura 5.4 Trajetórias de exploração: (a) $R_{1}$; (b) $R_{2}$; (c) $R_{3}$

Figura 5.5 Desempenho do mapeamento variando o método de ajuste de direção: (a) AEE; (b) AE; (c) UNI. 
Figura 5.6 Mapa de um robô: (a) Sem integração; (b) Com integração.

Figura 5.7 Gráficos de exploração variando-se a quantidade de robôs empregados no método AEE. Na coluna da esquerda, têm-se os gráficos sem a utilização da integração de mapas. Na coluna da direita, os gráficos correspondentes com a integração de mapas..

Figura 5.8 Gráficos de exploração variando-se o método de mapeamento no ambiente $A M B_{C}$ : (a) Grade de Ocupação com integração de mapas; (b) Thinning.

Figura 5.9 Mapeamento do ambiente $A M B_{C}$. Mapas métricos com integração de dados: (a) $R_{l}$; (b) $R_{2}$; (c) $R_{3}$; Mapas topológicos: (d) $R_{1}$; (e) $R_{2}$; (f) $R$

Figura 5.10 Gráficos de exploração variando-se o método de mapeamento no ambiente $A M B_{D}$ : (a) Grade de Ocupação com integração de mapas; (b) Thinning.

Figura 5.11 Mapeamento do ambiente $A M B_{D}$. Mapas métricos com integração de dados: (a) $R_{l}$; (b) $R_{2}$; (c) $R_{3}$; Mapas topológicos: (d) $R_{1}$; (e) $R_{2}$; (f) $R_{3}$ 
Tabela 5.1 Média e desvio padrão do desempenho do método de mapeamento variando o raio de comunicação.

Tabela 5.2 Média e desvio padrão dos métodos de ajuste de direção

Tabela 5.3 Comparação dos métodos de ajuste de direção.

Tabela 5.4 Desempenho do método de mapeamento variando a quantidade de robôs AEE.

Tabela 5.5 Desempenho do método de mapeamento variando a quantidade de robôs AE.

Tabela 5.6 Desempenho do método de mapeamento variando a quantidade de robôs UNI.

Tabela 5.7 Desempenho do método de mapeamento sem integração variando a quantidade de robôs - AEE.

Tabela 5.8 Desempenho do método de mapeamento sem integração variando a quantidade de robôs - AE.

Tabela 5.9 Desempenho do método de mapeamento sem integração variando a quantidade de robôs - UNI.

Tabela 5.10 Comparação do método de mapeamento com e sem integração de mapas AEE.

Tabela 5.11 Comparação do método de mapeamento com e sem integração de mapas UNI.

Tabela 5.12 Desempenho do método de mapeamento com integração variando a dimensão do ambiente - AEE

Tabela 5.13 Desempenho do método de mapeamento sem integração variando a dimensão do ambiente - AEE.

Tabela 5.14 Comparação entre métodos de mapeamento - Grade de Ocupação com integração de mapas e mapas topológicos Thinning.

Tabela 5.15 Desempenho do método de mapeamento empregando feromônios virtuais integrados - AEE.

Tabela 5.16 Desempenho do método de mapeamento com a integração de mapas desativada - AEE

Tabela 5.17 Comparação do método de mapeamento com e sem integração de mapas Feromônios virtuais. 
Tabela 5.18 Comparação do método de mapeamento - Mapa global de feromônio versus Feromônios virtuais integrados...

Tabela 5.19 Desempenho do método de mapeamento variando-se o parâmetro $i t_{\text {intervalo } . . .}$

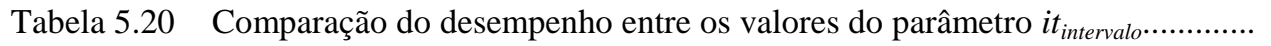

Tabela 5.21 Média e desvio padrão do método de mapeamento com formação...... 
ICMC: Instituto de Ciências Matemáticas e de Computação

USP: Universidade de São Paulo

SLAM: Simultaneous Localization and Mapping

GPS: Global Positioning System

IAS-SS: Inverse Ant System-Based Surveillance System

OG: Occupancy Grid

OCC: Sigla usada para denotar o estado ocupado de uma célula de uma grade de ocupação

EMP: Sigla usada para denotar o estado livre de uma célula de uma grade de ocupação

UNK: Sigla usada para denotar o estado desconhecido de uma célula de uma grade de ocupação

MAP: Maximum a posteriori

MRF: Markov Random Field

GVG: Grafos de Voronoi Generalizados

EKF: Extended Kalman Filter

C-SAM: Collaborative Smoothing and Mapping

PSO: Particle Swarm Optimization

AE: Amostragem Estocástica

AEE: Amostragem Estocástica Elitista

SAFS: Self-Adaptive Formation System

UNI: Sigla usada para denotar a estratégia uniforme de exploração 

1 INTRODUÇÃO.

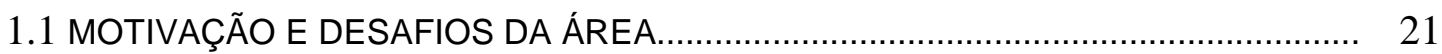

1.2 OBJETIVOS E DESCRIÇÃO PRELIMINAR DA PROPOSTA.................................. 23

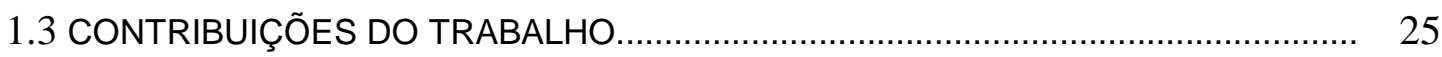

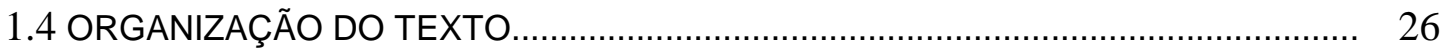

2 MAPEAMENTO DE AMBIENTES .................................................... 29

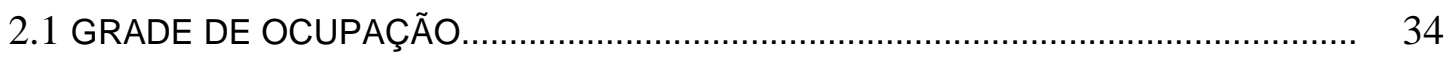

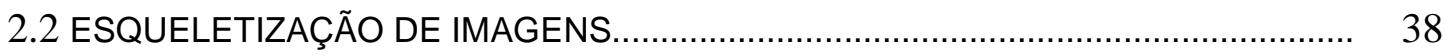

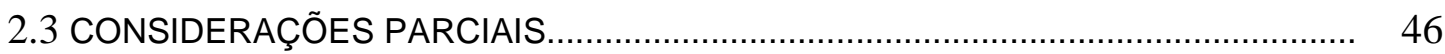

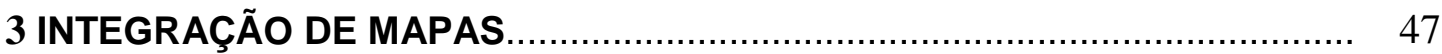

3.1 MÉTODO DE COMPARTILHAMENTO DE INFORMAÇÃO...................................... 52

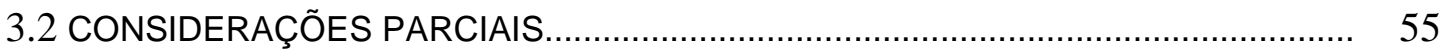

4 MÉTODO PROPOSTO

4.1 MÉTODO DE INTEGRAÇÃO DE MAPAS........................................................... 59

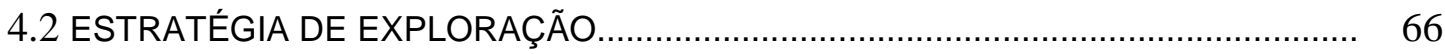

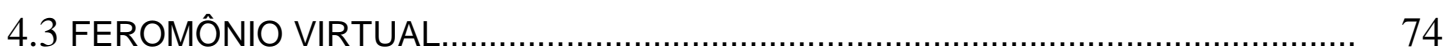

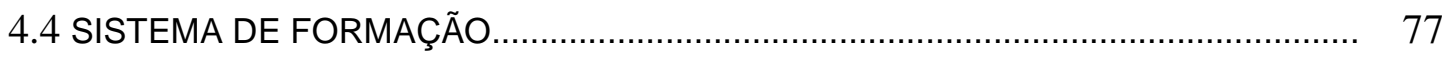

4.5 CONSIDERAÇÕES PARCIAIS ....................................................................... 82 
5 RESULTADOS EXPERIMENTAIS ....................................................... 85

5.1 CONFIGURAÇÃO DOS EXPERIMENTOS......................................................... 86

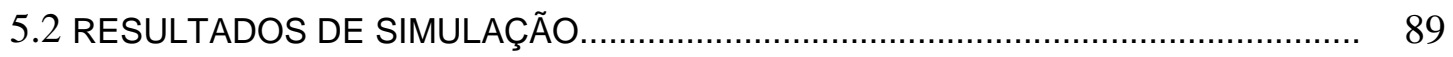

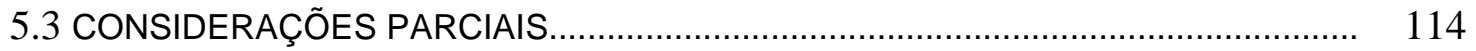

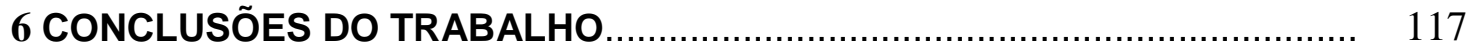

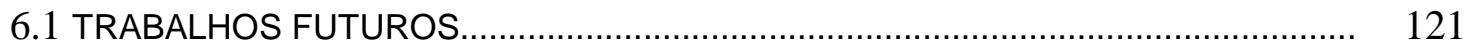

REFERÊNCIAS BIBLIOGRÁFICAS ............................................... 125 
CAPITULO

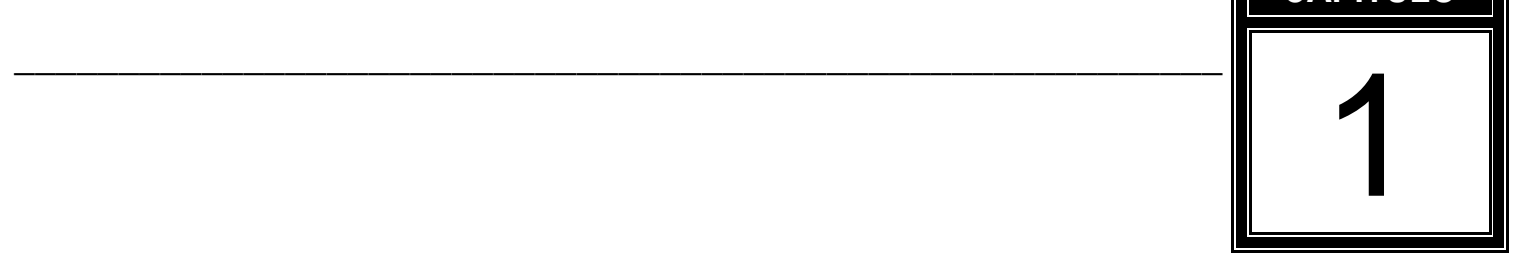

INTRODUÇÃO

O mapeamento robótico retrata o problema da aquisição de uma representação espacial do ambiente físico por meio de robôs móveis. Tais representações espaciais, denominados neste trabalho como mapas, são usualmente empregadas como suporte a tarefas de navegação, como por exemplo, o planejamento de trajetórias. A navegação autônoma de robôs móveis consiste no desenvolvimento de mecanismos de tomada de decisão para um ou mais robôs em um ambiente arbitrário, no qual os mesmos devem realizar tarefas autonomamente, enquanto se locomovem pelo mesmo. O problema de mapeamento é comumente considerado como um dos mais importantes problemas na busca por uma solução para se construir um robô móvel verdadeiramente autônomo.

Smithers (SMITHERS, 1997) apresenta uma definição abrangente para o termo autonomia, quando aplicado a um sistema de controle artificial. De acordo com esta definição, autonomia se refere não apenas à capacidade de ação e decisão independente de influências externa, mas sobretudo à capacidade de autoprodução dos mecanismos que geram a ação. Um sistema autônomo deve ser capaz de sintetizar suas próprias leis de ação sobre o meio em que se encontra.

É importante salientar que diversas abordagens de sistemas de navegação consideram o ambiente totalmente conhecido, tanto em relação à sua topologia quanto aos eventos cabíveis de ocorrer, ou seja, o sistema tem o conhecimento do mapa do ambiente e todos os possíveis eventos pertencem a um número finito de classes conhecidas. Neste caso, o sistema de navegação pode ser programado com antecedência e com poucos parâmetros adaptáveis. Em contrapartida, há grandes expectativas para aplicações de robótica em que o ambiente seja 
totalmente desconhecido, tornando a autonomia uma característica essencial para sistemas de controle e em particular para sistemas de navegação.

Deve-se observar que uma característica relevante em sistemas robóticos de navegação autônoma é a natureza do ambiente, que pode ser categorizada em duas vertentes: ambientes internos e externos, também referenciados neste trabalho como ambientes indoor e outdoor, respectivamente. Cobano et al. (COBANO et al., 2008) afirmam que diferentes tipos de informação são necessários para cada ambiente. Para uma estimativa de localização indoor, é possível criar mapas utilizando-se apenas informações provenientes da percepção direta do ambiente, por exemplo, por meio de sonares e sensores do tipo laser. Por outro lado, em uma estimativa outdoor, usualmente não é possível mapear o ambiente apenas com tais sensores, sendo necessário o emprego de dispositivos que ofereçam dados mais abrangentes acerca do ambiente, como por exemplo, a utilização de um GPS.

Para se construir um mapa de um determinado ambiente, os robôs utilizam sensores capazes de captar informações do ambiente no qual os mesmos estão inseridos, como sonares, câmeras, lasers, radares, bússolas e sensores táteis. Uma vez que os sensores possuem uma limitação natural em seus alcances, os robôs são compelidos a se locomoverem pelo ambiente a fim de obterem um mapa mais representativo.

Os controles de movimento emitidos durante a exploração do ambiente carregam uma informação importante para a construção do mapa, uma vez que transmitem informações sobre os locais nos quais as diferentes medidas sensoriais foram realizadas. Como consequência direta, mapas são construídos de modo incremental, incorporando informações recentes, adquiridas pelos sensores do robô, ao mapa produzido até então.

Segundo Amigoni et al. (AMIGONI et al., 2006) os mapas podem ser representados por meio de duas formas distintas: topologicamente, usualmente realizado por meio de estruturas de dados baseadas em grafos, ou geometricamente, comumente descrito por meio de estruturas de dados baseadas em grades de armazenamento. Os mapas baseados em grades exigem representações com altas dimensionalidades, capazes de armazenar milhares de dados, enquanto que os mapas baseados em grafos possuem, reconhecidamente, dimensionalidades significativamente menores. Analisando os paradigmas de mapeamento por outra perspectiva, os mapas baseados em grades possuem uma maior capacidade para descrever detalhes do ambiente, enquanto que os mapas baseados em grafos descrevem o ambiente de forma mais simples.

Uma categoria particular do problema de mapeamento tem atraído a atenção da comunidade científica, conhecida como mapeamento multi-robótico (YUN et al., 2005; 
GIFFORD et al., 2008; TONG et al., 2008; VIDAL-CALLEJA et al., 2009). Neste contexto, o mapeamento é realizado por meio da cooperação de múltiplos robôs móveis, visando obter uma maior robustez do processo de exploração e um menor tempo para se mapear uma determinada área. Deve-se observar que tal cooperação ocorre através da comunicação entre os robôs, de maneira que esta pode ocorrer de duas formas distintas: diretamente, por meio de um canal explícito de comunicação; ou indiretamente, por meio da observação de mudanças ocorridas no ambiente ou nos próprios agentes que compõem o coletivo.

Na Figura 1.1, é apresentado um pequeno exemplo do conceito de integração de mapas. Neste exemplo, dois robôs distintos, $R_{1}$ e $R_{2}$, exploram independentemente um mesmo ambiente e geram mapas independentes que representam as áreas que os mesmos percorreram. Na Figura 1.1 (c), é apresentada uma possível integração dos mapas ilustrados nas Figuras 1.1 (a) e 1.1 (b), obtidos pelos robôs $R_{1}$ e $R_{2}$, respectivamente. A maioria dos métodos propostos na literatura trata do problema de integração por meio da construção de mapas centrados nos robôs, realizando a integração considerando as posições relativas dos mesmos, as quais, consequentemente, necessitam ser conhecidas.

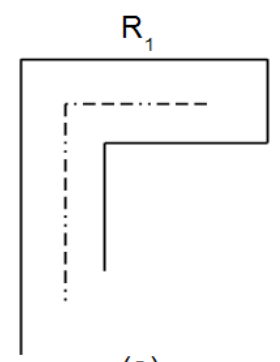

(a)

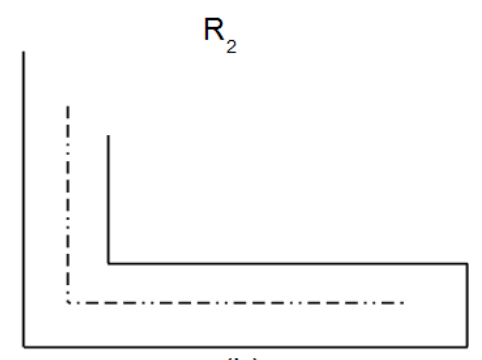

(b)

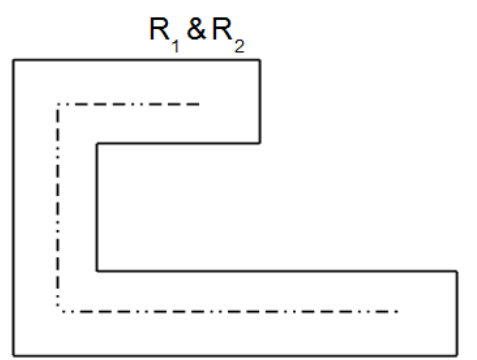

(c)

Figura 1.1 - Exemplo de integração: (a) Mapa gerado pelo robô $R_{l}$; (b) Mapa gerado pelo robô $R_{2}$; (c) Integração dos mapas de $R_{1}$ e $R_{2}$

A integração de mapas locais pode ser obtida basicamente por meio de dois caminhos distintos. O primeiro caminho é a busca por alinhamentos de landmarks entre dois mapas quaisquer (AMIGONI et al., 2006; AMIGONI; GASPARINI, 2008; YU et al., 2009). Nesse 
caso, a transformação mais provável é aquela que produz a maior correspondência entre os landmarks. Deve-se notar que a transformação baseada em landmarks possui como pressuposto fundamental a existência de regiões que se sobrepõem entre os mapas a serem integrados. O segundo caminho é a utilização de medidas de rendez-vous para computar a integração dos mapas (ZHOU; ROUMELIOTIS, 2006; ANDERSON; NYGARDS, 2009). Nessa abordagem, utiliza-se a relação das medidas de posição dos robôs quando estes se encontram, ou em outras palavras, quando dois robôs se encontram e capturam as distâncias relativas de um em relação ao outro, pode-se utilizar esta informação para computar a transformação requerida para unificar os dois mapas. As medidas de rendez-vous são também denominadas neste trabalho como observações inter-robôs.

A integração de mapas com foco no alinhamento de landmarks é uma estratégia projetada inicialmente para ser executada off-line, uma vez que a mesma depende apenas da estrutura dos mapas locais gerados por cada robô e não da percepção de um robô em relação ao outro. Além disso, como a integração é baseada na avaliação do melhor alinhamento de landmarks dentre todos os possíveis alinhamentos, a integração baseada em observações inter-robôs é menos custosa do que a abordagem baseada em alinhamentos de landmarks, assumindo como critério de desempenho o tempo computacional gasto no processamento da integração. Considerando que a estratégia de exploração do ambiente adotada neste projeto necessita de uma abordagem de integração de mapas que minimize o tempo gasto processando a junção dos sistemas de coordenadas e que ainda possa ser realizada durante todo o processo de exploração, uma estratégia de integração baseada em observações interrobôs mostra-se ser a mais adequada neste cenário.

Uma alternativa para realizar o processo de integração é estender paradigmas de Mapeamento e Localização Simultâneos (TOVAR et al., 2006; GRISETTI et al., 2007; CASTELLANOS et al., 2007; KIM et al., 2008), conhecidos na literatura como soluções SLAM - do inglês Simultaneous Localization and Mapping - para sistemas com múltiplos robôs (HOWARD, 2005; WEI et al., 2007). Olson (OLSON, 2000) define o processo de estimar a posição de um robô dentro do ambiente no qual está inserido como localização. De modo que para realizar tal processo é necessário que o robô defina um mapa que represente o mundo ao seu redor e estime por meio desta representação sua posição corrente e sua orientação, tornando assim a localização uma das pré-condições para a autonomia de robôs móveis (BURGARD et al., 1996; WOLF et al., 2005; ANDREASSON et al., 2007).

Técnicas SLAM são amplamente utilizadas no contexto de métodos com um único robô e se referem ao problema de se construir um mapa, e ao mesmo tempo, estimar a posição 
do robô no mapa em questão. É importante observar que a estimação da posição do robô não deve se apoiar apenas em cálculos sobre a sua posição inicial e sobre os seus deslocamentos, uma vez que as medidas odométricas inferidas pelo robô são naturalmente ruidosas, tornando a estimação suficientemente imprecisa. Deste modo, é encontrado na literatura um vasto repertório probabilístico que visa a localização de um robô dentro de uma representação espacial que é construída incrementalmente (LEE; CHUNG, 2006; MENEGATTI et al., 2006; ANDREASSON et al., 2007).

\subsection{MOTIVAÇÃO E DESAFIOS DA ÁREA}

O desenvolvimento de novos sistemas e tecnologias que visam o auxílio gradativo ao trabalho humano, tais como a estratégia de exploração e mapeamento distribuído proposta no presente trabalho, é uma vertente em ascensão na humanidade. Como pré-requisito para tal paradigma, estes sistemas e tecnologias devem ser capazes de executar suas tarefas de modo que não haja interferência externa. Sistemas que possuem esta característica são denominados sistemas autônomos. Há várias aplicações nas quais sistemas de navegação autônoma podem ser adotados, tais como: mapeamento de ambientes (KWON et al., 2006), transporte de objetos (FUJII et al, 2007; WU et al., 2011), sistemas de segurança (LEE et al., 2010) e atividades agrícolas (POTA et al., 2007).

Um importante desafio na tarefa de mapeamento é o processo de exploração do ambiente (THRUN, 2002). Enquanto a definição de estratégias de movimentos para um robô ideal é relativamente bem compreendida em um ambiente totalmente modelado, a geração de estratégias de movimento em representações espaciais parciais e incompletos é desafiadora. De modo geral, qualquer estratégia de exploração viável deve ser capaz de lidar com imprevistos que possam surgir durante a construção do mapa. Por esta razão, a exploração é um problema de planejamento crucial, pois ao se definir uma estratégia de movimento vários fatores devem ser considerados, tais como: o ganho de informação esperado para a construção do mapa, o tempo e a energia necessários para se obter tal informação. Por fim, a técnica de estimação do mapa deve ser capaz de gerar representações espaciais em tempo real, restrição esta que exclui muitas abordagens existentes na literatura.

Segundo Liu e Ma (LIU; MA, 2009) para que robôs móveis sejam capazes de explorar

eficientemente ambientes desconhecidos, visando completar alguma determinada tarefa 
requerida, é necessário que os mesmos possuam a capacidade de gerar seus próprios mapas do ambiente. De acordo com estes mesmos autores, as estratégias de geração de mapas desenvolvidas a partir da utilização de múltiplos robôs possuem uma série de vantagens quando comparadas às abordagens baseadas no emprego de um único robô. As principais vantagens que podem ser apresentadas são: o aumento da eficiência da etapa de mapeamento e a redução do tempo de construção do mapa por meio da colaboração e integração dos dados obtidos pelos diferentes robôs utilizados. Destacando ainda mais tais vantagens, Li et al. (LI et al., 2008) afirmam que as abordagens com múltiplos robôs são mais flexíveis e robustas, permitindo um maior ganho de informação e uma redução do tempo para a construção do mapa.

Contudo, é importante notar que as estratégias envolvendo a utilização de múltiplos robôs também proporcionam vários novos desafios ao paradigma de mapeamento autônomo de ambientes. Yu et al. (YU et al., 2009) destacam que os principais novos desafios são: a comunicação entre os robôs e a unificação dos mapas locais gerados individualmente por cada robô.

Para que um determinado sistema com múltiplos robôs seja considerado distribuído é necessário que o mesmo apresente um comportamento coletivo, de modo que um conjunto de ações conduza a um mesmo comportamento. Dudek et al. (DUDEK et al., 1996) afirmam que para que um sistema coletivo apresente um comportamento cooperativo inteligente é necessário que as partes integrantes do coletivo sejam capazes de se comunicar entre si, tornando assim a comunicação uma característica crucial em tal sistema.

Considerando agora o segundo desafio apresentado por Yu et al. (YU et al., 2009), a integração de mapas locais individuais torna-se um procedimento particularmente complexo quando os robôs não conhecem suas posições iniciais em relação a um mesmo sistema de coordenadas, fazendo com que seja necessário a definição de abordagens mais robustas para a unificação dos mapas locais. A estratégia de integração proposta neste trabalho assume um cenário em que estas posições iniciais são desconhecidas para os robôs.

Um importante desafio não destacado por $\mathrm{Yu}$ et al., envolvendo sistemas com múltiplos robôs, é o problema da coordenação dos agentes que compõem o sistema (WEIXING et al., 2006). As estratégias de coordenação baseadas apenas em formulações matemáticas e nos modelos dos ambientes são dependentes de diversos parâmetros e podem sofrer uma degradação significativa devido a falhas dos robôs (TAN et al, 2004; JIANG, 2006; FREEMAN et al., 2006). 
Capítulo 1 - Introdução

Diante de tais desafios as pesquisas na área do desenvolvimento de sistemas com múltiplos robôs vêm se fortalecendo, principalmente aquelas fundamentadas sobre o arcabouço da Inteligência Artificial. Certas técnicas oriundas da Inteligência Artificial dispensam, em geral, modelos matemáticos definidos a priori, tornando-as alternativas viáveis para a elaboração de estratégias que visam a solução de problemas de extrema complexidade, nos quais modelos matemáticos são difíceis de se obter ou de se equacionar previamente.

Um conjunto particular de tais técnicas é fortemente relacionado ao problema de coordenação e cooperação entre múltiplos robôs móveis. São técnicas inspiradas em sociedades biológicas do tipo enxame e induzem um comportamento sinérgico entre os agentes que formam o sistema. No contexto do presente trabalho, a sinergia compreende a habilidade dos robôs em alcançarem cooperativamente um determinado objetivo, de modo que cada um contribua na execução da tarefa, realizando alguma de suas possíveis frações. Entre tais técnicas, um conjunto particular que merece destaque são as técnicas baseadas em otimização por colônias de formigas, sendo estas utilizadas como modelo para resolver problemas de patrulhamento e cobertura de áreas (WAGNER et al., 1999; CHU et al., 2007; ZHANG; XIAO, 2013).

No presente projeto, a ação de interesse de um determinado robô é o seu deslocamento, posicionamento e orientação sobre o ambiente de atuação do sistema distribuído. Isoladamente, cada robô é dotado de um mecanismo de navegação que lhe permite explorar o ambiente, sem colisões com obstáculos, com o objetivo de mapear as áreas percorridas pelo mesmo. Assim, a autonomia compreende o relacionamento entre as informações fornecidas pelos sensores dos robôs e as ações executadas pelos mesmos para atingir os objetivos previamente definidos.

\subsection{OBJETIVOS E DESCRIÇÃO PRELIMINAR DA PROPOSTA}

O principal objetivo do presente trabalho é propor um método de integração de mapas locais baseado em observações inter-robôs, considerando como estratégia de exploração do ambiente o método proposto em (CALVO et al., 2011a; CALVO et al., 2011b), denominado Sistema de Vigilância baseado na Modificação do Sistema Colônias de Formigas (IAS-SS) do inglês Inverse Ant System-Based Surveillance System. O IAS-SS é inspirado em 
mecanismos biológicos que definem a organização social de sistemas de enxames. Especificamente, esta estratégia é baseada em uma modificação do tradicional algoritmo de otimização por colônias de formiga (DORIGO, 1992). O conceito biológico que sustenta esta estratégia é oriundo do fato de que formigas e outros insetos utilizam substâncias químicas, conhecidas como feromônios, para realizar diversas tarefas de comunicação e coordenação.

Na estratégia IAS-SS, os robôs são capazes de se comunicar indiretamente por meio de feromônios, de modo similar aos agentes biológicos nos quais foram inspirados. De modo geral, um robô deve perceber o feromônio do ambiente e tomar uma decisão a respeito da direção a ser seguida de acordo com a informação percebida. Contudo, a reação ao feromônio nestes agentes artificiais é distinta àquela demonstrada por suas contrapartidas biológicas, de maneira que, os ajustes na direção a ser seguida são definidos para guiarem os robôs preferencialmente para áreas nas quais a concentração de feromônio é menor. É importante notar que na estratégia proposta o feromônio é apenas um mecanismo para se monitorar o ambiente, sendo assim, os robôs não liberam efetivamente substâncias químicas no ambiente. O feromônio é apenas uma característica virtual e é discutido no Capítulo 3, que aborda a questão do ponto de vista do algoritmo de otimização por colônias de formigas, e no Capítulo 4, que o trata especificamente sob a ótica de sua aplicação como um dado virtual.

A estratégia IAS-SS é primariamente projetada para a coordenação de múltiplos robôs aplicados a tarefas de exploração e vigilância. Algumas características do IAS-SS são: descentralizado, on-line e independente do número de robôs e da estrutura do ambiente. Uma relevante consideração a ser destacada é o fato de que embora o método de integração proposto seja baseado no IAS-SS como estratégia de exploração do ambiente, o mesmo não é limitado às técnicas de otimização por colônia de formigas. O método proposto pode ser generalizado para outros algoritmos de otimização, desde que estes utilizem uma representação de mapa baseada em sistemas de coordenadas.

O método de integração proposto é uma extensão da abordagem elucidada em (TAN et al., 2004), na qual os robôs se espalham por uma certa área e compartilham informações acerca do ambiente por meio de uma rede Wireless. A estrutura gerada pelos múltiplos robôs forma uma rede de sensores móveis, que consiste de uma variedade de sensores dispostos em um agrupamento de robôs móveis. O objetivo do método na abordagem em questão é a cooperação de múltiplos robôs móveis na tarefa de cobertura de uma determinada área utilizando os sensores acoplados aos robôs. De acordo com Tan et al. (TAN et al., 2004), cada robô é responsável por monitorar determinada área $\Omega$ do espaço representado pelo ambiente 
Capítulo 1 - Introdução

inteiro, de forma que o sistema de coordenada de cada robô é diferente e variante em relação ao tempo.

Deve-se salientar que o método proposto por Tan et al. (TAN et al., 2004) não é capaz de mapear o ambiente, uma vez que o sistema de coordenadas de cada robô varia ao longo do tempo, impossibilitando a construção incremental do mapa. O sensoriamento e a fusão de dados executados por cada robô são realizados apenas em relação aos seus respectivos sistemas de coordenadas locais.

O método proposto neste trabalho integra mapas locais por meio de uma modificação no modelo de compartilhamento de informação proposto em (TAN et al., 2004), tornando o método invariante em relação ao tempo e possibilitando assim, a construção incremental do mapa do ambiente. O processo de junção de mapas é definido por meio de matrizes de transformações, representadas pela distância entre dois robôs e por suas respectivas posições relativas.

Especificamente, a modificação que torna o modelo de compartilhamento proposto por Tan et al. (TAN et al., 2004) invariante em relação ao tempo, e consequentemente capaz de realizar tarefas de mapeamento, está relacionada a centralização do sistema de coordenada de cada robô e é discutida a seguir. Diferentemente do modelo de compartilhamento tradicional, no método proposto neste trabalho os sistemas de coordenadas dos robôs não são centralizados em suas respectivas posições durante o processo de exploração do ambiente, metodologia esta empregada na abordagem original.

Na modificação proposta, o sistema de coordenadas de cada robô é centralizado em sua respectiva posição inicial, uma vez que estas posições não se alteram durante o processo de exploração. Uma vez que os sistemas de coordenadas são independentes e os robôs não possuem conhecimento prévio acerca do ambiente no qual se encontram, a posição inicial de cada robô é definida no centro de seu próprio mapa e esta é configurada como sendo a coordenada $(0,0)$ de seu sistema de coordenadas. Assume-se que o ângulo inicial de cada robô em seu próprio sistema de coordenadas é $0^{\circ}$.

\subsection{CONTRIBUIÇÕES DO TRABALHO}

Uma importante contribuição da técnica proposta neste trabalho em relação ao método elucidado em (TAN et al., 2004) é a capacidade de se monitorar todo o ambiente. Uma vez que o método de Tan et al. lida apenas com o problema de cobertura, o sensoriamento do 
ambiente depende do número de robôs utilizados e do raio de comunicação entre os mesmos. Contudo, nestas circunstâncias, não há garantia de que o ambiente inteiro será monitorado. Em contrapartida, uma vez que a técnica de integração proposta utiliza como estratégia de exploração o IAS-SS, o monitoramento de todo o ambiente é possível mesmo empregando um único robô, desde que iterações suficientes sejam atribuídas ao processo de exploração.

Deve-se notar que outra importante contribuição da abordagem proposta é a própria colaboração entre o método de integração e a estratégia de coordenação de múltiplos robôs IAS-SS. A estratégia IAS-SS lida apenas com problemas de exploração e vigilância de ambientes, de modo que a colaboração entre o IAS-SS e o método de integração produz um aperfeiçoamento na técnica de exploração por colônias de formigas proposta por Calvo et al. (CALVO et al., 2011a; CALVO et al., 2011b), tornando-a capaz de gerar cooperativamente mapas das áreas visitadas pelos robôs. Além disso, outra vantagem desta colaboração é o mapeamento dinâmico e contínuo do ambiente. A estratégia IAS-SS garante que o ambiente é continuamente explorado, baseando-se nos estímulos provocados pela detecção das concentrações de feromônio. Uma vez que o ambiente é periodicamente explorado, os mapas construídos pelos robôs são constantemente atualizados e qualquer mudança na estrutura do ambiente é reconhecida e compartilhada entre os robôs do sistema.

Por fim, outra contribuição relevante da união da estratégia IAS-SS com o método de integração de mapas proposto é a criação de uma abordagem que permite a utilização dos conceitos de feromônio em aplicações direcionadas a ambientes reais, sem a necessidade de se empregar sensores reais para liberação e detecção da substância. Tal abordagem se baseia na elaboração de uma estratégia baseada em feromônios virtuais, os quais são obtidos por meio da integração de mapas locais de feromônio, gerados individualmente por cada robô, utilizando-se a estratégia de exploração e vigilância IAS-SS.

\subsection{ORGANIZAÇÃO DO TEXTO}

Este trabalho está organizado da seguinte forma:

- Capítulo 2: é apresentada uma revisão de trabalhos referentes ao problema de mapeamento. Destacando-se uma técnica de mapeamento métrico, denominada Grade de Ocupação, e um método de mapeamento topológico baseado em um algoritmo de esqueletização de imagens. 
- Capítulo 3: métodos responsáveis por integrar mapas locais são discutidos. De maneira que uma descrição mais detalhada do método proposto por Tan et al. (TAN et al., 2004) também é apresentada.

- Capítulo 4: é apresentada a abordagem proposta para integração de mapas locais baseada em observações inter-robôs. Além disso, a estratégia de exploração IAS-SS, baseada em uma modificação do método de otimização por colônias de formigas também é descrita. Assim como é elucidado o conceito de feromônio virtual integrado, oriundo da colaboração do método proposto de integração com a estratégia IAS-SS. Por fim, no final do capítulo, uma extensão da estratégia de exploração, conhecida como SAFS, é apresentada.

- Capítulo 5: os principais resultados obtidos por meio de uma série de experimentos realizados em simulação são apresentados e discutidos neste capítulo. Para validação estatística dos resultados apresentados é realizada uma análise baseada no teste $t$ de Student.

- Capítulo 6: são elucidadas as principais conclusões referentes ao presente trabalho, assim como suas limitações e propostas de trabalhos futuros. 
Capítulo 1 - Introdução 
O mapeamento robótico pode ser formulado como a tarefa de adquirir uma representação espacial do ambiente físico por meio de robôs móveis. Tal tarefa é considerada na literatura como sendo uma das características essenciais para se construir robôs móveis verdadeiramente autônomos. O problema da aquisição de representações espaciais é complexo e está longe de ser completamente resolvido. Os seguintes fatores impõem limitações práticas na habilidade que um robô possui em aprender e utilizar precisamente as representações geradas (THRUN; BÜCKEN, 1996; THRUN, 1998; THRUN, 2002):

- Sensores: frequentemente os sensores não são capazes de medir diretamente o fator de interesse, tal como a localização exata dos obstáculos no ambiente;

- Limitações perceptuais: o grau de percepção da maioria dos sensores é limitado a uma pequena área em volta do robô, de modo que, para adquirir informações globais, o mesmo precisa explorar ativamente seu ambiente;

- Ruído sensorial: as leituras dos sensores são geralmente distorcidas por ruídos;

- Deslocamento: a movimentação do robô não é precisa, uma vez que os erros odométricos se acumulam com o tempo;

- Complexidade e dinamismo: o ambiente do robô é complexo e dinâmico, tornando impossível manter uma representação espacial exato; 
- Requisições em tempo real: o tempo de resposta para requisições requer normalmente uma representação simples e de fácil acesso.

Para lidar com estes fatores limitantes, os robôs devem apresentar um considerável nível de autonomia, tornando-se capazes de sentir, planejar e atuar em ambientes não estruturados. O robô precisa ser capaz de interagir coerentemente com o ambiente ao seu redor, tornando-se apto a elaborar descrições espaciais robustas e úteis por meio dos dados adquiridos pelos seus sensores. Os mapas desenvolvidos podem então ser utilizados em tarefas de planejamento e tomada de decisões, considerando cenários de atuação tanto no curto prazo quanto no longo prazo.

A pesquisa na área de mapeamento robótico se inicia aproximadamente na década de 80. De acordo com Thrun (THRUN, 2002), nesta época, a área de mapeamento foi dividida em duas abordagens, sendo estas: métricas e topológicas. Paradigmas métricos representam o ambiente por meio de propriedades geométricas, usualmente por meio de grades de armazenamento espaçadas uniformemente. Representações topológicas descrevem a conectividade dos diferentes locais que formam o ambiente, comumente por meio de grafos cujos nós representam situações, locais ou marcos distintos. Caso exista um caminho entre dois pontos distintos do ambiente, o mesmo é representado por meio de um arco que conecta os dois nós correspondentes no grafo.

Na Figura 2.1, é apresentado um exemplo das duas abordagens de mapeamento. O ambiente no qual cada estratégia é realizada é ilustrado na Figura 2.1(a). Na Figura 2.1(b), é apresentada sobre o ambiente de interesse, a grade de armazenamento que descreve a abordagem métrica. Cada célula desta grade pode conter uma estimativa que descreve o estado da área correspondente no ambiente. O mapeamento topológico do mesmo ambiente é ilustrado na Figura 2.1(c), por meio de um grafo cujos nós representam áreas de interesse daquele ambiente. Conforme elucidado por Thrun (THRUN, 2002), os mapas métricos capturam as propriedades geométricas do ambiente, enquanto que os mapas topológicos descrevem a conectividade entre os diferentes locais. Os métodos métricos podem gerar mapas bastante precisos, contudo sua complexidade dificulta geralmente tarefas de planejamento de trajetórias. Em contrapartida, métodos topológicos podem ser eficientemente utilizados em tais tarefas. Contudo, abordagens topológicas se tornam complexas em 
Capítulo 2 - Mapeamento

ambientes com grandes dimensões, uma vez que os dados sensoriais momentâneos podem se tornar substancialmente ambíguos.

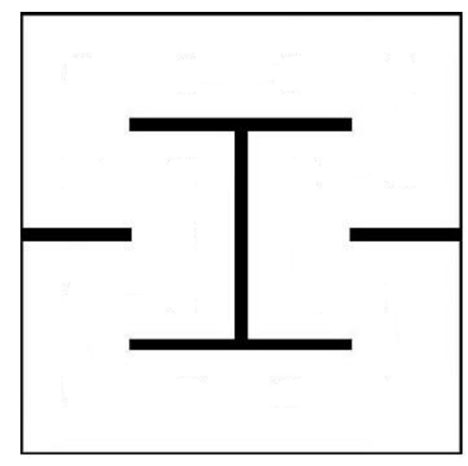

(a)

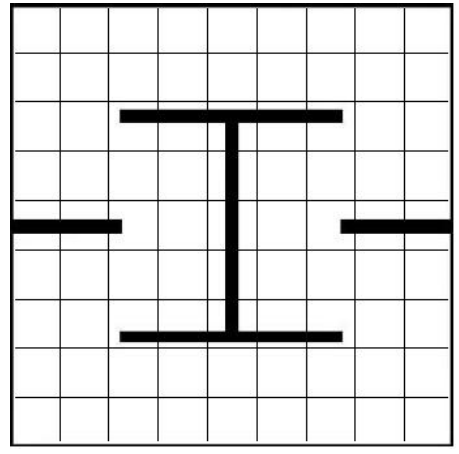

(b)

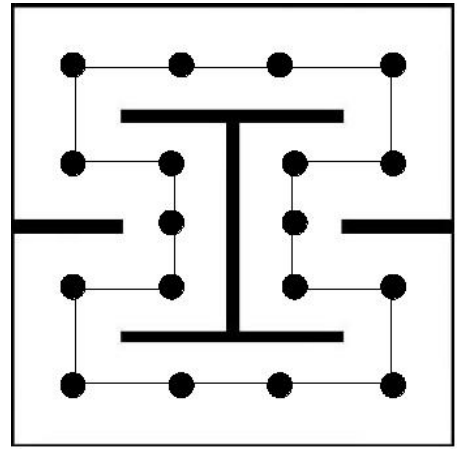

(c)

Figura 2.1 - Exemplo de estratégias de mapeamento: (a) Ambiente não mapeado; (b) Mapeamento métrico; (c) Mapeamento topológico

Uma importante proposta da abordagem métrica amplamente utilizada nos dias de hoje é o algoritmo de mapeamento baseado em grades de ocupação proposto por Elfes e Moravec (MORAVEC, 1988; ELFES, 1989a), na qual os mapas são representados por grades reticuladas para modelar os espaços ocupados e livres do ambiente. Esta proposta tem sido empregada em uma grande variedade de sistemas robóticos (BORENSTEIN; KOREN, 1991; BUHMANN et al., 1995; YAMAUCHI; LANGLEY, 1997; THRUN et al., 2000).

Uma proposta alternativa para mapeamento métrico foi elucidada por Chatila e Laumond (CHATILA; LAUMOND, 1985), utilizando conjuntos de poliedros para descrever a geometria dos ambientes. Exemplos de propostas topológicas incluem os trabalhos de Matarić (MATARIĆ, 1994) e KWON et al. (KWON et al., 2006), entre outros 
(KORTENKAMP; WEYMOUTH, 1994; ROQUE; DOERING, 2005; KALRA et al., 2009). Mapas topológicos descrevem o ambiente como uma lista de locais significantes que são conectados por arestas. De maneira que, as arestas são usualmente denotadas com a informação de como se navegar de uma área para outra.

É importante observar que, na verdade, a distinção entre abordagens métricas e topológicas é um pouco complexa, pois na prática, as propostas topológicas são desenvolvidas a partir de informações métricas. Como discutido anteriormente, mapas métricos descrevem o ambiente mais detalhadamente do que mapas topológicos. A maior resolução das propostas métricas traz inerentemente um maior custo computacional, contudo este fator também permite melhores mecanismos para a solução de problemas mais complexos.

Uma segunda categorização dos métodos de mapeamento é a divisão entre técnicas centradas no mundo e centradas no robô. Os mapas centrados no mundo são representados por meio de um espaço de coordenadas global. As características do ambiente descritas nestes mapas não carregam informação sobre as medidas sensoriais que levaram às suas descobertas. Em contrapartida, os mapas centrados nos robôs são descritos no espaço de medidas. Estas representações espaciais descrevem as medidas sensoriais que um determinado robô receberia nas diferentes áreas que compõem o ambiente.

Thrun (THRUN, 2002) afirma que a área de mapeamento robótico é dominada principalmente por técnicas probabilísticas, uma vez que estas apresentam um alto nível de desempenho no mundo real. A ideia central das abordagens probabilísticas é representar as informações incertas por meio de probabilidades. De acordo com Lee e Chung (LEE; CHUNG, 2006), as razões destas incertezas incluem: erros sistemáticos, abrangendo erros de modelagem dos parâmetros cinemáticos; erros não-sistemáticos, incluindo derrapagem das rodas; erros de leitura dos sensores; e erros causados por obstáculos dinâmicos e mudanças no ambiente. É importante salientar que os algoritmos probabilísticos alcançaram considerável sucesso quando comparados aos métodos convencionais não-probabilísticos (SIMMONS; KOENIG, 1995; THRUN et al., 2000).

Diversos trabalhos na literatura visam oferecer soluções para resolver o problema de mapeamento, assim como, simultaneamente, localizar a posição relativa de um determinado robô dentro de seu próprio mapa (TOVAR et al., 2006; GRISETTI et al., 2007; CASTELLANOS et al., 2007; KIM et al., 2008; BLANCO et al., 2008). Como salientado no capítulo anterior, este problema é comumente conhecido como SLAM. 
Uma família de abordagens probabilísticas que visam resolver o problema SLAM é baseada na utilização de filtros de Kalman para estimar tanto o mapa quanto a localização de um dado robô (NEWMAN, 2000; CASTELLANOS et al., 2000; DISSANAYAKE et al., 2001). Os mapas gerados usualmente descrevem a localização de landmarks ou características significativas do ambiente. Uma família alternativa de propostas é baseada no algoritmo de Maximização de Expectativas de Dempster (SHATKAY; KAELBLING, 1997; DELLAERT et al.; 2000; THRUN, 2001). Estas propostas lidam especificamente com o problema da correspondência no mapeamento, que consiste no problema de determinar se uma medida sensorial obtida em diferentes pontos do tempo corresponde à uma mesma entidade física no ambiente do mundo real. Por fim, uma terceira família de técnicas probabilísticas visa identificar entidades no ambiente, tais como o teto, as paredes, portas, mobílias ou objetos que se locomovem (LIU et al., 2001; BISWAS et al., 2002; AVOTS et al., 2002).

Uma tendência atual na implementação de todas estas técnicas, independentemente de sua família, é a utilização de sensores baseados em visão. Segundo Spacek e Burbridge (SPACEK; BURBRIDGE, 2007), entre todos os sensores disponíveis a um robô, a visão provê o maior ganho de informação com a maior precisão, sendo que a visão omnidirecional oferece informações detalhadas de todo o ambiente e é amplamente adequada em tarefas de localização de robôs móveis. Um dos diferenciais do uso de sensores do tipo visão é a sua passividade, ou seja, sensores baseados em visão não interferem na utilização de outros tipos de sensores.

Outra importante tendência atual relacionada agora à tarefa de mapeamento é o desenvolvimento de técnicas destinadas à construção de mapas semânticos (GALINDO et al., 2008; GOERKE; BRAUN, 2009; BLODOW et al., 2011). Em sistemas autônomos, o planejamento de tarefas requer a definição de uma sequência de ações de alto nível que permitam que um robô realize uma determinada tarefa. Tal planejamento de tarefas requer ainda que diversos tipos de conhecimento sejam codificados e interpretados pelos robôs, tais como: conhecimento causal, relacionado ao conhecimento sobre os efeitos ocasionados pelas ações do robô; e conhecimento do mundo, relacionado ao conhecimento sobre os objetos presentes no ambiente e suas respectivas propriedades e relações.

A maioria dos trabalhos na área de mapeamento se concentra apenas na representação da estrutura espacial do ambiente, tais como os mapas métricos e topológicos. Contudo, tais abordagens não exploram o conhecimento inerente relacionado às informações espaciais representadas em seus respectivos mapas. Por exemplo, um mapa métrico pode representar a 
forma de uma sala, porém o mesmo não indica se a sala em questão é um escritório ou uma cozinha. Os mapas semânticos integram o conhecimento de domínio semântico às abordagens tradicionais de mapeamento, oferecendo habilidades de dedução aos sistemas robóticos. O emprego do conhecimento semântico permite que os robôs executem tarefas quaisquer de forma mais inteligente e autônoma.

A tarefa de mapeamento de ambientes consiste de dois processos distintos: síntese de mapa e exploração. O processo de mapeamento é passivo e se caracteriza pela construção de uma representação espacial do ambiente, dadas as observações realizadas pelo robô. Em contrapartida, a exploração é um processo ativo que visa controlar o robô para que o mesmo explore todo o ambiente por meio de seus sensores. A estratégia de exploração adotada neste trabalho é descrita no Capítulo 4.

A seguir são apresentadas duas técnicas de mapeamento de ambientes. Tais técnicas são diretamente relacionadas ao presente trabalho, pois são utilizadas como métodos de mapeamento nos experimentos realizados nesta proposta. Na Seção 2.1, é apresentada uma técnica de mapeamento métrico probabilístico, conhecida como Grade de Ocupação (ELFES, 1989a; BIRK; CARPIN, 2006; NOYKOV; ROUMENIN, 2007; MULLANE et al., 2009; SANTANA et al., 2011), e em sequência, na Seção 2.2, é apresentada uma técnica de mapeamento topológico baseada em esqueletização de imagens (KO et al., 2004; KWON et al.; 2006; OLIVEIRA; ROMERO, 2009; OLIVEIRA et al., 2009).

\subsection{GRADE DE OCUPAÇÃO}

Um dos métodos mais utilizado para mapeamento métrico é a técnica Grade de Ocupação proposta por Elfes e Moravec (MORAVEC, 1988; ELFES, 1989a). O método Grade de Ocupação, abreviado como OG - do inglês Occupancy Grid - usa uma representação probabilística e reticulada da informação para modelar o ambiente. A grade de ocupação é definida como um campo aleatório multidimensional que contém estimativas estocásticas dos estados das células que compõem o espaço reticulado.

A representação dos mapas na grade de ocupação é uma matriz de ocupação multidimensional, normalmente 2D ou 3D, que mapeia o espaço em células, de forma que cada célula armazena uma estimativa probabilística de seu estado. As estimativas dos estados de cada célula são obtidas por meio da interpretação das leituras de distâncias obtidas pelos 
sensores do robô. Procedimentos de estimativas Bayesianos permitem a atualização incremental da grade de ocupação por meio de leituras realizadas sobre múltiplos pontos de vista em diferentes intervalos de tempo.

Elfes (ELFES, 1989b) afirma que por meio deste esquema de representação e dos modelos sensoriais probabilísticos, o método permite o desenvolvimento de mecanismos de interpretação sensoriais ágeis e robustos, a realização incremental do processo de descoberta, a manipulação explicita da incerteza, a integração multissensorial da informação e a elaboração de um raciocínio espacial das tarefas a serem realizadas.

A variável de estado $s\left(C_{i}\right)$, associada à célula $C_{i}$ da grade de ocupação, pode ser definida como uma variável aleatória discreta que possui dois estados distintos, ocupada e vazia, denotadas neste trabalho por $O C C$ e $E M P$, respectivamente. Sendo assim, a grade de ocupação corresponde a uma matriz de taxas de ocupação que pode ser interpretada por meio de um campo aleatório de estados discretos. Uma vez que os estados das células são exclusivos e exaustivos (ELFES, 1989c), tem-se que:

$$
P\left[s\left(C_{i}\right)=O C C\right]+P\left[s\left(C_{i}\right)=E M P\right]=1
$$

em que $P\left[s\left(C_{i}\right)=O C C\right]$ é a probabilidade do estado da célula $C_{i}$ ser ocupada e $P\left[s\left(C_{i}\right)=\right.$ $E M P]$ é a probabilidade do estado da célula $C_{i}$ ser vazia.

Contrapondo a definição dos estados discretos pertinentes a cada célula da grade de ocupação elucidada por Elfes, neste trabalho se assume que a variável $s\left(C_{i}\right)$ possui na verdade três estados distintos: ocupada, vazia e desconhecida. Denotadas assim como OCC, EMP e $U N K$, respectivamente. Vale destacar que, na prática, os próprios autores que propuseram o método Grade de Ocupação, Elfes e Moravec, também consideram estes mesmos três estados, contudo tal consideração é realizada implicitamente.

O terceiro estado UNK é utilizado para denotar a situação na qual não se pode inferir se uma determinada célula $C$ está ocupada ou vazia. Esta situação pode ocorrer, por exemplo, quando uma determinada área do ambiente ainda não tenha sido explorada. Na Figura 2.2, é ilustrado um exemplo de uma grade de ocupação discretizada nos estados $O C C, E M P$ e $U N K$. Este exemplo foi obtido por meio de um experimento em um ambiente real utilizando-se um robô Pioneer 3DX equipado com o sensor laser SICK LMS 200. Os estados OCC são representados na cor branca, EMP na cor preta e $U N K$ na cor cinza. Esta nomenclatura de cores é mantida ao longo de todo o trabalho. 


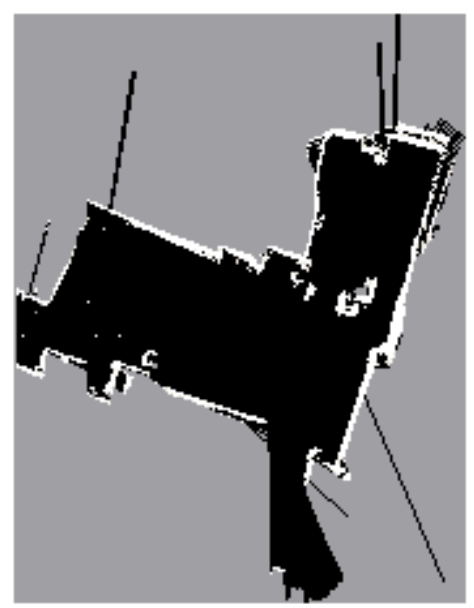

Figura 2.2 - Grade de ocupação discretizada

Uma importante característica da técnica Grade de Ocupação que pode ser observada é a sua capacidade de geração de modelos mais gerais quando necessário, por meio da codificação de múltiplas propriedades em cada célula da grade. Neste caso, consequentemente, cada célula da matriz é representada por um vetor de estados correspondente às propriedades a serem exploradas. Elfes (ELFES, 1989b) se refere a estas representações como grades de inferência.

Para interpretar as medidas de distâncias referentes aos dados sensoriais é utilizado um modelo estocástico do sensor. O modelo é definido por uma função de densidade de probabilidade na forma $p(r \mid z)$, que relaciona a leitura $r$ ao parâmetro de espaço $z$ referente a uma posição do mapa. Esta função de densidade é subsequentemente utilizada em um procedimento de estimativa Bayesiano para determinar as probabilidades de estado das células da grade de ocupação. Partindo-se da estimativa corrente do estado da célula $C_{i}$ no instante de tempo $t$, a estimativa atualizada no instante $t+l$ é dada por:

$$
P\left[s\left(C_{i}\right)=O C C \mid\{r\}_{t+1}\right]=\frac{p\left[\{r\}_{t+1} \mid s\left(C_{i}\right)=O C C\right] P\left[s\left(C_{i}\right)=O C C \mid\{r\}_{t}\right]}{\sum_{s\left(C_{i}\right)} p\left[\{r\}_{t+1} \mid s\left(C_{i}\right)\right] P\left[s\left(C_{i}\right) \mid\{r\}_{t}\right]}
$$

em que $P\left[s\left(C_{i}\right)=O C C \mid\{r\}_{t}\right]$ é a estimativa corrente; $\{r\}_{t}$ são as observações obtidas pelo robô até o instante $t$.

A partir dessa formulação recursiva, a estimativa corrente do estado da célula, $P\left[s\left(C_{i}\right)\right.$ $\left.=O C C \mid\{r\}_{t}\right]$, serve como priori e é obtida diretamente da grade de ocupação. Deste modo, a 
nova estimativa é armazenada na matriz, obtendo-se um mapa que expressa as probabilidades de ocupação de cada célula. Uma vez que as probabilidades de ocupação das células são definidas, uma representação determinística do ambiente pode ser obtida. Por exemplo, considerando uma regra de decisão de máximo a posteriori, conhecida na literatura como regra MAP. As regras para atribuição de estados discretos a cada célula da grade neste trabalho são definidas a seguir: uma célula $C_{i}$ assume o estado $O C C$ se $P\left[s\left(C_{i}\right)=O C C\right]>$ $P\left[s\left(C_{i}\right)=E M P\right] ; E M P$ se $P\left[s\left(C_{i}\right)=O C C\right]<P\left[s\left(C_{i}\right)=E M P\right]$; e $U N K$ se $P\left[s\left(C_{i}\right)=O C C\right]=$ $P\left[s\left(C_{i}\right)=E M P\right]$.

Outro critério de decisão também poderia ser empregado, tal como, por exemplo, a estimativa de custo mínimo. Dependendo do contexto especifico, também poderia ser útil definir um intervalo para o estado $U N K$, ao invés de utilizar um único valor limite. Contudo, é importante salientar que diversas tarefas robóticas podem ser realizadas diretamente sobre as estimativas da grade de ocupação, excluindo a necessidade de transformação de valores discretos dos estados individuais das células. Em tarefas de planejamento de trajetórias, por exemplo, pode-se calcular o custo do caminho em termos do fator de risco associado diretamente às probabilidades de ocupação.

De acordo com Elfes (ELFES, 1989b), a técnica Grade de Ocupação é modelada como um campo aleatório de Markov, abreviado como MRF - do inglês Markov Random Field - de ordem zero, assim o estado de uma célula individual da matriz de ocupação pode ser estimado considerando-o como uma variável aleatória independente. Contudo, podem-se empregar procedimentos computacionalmente mais robustos para o cálculo de campos aleatórios de Markov de ordem superior.

Uma importante vantagem do método é a sua capacidade para integração multissensorial. Usualmente, aumentar o desempenho dos sistemas robóticos envolve o suporte aos diferentes tipos de sensores que podem ser utilizados nas tarefas realizadas pelo robô. Uma vez que diferentes tipos de sensores possuem diferentes características operacionais e módulos de falha, um determinado sensor pode ser utilizado de forma a complementar a informação obtida por outro sensor. Por meio desta estratégia, é possível desenvolver representações espaciais diferenciadas que possuem um alto grau de segurança e de tolerância a falhas.

Dentro do contexto da técnica Grade de Ocupação, a integração de diferentes sensores pode ser obtida por meio da utilização de um conceito similar ao expresso na Equação 2.2. Considerando dois sensores distintos $S R_{1}$ e $S R_{2}$, e seus respectivos modelos sensoriais $p_{1}(r \mid z)$ 
e $p 2(r \mid z)$, a integração sensorial pode ser realizada por meio da atualização da mesma matriz de ocupação pelos diferentes sensores utilizados operando independentemente (ELFES, 1989a).

Outro trabalho que lida com grades de ocupação é apresentado em (MULLANE et al., 2009). O trabalho mencionado explora o problema de detecção de sinal para executar o mapeamento do ambiente. É apresentado nesta proposta que por meio da teoria de detecção de sinal é possível se obter uma variável aleatória de ocupação cuja medida de probabilidade é mais precisa do que os métodos tradicionais. Sendo assim, um método baseado em filtros de partículas é desenvolvido para estimar a distribuição a posteriori da variável de ocupação e para executar o mapeamento do ambiente.

Um método baseado em lógica fuzzy para modelamento de sensores do tipo sonar em tarefas de mapeamento com grades de ocupação é elucidado em (NAGLA et al., 2012). Este método visa reduzir a influência das incertezas referentes à reflexão especular. Segundo Nagla et al. (NAGLA et al., 2012), tal redução das incertezas é necessária no mapeamento com grades de ocupação baseado em sonares, pois uma falsa informação sensorial pode levar a um desempenho insatisfatório da tarefa de mapeamento. Para obter uma grade de ocupação com um melhor desempenho, este método também se utiliza de uma atualização Bayesiana da grade de ocupação.

\subsection{ESQUELETIZAÇÃO DE IMAGENS}

Os métodos de esqueletização de imagens são algoritmos de processamento de imagens utilizados para extrair um conjunto de pontos no interior de um dado objeto de modo que tal conjunto possa representá-lo (BAXES, 1994). Este conjunto de pontos é chamado de esqueleto do objeto. Na Figura 2.3(a), é ilustrado uma imagem de dois corredores que se cruzam na forma de um T. O esqueleto desta imagem é apresentado na Figura 2.3(b). No contexto deste trabalho, o método de esqueletização de imagens é responsável por definir as linhas topológicas de um mapa métrico.

A utilização de linhas topológicas como percursos de navegação pode ser justificada em parte pelo campo de atuação dos sensores. Se o robô navega ao longo de caminhos equidistantes dos diversos obstáculos, os quais correspondem às linhas topológicas, o mesmo 
possui maior oportunidade de capturar mais informações sobre o ambiente do que se percorresse outros caminhos. Segundo Kwon et al (KWON et al., 2006) esse aumento de informação pode conduzir a melhorias no desempenho de certos métodos de localização, como por exemplo a Localização de Monte Carlo (THRUN et al., 2001; KÖSE; AKIN, 2007; KOOTSTRA; BOER, 2009).

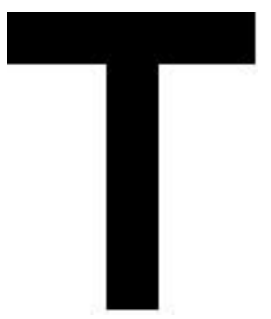

(a)

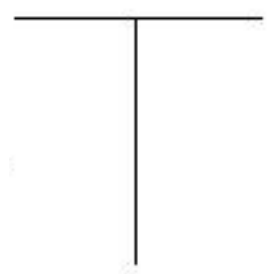

(b)

Figura 2.3 - Conceito de esqueletização de imagens: (a) Imagem original; (b) Imagem resultante

O princípio geral da construção do mapa topológico baseado em esqueletização de imagens é descrito a seguir. Inicialmente, o robô coleta os dados do ambiente por meio de seus sensores. A probabilidade de ocupação de cada célula do mapa métrico é então atualizada baseada na fórmula de atualização Bayesiana descrita na Equação 2.2. A cada amostragem, baseado nos dados capturados, a matriz de ocupação e o seu respectivo mapa topológico são construídos. Deste modo, o mapa topológico é constantemente modificado à medida que o mapa métrico é atualizado. O método de esqueletização de imagens proposto por Ko et al. (KO et al., 2004) e implementado nesse trabalho é denominado Thinning.

O método Thinning realiza uma análise sobre os estados das células de uma determinada imagem binária. Esta análise é baseada sempre em uma estrutura de nove células adjacentes, de maneira que, cada célula da imagem é verificada adotando-se a mesma como a célula central da estrutura.

Na Figura 2.4, é apresentada a estrutura formada pelo agrupamento de nove células quaisquer. Como os valores assumidos por cada célula são exclusivamente binários, uma determinada célula recebe o valor 1 caso a mesma esteja preenchida e o valor 0 caso esteja vazia. 


\begin{tabular}{|c|c|c|}
\hline$C_{9}$ & $C_{2}$ & $C_{3}$ \\
\hline$C_{8}$ & $C_{1}$ & $C_{4}$ \\
\hline$C_{7}$ & $C_{6}$ & $C_{5}$ \\
\hline
\end{tabular}

Figura 2.4 - Conjunto de nove células

Considerando como referência a célula central $C_{l}$ da estrutura formada pelo agrupamento de nove células adjacentes quaisquer e assumindo que a mesma esteja ocupada, o funcionamento da técnica de esqueletização de imagens Thinning é descrito por meio da verificação de oito condições divididas igualmente em duas etapas. As condições do método são:

- Etapa A

- Condição 1: $2 \leq N\left(C_{1}\right) \leq 6$;

- Condição 2: $M\left(C_{1}\right)=1$;

- Condição 3: $s\left(C_{2}\right) * s\left(C_{4}\right) * s\left(C_{6}\right)=0$;

- Condição 4: $s\left(C_{4}\right) * s\left(C_{6}\right) * s\left(C_{8}\right)=0$.

- Etapa B

- Condição 1: $2 \leq N\left(C_{1}\right) \leq 6$;

- Condição 2: $M\left(C_{1}\right)=1$;

- Condição 3: $s\left(C_{2}\right) * s\left(C_{4}\right) * s\left(C_{8}\right)=0$;

- Condição 4: $s\left(C_{2}\right) * s\left(C_{6}\right) * s\left(C_{8}\right)=0$.

em que: $N\left(C_{1}\right)$ é a quantidade de células ocupadas ao redor de $C_{1}$, ou seja, $N\left(C_{1}\right)=s\left(C_{2}\right)+$ $s\left(C_{3}\right)+s\left(C_{4}\right)+s\left(C_{5}\right)+s\left(C_{6}\right)+s\left(C_{7}\right)+s\left(C_{8}\right)+s\left(C_{9}\right) ; M\left(C_{1}\right)$ é a quantidade de mudanças de 0 para 1 na sequência $C_{2}, C_{3}, \ldots ., C_{9}$.

Se as oito células vizinhas de $C_{1}$ satisfazem as condições de uma das etapas, então a célula central é convertida em uma célula vazia, pois a mesma não faz parte do esqueleto da imagem original. Quando as etapas A e B são realizadas sequencialmente as células mais externas, correspondentes ao contorno do objeto, são eliminadas, ou seja, convertidas em células vazias. 
Esse processo é repetido até que restem somente as células ocupadas pertencentes ao esqueleto da imagem. É fundamental observar que há uma peculiaridade na aplicação desta técnica na tarefa de mapeamento proposta neste trabalho. Como no mapeamento topológico o que se deseja é a linha mediana do espaço livre, e não os esqueletos dos objetos e obstáculos, durante o processo de discretização da grade de ocupação as células vazias são representadas, na verdade, pelo valor 1 e as células ocupadas pelo valor 0 , obtendo-se assim as linhas medianas do espaço de interesse.

Na Figura 2.5, são apresentados dois exemplos da aplicação do método Thinning. Os estados das células representadas pela cor cinza são iguais a 1, correspondendo aos estados $E M P$ das células da grade de ocupação. Os estados das células representadas pela cor branca são iguais a 0 , denotando os estados $O C C$ das células da grade. Considerando novamente a célula $C_{1}$ como referência e assumindo que seu estado é igual a 1 , de acordo com as oito condições de método tem-se que, na Figura 2.5(a), o estado da célula $C_{l}$ não é alterado após a aplicação da técnica de esqueletização de imagens. Uma vez que $N\left(C_{1}\right)$ é menor do que 2 e portanto não satisfaz a primeira condição da etapa A. Por outro lado, na Figura 2.5(b), o estado da célula $C_{1}$ é modificado para 0 , pois todas as condições do método são satisfeitas.

\begin{tabular}{|c|c|c|}
\hline $\mathrm{C}_{9}$ & $\mathrm{C}_{2}$ & $\mathrm{C}_{3}$ \\
\hline $\mathrm{C}_{8}$ & $\boldsymbol{C}_{\boldsymbol{1}}$ & $\mathrm{C}_{4}$ \\
\hline $\mathrm{C}_{7}$ & $\mathrm{C}_{6}$ & $\mathrm{C}_{5}$ \\
\hline
\end{tabular}

(a)

\begin{tabular}{|c|c|c|}
\hline $\mathrm{C}_{9}$ & $\mathrm{C}_{2}$ & $\mathrm{C}_{3}$ \\
\hline $\mathrm{C}_{8}$ & $\boldsymbol{C}_{\boldsymbol{1}}$ & $\mathrm{C}_{4}$ \\
\hline $\mathrm{C}_{7}$ & $\mathrm{C}_{6}$ & $\mathrm{C}_{5}$ \\
\hline
\end{tabular}

(b)

Figura 2.5 - Exemplo do método de esqueletização: (a) Estado de $C_{I}$ não alterado; (b) Estado de $C_{I}$ alterado

No Algoritmo 2.1, são apresentados os princípios gerais do método de esqueletização Thinning combinado com a técnica de mapeamento métrico OG. Para realizar a implementação desse método no sistema de navegação autônoma desenvolvido neste trabalho alguns ajustes foram necessários para adequar o método à estrutura do sistema. Dentre estes ajustes, deve-se mencionar principalmente que as alterações dos estados das células durante o processo de esqueletização se dão por meio de dois passos distintos. 
Em um primeiro passo, buscam-se descobrir apenas quais são as células pertencentes ao mapa métrico que deverão ter seus estados alterados para se gerar o mapa topológico. Em seguida, em um segundo passo, os estados das células são efetivamente alterados. Tais passos se tornam necessários pelo fato de que como o processo de esqueletização verifica a vizinhança de todas as células do mapa, a alteração imediata do estado de qualquer célula afeta diretamente a avaliação das células pertencentes a sua vizinhança. Sendo assim, torna-se necessário realizar os passos de verificação e atualização em fases completamente distintas.

Algoritmo 2.1 - Algoritmo do método de esqueletização de imagens

thinning $(C)$

VARIAVÉIS

$i, j$, continue, $N C, M C$ : Inteiro;

\section{INÍ́CIO}

\section{REPITA}

continue $=0$;

\section{PARA $i=(B r d S u p+1)$ ATÉ BrdInf FAÇA}

PARA $j=(B r d E s q+1)$ ATÉ BrdDir FAÇA

SE $\left(\mathrm{s}\left(\mathrm{C}_{\mathrm{i}, \mathrm{j}}\right)\right)$ ENTÃO

$$
\begin{aligned}
N C= & s\left(C_{i-1, j}\right)+s\left(C_{i-1, j+1}\right)+s\left(C_{i, j+1}\right)+s\left(C_{i+1, j+1}\right)+s\left(C_{i+1, j}\right)+s\left(C_{i+1, j-1}\right)+s\left(C_{i, j-1}\right) \\
& +s\left(C_{i-1, j-1}\right) ;
\end{aligned}
$$

Calcule a quantidade de mudanças de " 0 " para "1" ao redor da célula $C_{i, j}$ (variável $M C$ );

$\mathbf{S E}\left(((N C>=2) \mathbf{E}(N C<=6)) \mathbf{E}(M C==1) \mathbf{E}\left(s\left(C_{i-1, j}\right) * s\left(C_{i, j+1}\right) * s\left(C_{i+1, j}\right)==\right.\right.$ 0) $\left.\mathbf{E}\left(s\left(C_{i, j+1}\right) * s\left(C_{i+1, j}\right) * s\left(C_{i, j-1}\right)==0\right)\right) \mathbf{E N T} \tilde{\mathbf{A}} \mathbf{O}$ $s\left(C_{i, j}\right)=0$;

continue $=1$;

\section{FIM-SE}

$\mathbf{S E}\left(((N C>=2) \mathbf{E}(N C<=6)) \mathbf{E}(M C==1) \mathbf{E}\left(s\left(C_{i-1, j}\right) * s\left(C_{i, j+1}\right) * s\left(C_{i, j-1}\right)==\right.\right.$

0) $\left.\mathbf{E}\left(s\left(C_{i-1, j}\right) * s\left(C_{i+1, j}\right) * s\left(C_{i, j-1}\right)==0\right)\right) \mathbf{E N T} \tilde{\mathbf{O}}$ $s\left(C_{i, j}\right)=0$;

continue $=1$;

\section{FIM-SE}

\section{FIM-SE}

FIM-PARA 


\section{FIM-PARA}

ENQUANTO (continue $==1$ );

\section{FIM}

No algoritmo em questão, a variável $C$ representa a matriz contendo os valores dos estados das células da grade de ocupação. A variável $M C$ representa a quantidade de mudanças de 0 para 1 ao redor da célula de referência $C_{i, j}$ da matriz. A variável $N C$ expressa a quantidade de células com valor 1 ao redor da célula de referência. As variáveis BrdSup, BrdInf, BrdEsq e BrdDir são as bordas superior, inferior, esquerda e direita, respectivamente, responsáveis por delimitar as dimensões dos mapas gerados.

Atualmente, representações híbridas (RAWLINSON; JARVIS, 2008b; BLANCO et al., 2009; RIZZINI; CASELLI, 2009) que combinam as informações obtidas pelo mapeamento métrico e pelo mapeamento topológico têm sido propostos como uma solução promissora para lidar com ambientes reais amplos e complexos. Usualmente, propostas híbridas alocam mapas geométricos locais, adequados para os algoritmos de localização, nos nós de uma representação topológica, adequada para tarefas de planejamento de trajetórias.

Geralmente o mapa topológico é gerado por meio de técnicas baseadas em diagramas ou grafos de Voronoi (THRUN, 1998; CHOSET; NAGATANI, 2001; BOADA et al., 2004; KALRA et al., 2009). Rawlinson e Jarvis (RAWLINSON; JARVIS, 2008a) afirmam que métodos baseados em diagramas de Voronoi generalizados são os mais usualmente utilizados para a geração de mapas híbridos que contenham informações métricas e topológicas em representações paralelas. Tipicamente, o diagrama de Voronoi generalizado é computado a partir de dados globais de uma grade de ocupação, de modo que a principal vantagem do método é um planejamento topológico eficiente.

De acordo com Kwon et al (KWON et al., 2006), os métodos baseados em Grafos de Voronoi Generalizados, abreviados como GVG, são robustos para vários ambientes e podem ser estendidos a espaços de maiores dimensões. Contudo, as representações espaciais geradas por meio dos métodos GVG podem gerar linhas desfavoráveis ao mapeamento topológico. Tais linhas conectam pontos de junção, ou vértices do grafo de Voronoi, a pontos presentes nas regiões côncavas do ambiente, Figura 2.6(a). Por outro lado, como ilustrado na Figura 2.6(b), as técnicas de esqueletização de imagens não geram este tipo de situação. Dessa forma, os métodos Thinning são robustos a ruídos sensoriais e podem ser aplicados a diversos 
tipos de ambiente. Segundo Kwon et al (KWON et al., 2006), a técnica de esqueletização de imagens apresenta de modo geral um desempenho melhor do ponto de vista de eficiência computacional e da capacidade de representação das diversas características geométricas do ambiente.

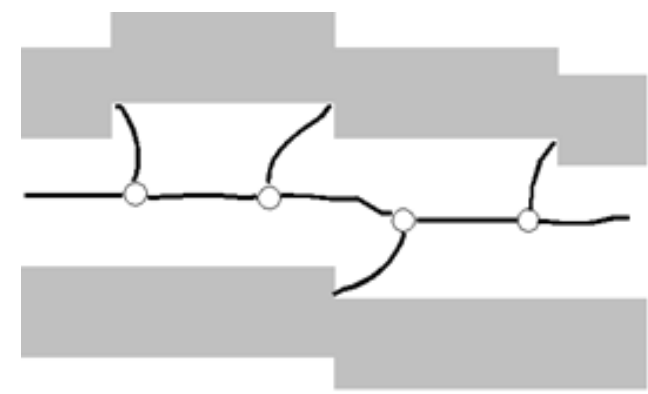

(a)

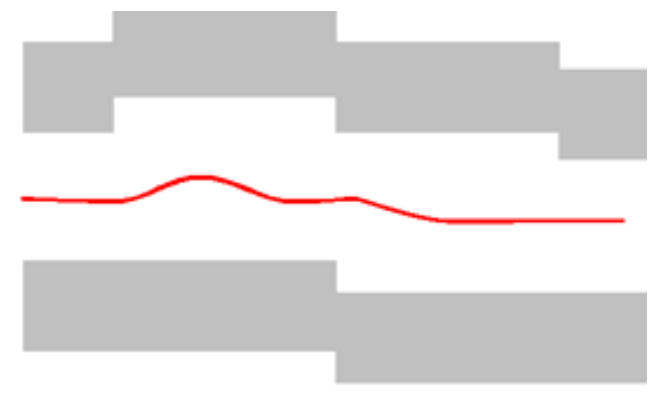

(b)

Figura 2.6 - Linhas topológicas: (a) Baseadas em GVG; (b) Baseadas em esqueletização de imagens

Oliveira et al. (OLIVEIRA et al., 2009) propõem um conjunto de filtros morfológicos que visam reduzir a influência de ruídos nos mapas gerados pela técnica Thinning. Os ruídos tratados no trabalho em questão são causados pelos próprios sensores do robô, de maneira que os mapas gerados por meio da esqueletização dos estados da grade de ocupação apresentam uma série de linhas topológicas que são desnecessárias para tarefas de navegação autônoma. Os filtros propostos reduzem a influência de tais ruídos, permitindo uma construção mais eficiente de mapas topológicos, por meio do método de esqueletização de imagens Thinning, em ambientes reais.

Na Figura 2.7, é apresentado um exemplo da construção incremental do mapa topológico a partir da técnica de esqueletização Thinning para o caso do ambiente simulado da Figura 2.1(a). A construção do mapa é realizada por partes, uma vez que o robô atualiza gradualmente o mapa métrico, utilizado para se determinar as linhas topológicas, enquanto explora o ambiente. Deve-se lembrar de que o mapa métrico adotado neste trabalho é obtido por meio do método OG proposto por Elfes (ELFES, 1989a). As linhas verdes observadas no mapa representam o mapa topológico. 


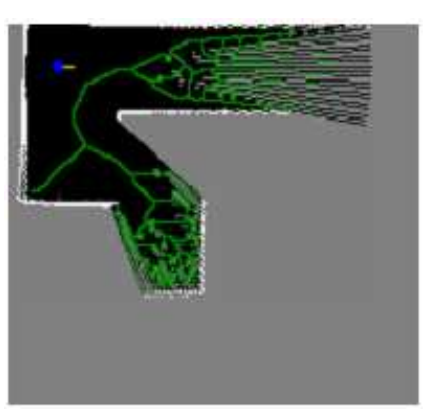

(a)

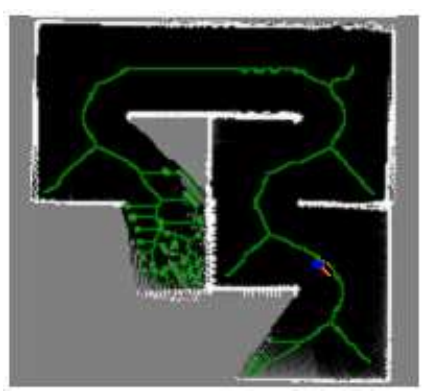

(d)

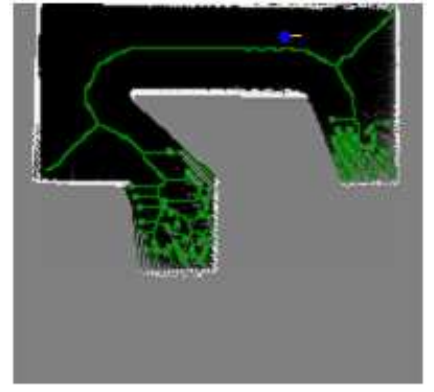

(b)

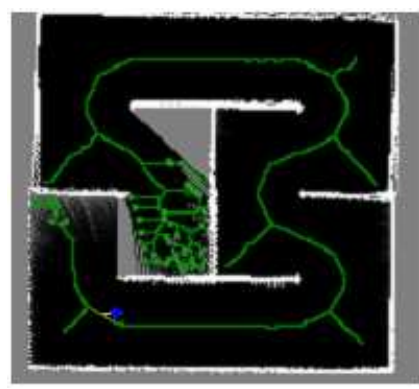

(e)

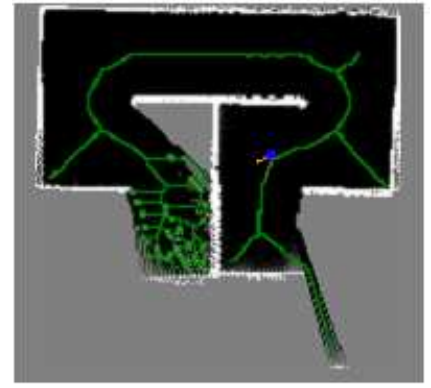

(c)

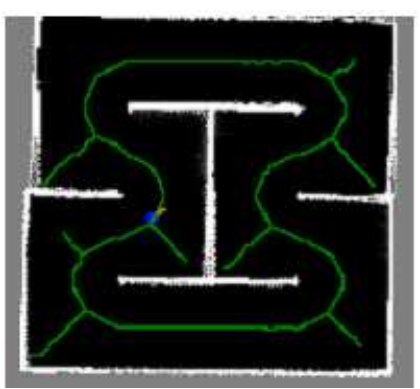

(f)

Figura 2.7 - Atualização incremental do mapa topológico

Na Figura 2.7(a), o primeiro estágio do mapeamento é ilustrado, no qual o robô adquire as primeiras leituras sensoriais do espaço livre do ambiente. Como pode ser observada, a região próxima ao robô é convertida no seu mapa topológico correspondente. Contudo, a região mais distante do robô ainda não está bem definida, uma vez que a região explorada é limitada pelo alcance dos sensores do próprio robô. À medida que a região superior do mapa é explorada, Figuras 2.7(b) e 2.7(c), e os estados das células correspondentes a esta região na grade de ocupação são atualizadas, as linhas topológicas são novamente computadas e corrigidas. Ao se completar a exploração do ambiente, Figura 2.7(f), o mapa topológico é finalmente obtido.

É importante observar, conforme ilustrado na Figura 2.7, que mesmo com a aplicação da técnica Thinning o mapa topológico do ambiente ainda apresenta algumas linhas topológicas desfavoráveis ao mapeamento, uma vez que tais linhas se aproximam das regiões côncavas do ambiente. Deve-se salientar que tais ocorrências não são causadas pela conexão de pontos pertencentes às linhas topológicos a pontos presentes em tais regiões côncavas, mas sim são provocadas como uma consequência natural da própria estrutura do ambiente durante a esqueletização do mesmo. Sendo assim, observa-se na prática que o mapeamento topológico baseado na técnica Thinning na verdade minimiza a ocorrência de tais linhas topológicas 
desfavoráveis ao mapeamento, porém não elimina por completo a presença destas linhas conforme apresentado por Kwon et al. (KWON et al., 2006).

\subsection{CONSIDERAÇÕES PARCIAIS}

Neste capítulo foram apresentados os principais conceitos referentes ao problema de mapeamento de ambientes. Duas técnicas diferentes de mapeamento de ambientes internos em particular foram discutidas. A primeira, denominada Grade de Ocupação, oriunda do paradigma métrico, trata o ambiente como um espaço reticulado, no qual cada célula da grade possui um valor real compreendido no intervalo [0,1] que é associado á probabilidade de ocupação da célula em questão. A segunda técnica, provenientes do paradigma topológico, é conhecida como Thinning. Sendo uma técnica de esqueletização de imagens, o mapa topológico obtido por meio da mesma é gerado considerando um processo iterativo de avaliação dos estados discretos das células pertencentes ao mapa métrico obtido com a primeira técnica.

Tais técnicas foram descritas porque as mesmas são utilizadas como métodos de mapeamento para avaliação da técnica de integração de mapas proposta neste trabalho. As representações espaciais métricas obtidas pelo método OG são os mapas propriamente utilizados no processo de integração de dados proposto. Enquanto que os mapas topológicos gerados pelo método Thinning são empregados apenas como ferramentas para se realizar comparações entre abordagens de mapeamento diferentes. Os critérios de comparação entre os mapas são explicados no Capítulo 5, que trata dos resultados obtidos com o presente trabalho.

O capítulo seguinte é dedicado a elucidar os aspectos referentes a algumas das diversas técnicas de integração de mapas encontradas na literatura. 
Como salientado anteriormente no Capítulo 1, a tarefa de integração de mapas pode ser categorizada em dois paradigmas distintos. O primeiro paradigma é baseado no alinhamento de landmarks presentes nos próprios mapas. Contudo, esta abordagem pode se tornar custosa, em termos de recursos computacionais, se o processo de transformação de coordenadas entre os mapas não encontra um alinhamento satisfatório para os mesmos. Esta circunstância em particular pode ocorrer quando as áreas exploradas por cada robô não possuem um ponto de interseção em comum, ou seja, cada área do ambiente é explorada exclusivamente por um robô diferente. O segundo paradigma é baseado nas observações de posição entre os robôs para realizar o alinhamento de mapas locais, tais observações são conhecidas como medidas de rendez-vous. Este paradigma possui como pressuposto fundamental que os robôs se encontrem pelo menos uma única vez durante a exploração do ambiente para realizar a integração de dados.

Burgard et al. (BURGARD et al., 2005) elucidam uma proposta na qual todos os robôs pertencentes ao sistema de exploração se encontram dentro de uma rede de comunicação com alcance ilimitado, possibilitando desta forma a transferência de informação sobre o mapeamento realizado por um determinado robô para todos os demais robôs pertencentes à rede de comunicação. Contudo, modificações para adequar esta proposta a redes com alcance restrito também são apresentadas pelos autores. No método em questão, independentemente do alcance da rede, cada agente do sistema armazena para cada outro robô um $\log$ das 
medidas sensoriais obtidas por este último. Adicionalmente ao $\log$, os robôs também possuem uma estrutura de dados que armazena o tempo decorrido desde a última transferência de dados realizada com um determinado robô, permitindo que os agentes avaliem e, consequentemente, descartem as medidas que forem consideradas redundantes. Esta prática visa evitar a transferência consecutiva de dados similares entre os robôs, uma vez que os agentes móveis poderiam enviar repetidamente uma mesma informação local às demais unidades da rede.

Um método onde robôs constroem mapas topológicos a partir de mapas métricos de tamanho fixo, baseados em grados de ocupação, é proposto por Chang et al. (CHANG et al., 2007). Nessa abordagem cada vértice do mapa topológico representa uma região e inclui um mapa métrico local. Se um robô viaja entre dois vértices, uma ligação é inserida para conectar essas duas regiões. Além disso, o método proposto leva em consideração o cálculo das matrizes de transformação necessárias para descrever o relacionamento entre vértices conectados de acordo com as posições relativas de cada robô.

Tong et al. (TONG et al., 2008) descrevem uma abordagem que estende a estratégia Extended Kalman Filter, abreviada como EKF e desenvolvida originalmente para um único robô, para um sistema com múltiplos robôs. As observações realizadas pelos robôs são utilizadas para atualizar tanto o posicionamento de cada robô quanto a localização dos landmarks do ambiente. Similarmente ao método proposto por Burgard et al. (BURGARD et al., 2005) , nesta abordagem as observações obtidas por um determinado robô também são transmitidas a todos os robôs que formam o sistema distribuído. Deste modo, o processo de mapeamento e localização baseado no EKF é realizado de acordo com a transferência destas observações.

Uma proposta que utiliza um filtro de partículas adaptado para determinar se, e como, dois mapas locais provenientes de dois robôs diferentes se sobrepõem é elucidada em (VINCENT et al., 2008). Antes de combinar as informações locais dos robôs em um único mapa global, a abordagem proposta realiza uma etapa preliminar de estimação das posições relativas entre pares de robôs. De acordo com a técnica, o processo de estimação é realizado apenas entre pares de robôs porque a complexidade de estimação das localizações relativas cresce exponencialmente em relação ao número de robôs considerados neste processo.

Uma técnica de junção de mapas utilizando como estratégia de detecção de landmarks o alinhamento de segmentos de linhas de um mapa topológico é proposta por Yu et al. (YU et al., 2009). O método em questão considera que os robôs estão dispersos em um ambiente 
desconhecido e os mesmos não conhecem suas posições globais e orientações iniciais. Dessa maneira, cada robô possui seu próprio sistema de coordenadas baseado em sua posição e orientação inicial. A técnica de integração é realizada considerando cinco passos, descritos a seguir:

- Padronização de landmarks geométricos: Sejam $M p_{1}$ e $M p_{2}$ os mapas locais de dois robôs quaisquer. Cada segmento de linha é representado em seu respectivo mapa local como um ponto inicial $\left(x_{1}, y_{1}\right)$ e um ponto final $\left(x_{2}, y_{2}\right)$. Considerando esta representação, pode-se tomar os ângulos entre pares de segmentos de linhas como landmarks naturais do ambiente;

- Busca de uma possível transformação: Dois ângulos são considerados iguais quando a diferença entre seus valores é menor do que uma constante pré-estabelecida. Se pelo menos um par de ângulos iguais é identificado, uma transformação de coordenadas pode ser aplicada para integrar os mapas em um mesmo sistema de coordenadas global;

- Avaliação da melhor transformação: Cada transformação sobre pares de ângulos iguais precisa ser avaliada para identificar o melhor alinhamento. Adotando o sistema de coordenadas de $M p_{1}$ como referência, a qualidade da transformação pode ser determinada por meio da obtenção do mapa $M p_{2}$ rotacionado e transladado no sistema de referência de $M p_{1}$. Quanto maior a sobreposição entre estes mapas, maior é a qualidade da transformação. Em mapas baseados em segmentos de linhas, o valor da transformação é equivalente ao tamanho dos segmentos de linhas produzidos pela transformação. Se uma transformação produz o maior somatório dos tamanhos, então esta transformação é considerada a mais apropriada;

- Redução do custo computacional do alinhamento: Em um mapa local, é comum que o vértice de um determinado ângulo tenha distâncias diferentes em relação aos vértices dos demais ângulos ao seu redor. Se dois ângulos iguais em $M p_{1}$ e $M p_{2}$ possuem a mesma informação de distância em relação aos ângulos adjacentes, então este par de ângulos iguais é considerado como um landmark fortemente notável. Além disso, este landmark e os demais ângulos ao seu redor são classificados como um cluster de características geométricas. É importante notar que o cluster é mais representativo do que um único par de ângulos. Considerando tal agregação, o número de clusters é 
menor do que o número de ângulos, reduzindo dessa forma o número de transformações necessárias para alinhar os dois mapas locais;

- Melhoramento da taxa de precisão do alinhamento: Se o sistema tem acesso às informações odométricas dos robôs, pode-se utilizar as medidas de imprecisão para minimizar a taxa de erro do processo de alinhamento de landmarks.

Zhou e Roumeliotis (ZHOU; ROUMELIOTIS, 2006) propõem um método para integração de mapas locais, individualmente gerados, baseado nas observações inter-robôs obtidas ao longo do processo de mapeamento realizado por cada robô. Nessa estratégia, o problema de alinhamento de mapas é resolvido por meio do processamento simultâneo das medidas de direção e distância relativa. Se os mapas gerados pelos robôs se sobrepõem, então landmarks duplicados podem ser identificados no mapa integrado. Impondo restrições nas posições dos landmarks alinhados, pode-se melhorar significativamente a qualidade da integração dos mapas locais. Considerando dois robôs $R_{1}$ e $R_{2}$, e seus respectivos mapas locais $M p_{1}$ e $M p_{2}$, os seguintes requisitos são necessários para a integração do mapa do robô $R_{2}$ com o mapa do robô $R_{l}$ : (a) uma estimativa da posição do robô $R_{l}$; (b) uma estimativa da posição do robô $R_{2}$; e (c) as medidas relativas de distância e direção entre os robôs.

Outro método de integração baseado em observações inter-robôs é proposto por Anderson e Nygards (ANDERSON; NYGARDS, 2009). Esta abordagem considera as medidas de rendez-vous obtidas ao longo das trajetórias percorridas por cada robô, sendo que o método proposto é baseado na técnica Collaborative Smoothing and Mapping, abreviada como C-SAM. Uma interessante característica desta técnica é que a mesma permite recuperar naturalmente a trajetória completa de um determinado robô. A solução proposta é dividida em duas etapas. A primeira etapa consiste em eliminar medidas falsas e criar um subconjunto válido de observações inter-robôs. A segunda etapa é responsável por encontrar observações consistentes entre todas as observações válidas e realizar a integração dos mapas locais.

Uma abordagem para mapeamento distribuído baseada em algoritmos de otimização por enxame de partículas, abreviado como PSO - do inglês Particle Swarm Optimization, e curva de Hilbert é proposta em (LIU; MA, 2009). Um método de mapeamento baseado em grades de ocupação é utilizado para modelar o ambiente, o qual é dividido em um número de subáreas. O PSO é adotado para selecionar uma subárea ótima para cada robô e o algoritmo de curva de Hilbert é utilizado como estratégia de exploração de cada subárea. A divisão do 
Capítulo 3 - Integração de Mapas

ambiente em subáreas é uma interessante característica que permite uma análise de desempenho baseada na porcentagem de exploração do ambiente. Um mecanismo de divisão similar ao proposto por Liu e Ma (LIU; MA, 2009) é adotado no presente trabalho e é descrito no Capítulo 5, contudo o único objetivo da divisão do ambiente no método de integração proposto é a análise de desempenho da estratégia.

De acordo com Topal et al. (TOPAL et al., 2013), embora os métodos de integração de mapas baseados em landmarks tenham demonstrado certo sucesso, tais propostas permanecem inviáveis para lidar com ambientes complexos e não estruturados, uma vez que a extração de características nesses ambientes é difícil de ser realizada e não existe nenhuma informação a priori sobre o mesmo. Sendo assim, segundo Topal et al., métodos de mapeamento baseados em grades de ocupação voltados para o modelamento do ambiente e para as tarefas de unificação de mapas locais têm se mostrado uma abordagem mais promissora.

Topal et al. (TOPAL et al., 2013) propõem um método de unificação de grades de ocupação baseado na seleção de características que levam em consideração a área e a intensidade de ocupação das células da grade. O método proposto é capaz de integrar mapas locais que possuem um grau limitado de regiões que se sobrepõem, aumentando assim a eficiência da tarefa de mapeamento. Os mapas são integrados sem o conhecimento da posição e orientação inicial dos robôs.

Outra abordagem voltada para a integração de grades de ocupação é apresentada em (BLANCO et al., 2013). Nesta abordagem, a integração é realizada considerando a busca de correspondências entre conjuntos de características esparsas detectadas nos mapas locais. Para lidar com a incerteza e ambiguidade proveniente da integração das grades, o método proposto realiza uma busca por subconjuntos de características similares entre pares de grades de ocupação. Os subconjuntos são utilizados para definir hipóteses sobre a translação e rotação necessárias para se unificar os pares de mapas analisados. A transformação entre os pares de grades de ocupação é definida de acordo com uma conversão das grades em suas imagens de mapa correspondentes. Tais imagens de mapa são resultantes da conversão da grade para imagens em escala de cinza, obtidas por meio da interpretação das células da grade como pixels e das probabilidades de ocupação como níveis de cinza.

A seguir, na Seção 3.1, é apresentada uma estratégia de compartilhamento de informações proposta por Tan et al. (TAN et al., 2004) para múltiplos robôs móveis. Esta estratégia é utilizada para o sensoriamento do ambiente e não para o mapeamento do mesmo. 
Contudo, por meio de uma adaptação em seu processo de translação dos sistemas de coordenadas é possível utilizar esta estratégia como uma técnica de integração de mapas locais baseada em observações inter-robôs. A adaptação da mencionada estratégia é elucidada e proposta na presente tese de Doutorado, de maneira que, mapas baseados em grades de ocupação são compartilhados e integrados entre os robôs que formam o sistema distribuído de exploração e vigilância do ambiente.

\subsection{MÉTODO DE COMPARTILHAMENTO DE INFORMAÇÃO}

A técnica de compartilhamento de informação baseada em observações inter-robôs proposta por Tan et al. (TAN et al., 2004) é um modelo distribuído para sistemas cooperativos que lida com tarefas relacionadas a cobertura e sensoriamento de ambiente. De acordo com este modelo, cada robô possui um sistema de coordenadas inercial local, de forma que o relacionamento entre os sistemas de coordenadas locais de robôs vizinhos pode ser considerado o critério determinante para o compartilhamento significativo de informações entre os mesmos.

Segundo Gage (GAGE, 1992), o problema de cobertura é definido como a maximização da área monitorada por um grupo de robôs em um determinado momento, de modo que a área de cobertura é observada se a região sobre a qual o sensoriamento é realizado é totalmente contígua em cada instante, ou seja, não há espaços não monitorados pelo sensoriamento obtido pelo grupo de robôs.

O método compartilha informações sobre o ambiente por meio de uma rede de comunicação Wireless, considerando o problema de cobertura de ambientes. Uma vez que o modelo proposto consiste de uma variedade de sensores acoplados a um grupo de robôs móveis, o sistema distribuído apresenta um comportamento cooperativo e orientado ao controle de formação de uma rede de sensores móveis. É importante notar que o método apenas compartilha informação sobre o estado do ambiente, mas não é responsável por criar uma representação espacial que descreve o mesmo. Sendo assim, se um determinado robô detecta um objeto em sua área de sensoriamento, o mesmo irá apenas compartilhar esta informação com os seus robôs vizinhos. 
O modelo de compartilhamento descrito por Tan et al. (TAN et al., 2004) define o relacionamento geográfico dos diferentes robôs empregados por meio de diagramas de Voronoi e triangularização de Delaunay (GUIBAS; STOLFI, 1985; SHEWCHUCK, 1997; KALLMAN et al., 2003; DE BERG et al., 2008). De maneira que, a triangularização de Delaunay é responsável por definir o relacionamento entre robôs vizinhos, enquanto que os diagramas de Voronoi são responsáveis por identificar e delimitar a área de cobertura de cada robô. Para compartilhar informações entre os robôs, uma matriz de transformação é computada considerando pares específicos de robôs.

No modelo em questão, os sistemas de coordenadas locais dos robôs podem ser completamente distintos, como ilustrado na Figura 3.1 pelos robôs $R_{i}$ e $R_{j}$. Para compartilhar eficientemente a informação entre os robôs, Tan et al. (TAN et al., 2004) propõem a utilização de uma matriz de transformação de coordenadas. De modo que, para que um robô $R_{j}$ compartilhe a informação sobre um objeto $\xi_{s}^{j}$ detectado em seu sistema de coordenadas local $\Sigma_{j}$ com o robô $R_{i}$, o relacionamento entre os dois sistemas de coordenadas $\Sigma_{i}$ e $\Sigma_{j}$ precisa ser determinado.

O relacionamento entre os sistemas de coordenadas de $R_{i}$ e $R_{j}$ pode ser definido pelas matrizes de transformação $T_{i j}$ e $T_{j i}$, sendo estas representadas pela distância entre os dois robôs e suas respectivas orientações relativas. Para dois robôs adjacentes $R_{i}$ e $R_{j}, R_{i}$ envia a $R_{j}$ sua percepção sobre as coordenadas $x$ e $y$ de $R_{j}$ em relação ao seu próprio sistema de coordenadas $\Sigma_{i}$. Em contrapartida, $R_{j}$ envia a $R_{i}$ sua percepção das coordenadas $x$ e $y$ de $R_{i}$ em relação ao seu sistema de coordenadas $\Sigma_{j}$.

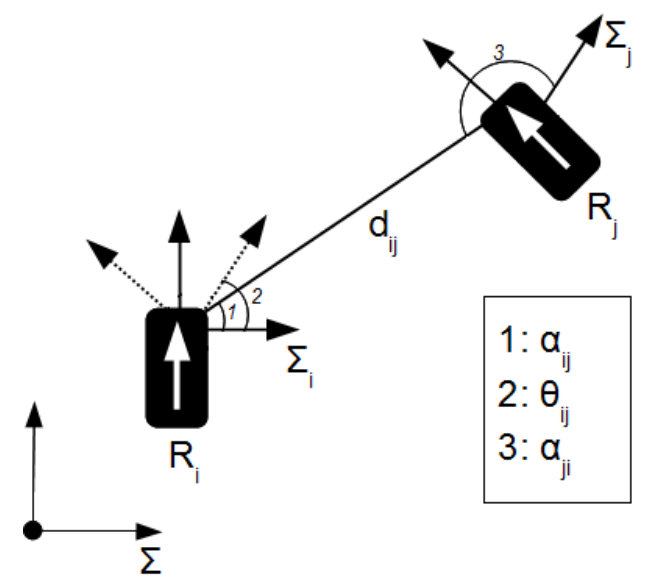

Figura 3.1 - Sistemas de coordenadas locais 
Baseados na comunicação direta entre os robôs $R_{i}$ e $R_{j}, \alpha_{i j}$ e $\alpha_{j i}$ são conhecidos para ambos os robôs, em que $\alpha_{i j}$ é a orientação do robô $R_{j}$ no sistema de coordenadas de $R_{i}$ e $\alpha_{j i}$ é a orientação de $R_{i}$ no sistema de coordenadas de $R_{j}$. A orientação relativa entre os eixos dos dois robôs é denotada por $\theta_{i j}$. Ambos os robôs são capazes de calcular a matriz de transformação $T_{i j}$, ou $T_{j i}$, por meio do compartilhamento de informações, segundo a Equação 3.1:

$$
T_{i}^{j}=\left[\begin{array}{cccc}
\cos \theta_{i j} & -\operatorname{sen} \theta_{i j} & 0 & d_{i j} \cos \alpha_{j i} \\
\operatorname{sen} \theta_{i j} & \cos \theta_{i j} & 0 & d_{i j} \cos \alpha_{j i} \\
0 & 0 & 1 & 0 \\
0 & 0 & 0 & 1
\end{array}\right]
$$

em que, $d_{i j}$ é a distância entre os robôs $R_{i}$ e $R_{j}$. Em cada sistema de coordenadas local, uma matriz de transformação define o relacionamento entre dois robôs quaisquer, de tal maneira que informações locais sobre o ambiente podem ser compartilhadas em um único sistema de coordenadas global.

Considere um ponto $P$ qualquer pertencente à $\Sigma_{i}, P=\left(x_{P}, y_{P}\right)$. A transformação do ponto $P$ para o sistema de coordenadas do robô $R_{j}$ se dá considerando dois passos distintos. Em um primeiro passo, segundo a Equação 3.2, o ponto $P$ sofre um processo de rotação baseado no ângulo relativo entre os robôs $R_{i}$ e $R_{j}$, de forma que um novo ponto $P$ ' é estabelecido.

$$
\begin{aligned}
& x_{P}^{\prime}=x_{P} \cos \theta_{i j}-y_{P} \operatorname{sen} \theta_{i j} \\
& y_{P}^{\prime}=x_{P} \operatorname{sen} \theta_{i j}+y_{P} \cos \theta_{i j}
\end{aligned}
$$

Em seguida, uma vez que o ponto $P$ pertencente ao sistema de coordenadas de $R_{i}$ é rotacionado, o próximo passo é a translação do ponto $P^{\prime}$ para o sistema de coordenadas $\Sigma_{j}$, como apresentado na Equação 3.3. O ponto $P^{*}$, oriundo desta translação, resulta em uma posição de coordenada de $\Sigma_{j}$ que dever ser integrada com a coordenada do ponto $P$ pertencente a $\Sigma_{i}$.

$$
\begin{aligned}
& x_{P}^{*}=x_{P}^{\prime}+d_{i j} \cos \alpha_{j i} \\
& y_{P}^{*}=y_{P}^{\prime}+d_{i j} \operatorname{sen} \alpha_{j i}
\end{aligned}
$$

Uma importante observação sobre a matriz de transformação elucidada por Tan et al. (TAN et al., 2004) é que a mesma é idealizada para um processo de compartilhamento no qual 
Capítulo 3 - Integração de Mapas

cada robô sempre ocupa a posição central de seu sistema de coordenadas, ou seja, o sistema de coordenadas de cada robô é variante em relação ao tempo. Considerando uma situação em que o robô se locomova através do ambiente, o centro do sistema de coordenadas deste robô acompanhará continuamente a trajetória do mesmo ao longo deste percurso, dificultando assim a construção incremental de uma representação espacial do ambiente. Deste modo, o método proposto de integração de mapas locais visa sanar esta limitação do modelo de compartilhamento de Tan et al., tornando-o capaz de integrar eficientemente mapas baseados em sistemas de coordenadas obtidos por múltiplos robôs móveis.

\subsection{CONSIDERAÇÕES PARCIAIS}

Neste capítulo, foram abordados alguns trabalhos referentes à integração de mapas locais produzidos por um sistema com múltiplos robôs móveis. Tais trabalhos podem ser categorizados em dois grandes paradigmas: aqueles baseados no alinhamento de landmarks presentes no ambiente e os baseados em observações inter-robôs de distância e orientações relativas.

Além das técnicas de integração apresentadas, um método de compartilhamento de informação, voltado para tarefas de cobertura de ambientes, proposto por Tan et al. (TAN et al., 2004) também foi descrito. Embora o método em questão não leve em consideração tarefas de mapeamento, a proposta de integração de mapas abordada nesta tese de doutorado é baseada em uma modificação do referido método.

No Capítulo 4, é apresentada a estratégia de integração de mapas baseados em grades de ocupação proposta no presente trabalho. Além disso, a técnica de exploração e vigilância de ambientes, baseada em uma modificação do algoritmo de otimização por colônias de formigas, é igualmente apresentada. 
Capítulo 3 - Integração de Mapas 
Considerando a estratégia proposta de integração de mapas locais baseados em grades de ocupação, envolvendo múltiplos robôs móveis, cada indivíduo do grupo de robôs é dotado de um sistema de navegação autônoma independente. Sistema este responsável tanto pela exploração do ambiente quanto pelo mapeamento do mesmo. Os mapas representados a partir desta proposta são definidos por uma grade de inferência (ELFES, 1989b; ELFES, 1989c) constituída de quatro níveis.

As células do nível um da grade são correspondentes às probabilidades de ocupação obtidas a partir do método de mapeamento métrico proposto por Elfes (ELFES, 1989a). O nível dois da grade é representado pela discretização das probabilidades do primeiro nível nos estados $O C C, E M P$ e $U N K$. Esta discretização ocorre segundo uma regra de decisão de máximo a posteriori, ou regra MAP.

No nível três, é representado o mapa topológico do ambiente, gerado por meio da técnica de esqueletização de imagens Thinning elucidada em (KO et al., KWON et al., 2006; OLIVEIRA; ROMERO, 2009; OLIVEIRA et al., 2009). É importante salientar que estas três camadas iniciais devem ser geradas necessariamente nesta ordem especifica, uma vez que determinado nível da grade depende diretamente dos resultados obtidos no nível anterior.

Finalmente, as células do nível quatro são constituídas por valores reais compreendidos no intervalo $[0,1]$, de maneira que tais valores correspondem à concentração do feromônio na região do ambiente relacionada àquela célula. As concentrações de 
feromônio são utilizadas como critérios de decisão em relação a direção a ser tomada por cada robô durante a exploração do ambiente.

Uma importante vantagem da aplicação desta abordagem baseada nas concentrações de feromônio como estratégia de exploração é o fato de que nenhuma posição meta específica necessita ser determinada, desse modo, o sistema atua autonomamente sem a necessidade de um agente externo conduzir o processo de exploração do ambiente. A estratégia de exploração baseada nas concentrações de feromônio é descrita na Seção 4.2. Na Figura 4.1, é apresentada a grade de inferência adotada no presente trabalho.

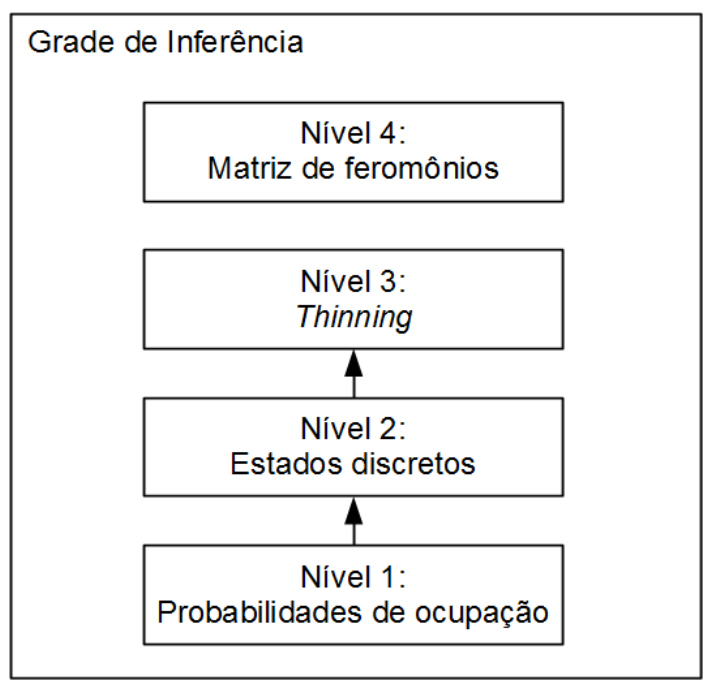

Figura 4.1 - Grade de Inferência

Tomando os robôs isoladamente, o objetivo de cada indivíduo é explorar de forma segura o ambiente no qual se encontra, construindo simultaneamente uma representação espacial da região sensoriada pelo mesmo. Em contrapartida, tomando-se o sistema por completo, os robôs móveis também possuem o objetivo de transmitir aos demais indivíduos do grupo seus respectivos mapas locais, de forma que, por meio da troca de informações, seja possível construir mapas mais representativos do ambiente em um menor intervalo de tempo.

A seguir, na Seção 4.1, é apresentado o método de integração de mapas locais proposto na presente tese de doutorado. 


\subsection{MÉTODO DE INTEGRAÇÃO DE MAPAS}

A técnica de integração de mapas proposta neste trabalho é baseada na matriz de transformação de sistemas de coordenadas elucidada por Tan et al. (TAN et al., 2004). A matriz de transformação original é utilizada em tarefas de compartilhamento de informações em problemas de cobertura. Como discutido anteriormente na Seção 3.1, a técnica de Tan et al. é idealizada para um processo de compartilhamento de informação no qual cada robô sempre ocupa a posição $(0,0)$ de seu sistema de coordenadas.

No contexto do mapeamento, esta restrição obriga que todo mapa do robô seja recalculado a cada movimento do mesmo, de forma a garantir que o robô sempre ocupe o centro de seu próprio sistema de coordenadas. Visando eliminar esta restrição e permitir a utilização do método de compartilhamento proposto por Tan et al. em tarefas de mapeamento, a técnica de integração proposta altera o centro do sistema de coordenadas de cada robô para as suas respectivas posições iniciais, uma vez que as mesmas não se alteram ao logo da exploração do ambiente.

Como os sistemas de navegação dos robôs são independentes e estes últimos não possuem nenhum conhecimento prévio sobre o ambiente no qual se encontram, a posição inicial de cada robô em seu respectivo sistema de coordenadas é definida como a posição $(0,0)$, além disso, define-se também que a orientação inicial de cada robô é o ângulo $0^{\circ}$ no seu sistema de coordenadas.

É importante notar que mesmo que um determinado robô se locomova pelo ambiente, o centro de seu sistema de coordenadas permanece, neste caso, configurado na posição inicial do robô e não em sua correspondente posição no ambiente. Outro trabalho na literatura que também lida com sistemas de coordenadas independentes é apresentado por Yu et al. (YU et al., 2009), sendo este discutido no Capítulo 3.

A formulação matemática do processo de integração de mapas locais é descrita a seguir. Considere dois robôs $R_{i}$ e $R_{j}$ adjacentes com seus respectivos mapas locais $M p_{i}$ e $M p_{j}$, descritos nos sistemas de coordenadas $\Sigma_{i}$ e $\Sigma_{j}$ correspondentes. Dois robôs $R_{i}$ e $R_{j}$ são considerados adjacentes se o robô $R_{i}$ está dentro do alcance do raio de comunicação $R C_{j}$ do robô $R_{j}$, assim como $R_{j}$ está dentro do alcance do raio de comunicação $R C_{i}$ do robô $R_{i}$. Uma vez que os robôs sejam adjacentes, o robô $R_{i}$ envia a $R_{j}$ seu próprio mapa local $M p_{i}$ e sua própria posição (xi,yi) dentro de $M p_{i}$, em contrapartida, $R_{j}$ envia a $R_{i}$ seu mapa local $M p_{j}$ e sua própria posição $(x j, y j)$ dentro de $M p_{j}$. Baseados na percepção entre os robôs $R_{i}$ e $R_{j}, \alpha_{i j}$ e $\alpha_{j i}$ 
são conhecidos para ambos os robôs, em que $\alpha_{i j}$ é a orientação de $R_{j}$ no sistema de coordenadas de $R_{i}$ e $\alpha_{j i}$ é a orientação de $R_{i}$ no sistema de coordenadas de $R_{j}$. A distância entre os robôs $R_{i}$ e $R_{j}$ é diretamente observada pelos mesmos e é denotada por $d_{i j}$ ou $d_{j i}$.

A orientação relativa entre os eixos dos robôs $R_{i}$ e $R_{j}$ é expressa por $\theta_{i j}$, como ilustrado na Figura 4.2(a). Assumindo um cenário no qual ocorre o compartilhamento do mapa do robô $R_{j}$ com o robô $R_{i}$, são apresentados na Figura 4.3(b), a distância $d_{i j}$ entre os mesmos e a orientação observada de $R_{j}$ no sistema de coordenadas de $R_{i}$.

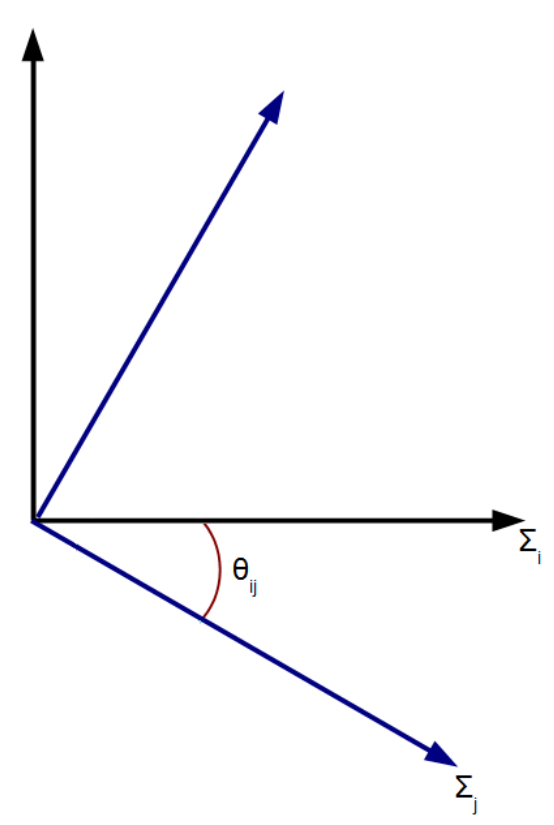

(a)

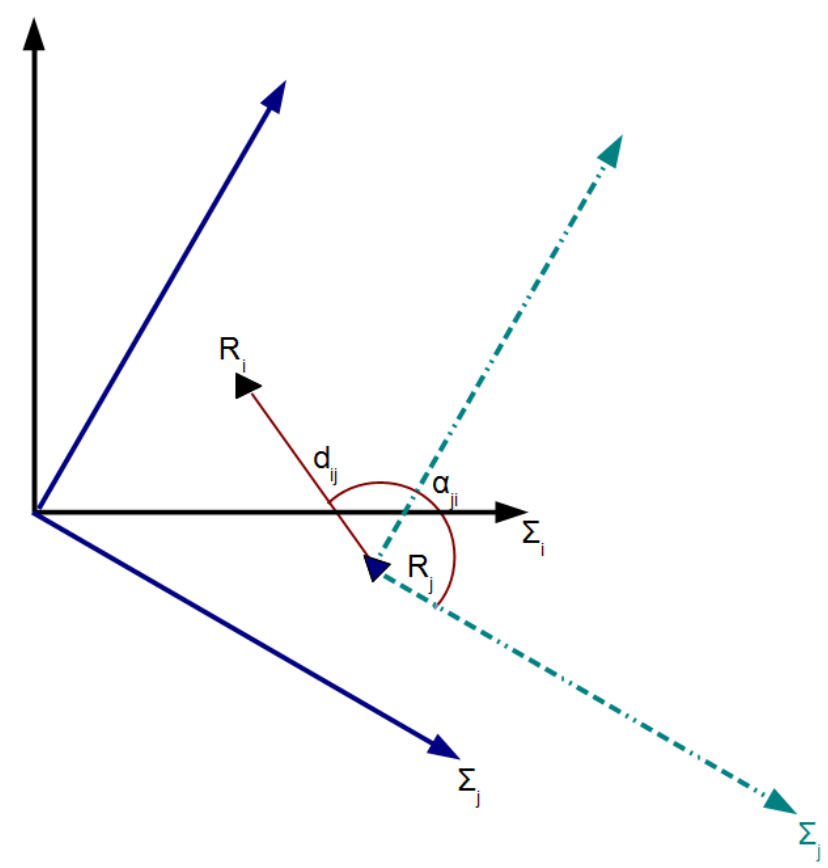

(b)

Figura 4.2 - Parâmetros do método de integração

Considere como exemplo um ponto $P$ qualquer pertencente à $M p_{i}$, tal que $P=\left(x_{P}, y_{P}\right)$, como apresentado na Figura 4.3(a). Deve se observar que o comportamento esperado do método de integração de mapas locais proposto, considerando como referência o ponto $P$, é a definição de um novo ponto $P^{*}=\left(x_{P}^{*}, y_{P}^{*}\right)$, agora em $M p_{j}$, tal que suas coordenadas correspondam à mesma região espacial descrita pelo ponto $P$, assim como ilustrado na Figura 4.3(b). Nesta situação, a integração dos mapas ocorre através da união das informações espaciais contidas nas coordenadas dos pontos $P$ e $P^{*}$, presentes nos mapas de $M p_{i}$ e $M p_{j}$, respectivamente. 


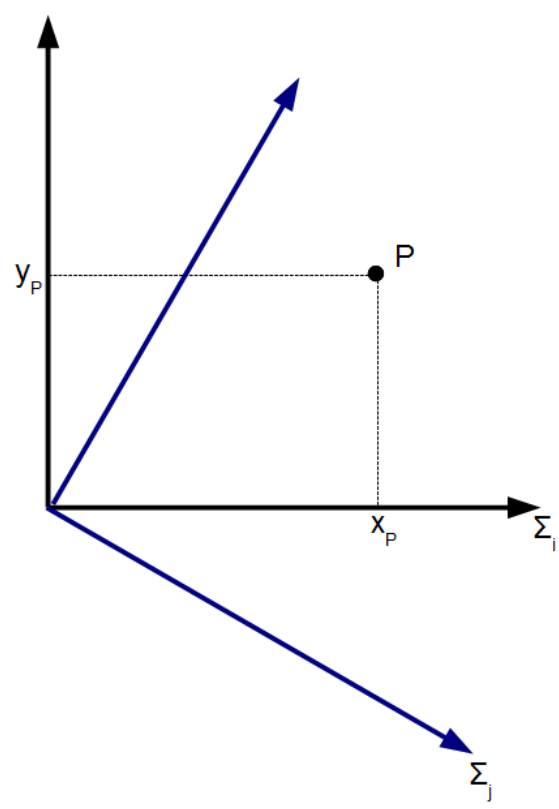

(a)

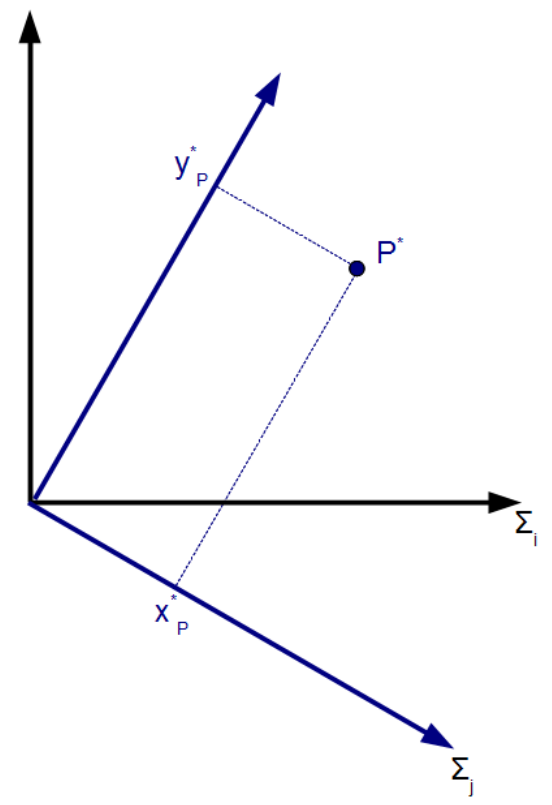

(b)

Figura 4.3 - Exemplo do método de integração

O método de integração de mapas locais pode então ser definido segundo a Equação 4.1 apresentada a seguir. Como pode ser observado, esta equação transcreve tanto o processo de rotação do ponto $\mathrm{P}$, segundo a orientação relativa $\theta_{i j}$ entre os eixos dos robôs $R_{i}$ e $R_{j}$, quanto o processo de translação do mesmo para o sistema de coordenadas do robô $R j$. Deve-se mencionar que assim como o modelo de compartilhamento de Tan et al. (TAN et al., 2004) pode ser definido através das matrizes de transformação $T_{i j}$ e $T_{j i}$, o método de integração de mapas proposto também pode ser aplicado tanto do mapa do robô $R_{i}$ para $R_{j}$, quanto de $R_{j}$ para $R_{i}$, tomando-se os devidos cuidados referentes aos índices da Equação 4.1.

$$
\left[\begin{array}{l}
x_{P}^{*} \\
y_{P}^{*}
\end{array}\right]=\left[\begin{array}{l}
\cos \theta_{i j}-\operatorname{sen} \theta_{i j} \\
\operatorname{sen} \theta_{i j}+\cos \theta_{i j}
\end{array}\right]\left[\begin{array}{l}
x_{P} \\
y_{P}
\end{array}\right]-\left[\begin{array}{l}
\cos \theta_{i j}-\operatorname{sen} \theta_{i j} \\
\operatorname{sen} \theta_{i j}+\cos \theta_{i j}
\end{array}\right]\left[\begin{array}{l}
x_{i} \\
y_{i}
\end{array}\right]+\left[\begin{array}{l}
x_{j}+d_{i j} \cos \alpha_{j i} \\
y_{j}+d_{i j} \operatorname{sen} \alpha_{j i}
\end{array}\right]
$$

Analisando-se o processo de integração de mapas locais por partes, inicialmente o ponto $P$ - Figura 4.4(a) - sofre um processo de rotação baseado no ângulo relativo entre os robôs, de forma que uma nova coordenada $P^{\prime}=\left(x_{P}^{\prime}, y_{P}^{\prime}\right)$ é estabelecida, como apresentado na 
Equação 4.2. Uma vez que o ponto $P$ é rotacionado de acordo com o ângulo relativo, torna-se necessário definir a posição do robô $R_{i}$ - Figura 4.4(a) - segundo esta rotação realizada. De modo similar a equação anterior, obtém-se a posição rotacionada do robô $R_{i}$ por meio da Equação 4.3.

$$
\begin{aligned}
x_{P}^{\prime} & =x_{P} \cos \theta_{i j}-y_{P} \operatorname{sen} \theta_{i j} \\
y_{P}^{\prime} & =x_{P} \operatorname{sen} \theta_{i j}+y_{P} \cos \theta_{i j} \\
x_{i}^{\prime} & =x_{i} \cos \theta_{i j}-y_{i} \operatorname{sen} \theta_{i j} \\
y_{i}^{\prime} & =x_{i} \operatorname{sen} \theta_{i j}+y_{i} \cos \theta_{i j}
\end{aligned}
$$

Considerando a rotação do sistema de coordenadas do mapa de $R_{i}$, segundo o ângulo relativo entre os robôs, calcula-se a seguir a distância no eixo $x$ e no eixo $y$ do ponto $P$ ' à posição rotacionada do robô $R_{i}$ - Figura 4.4(b) - segundo a Equação 4.4:

$$
\begin{aligned}
& x_{i}^{P}=x_{P}^{\prime}-x_{i}^{\prime} \\
& y_{i}^{P}=y_{P}^{\prime}-y_{P}^{\prime}
\end{aligned}
$$

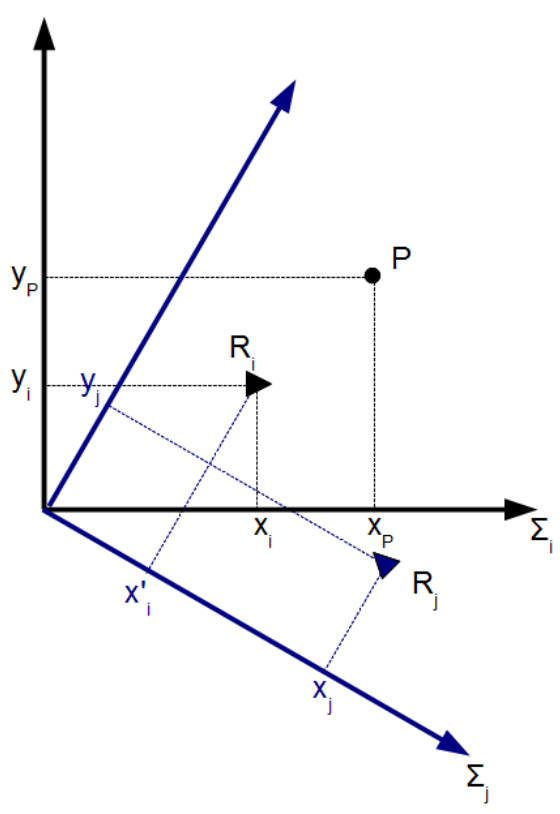

(a)

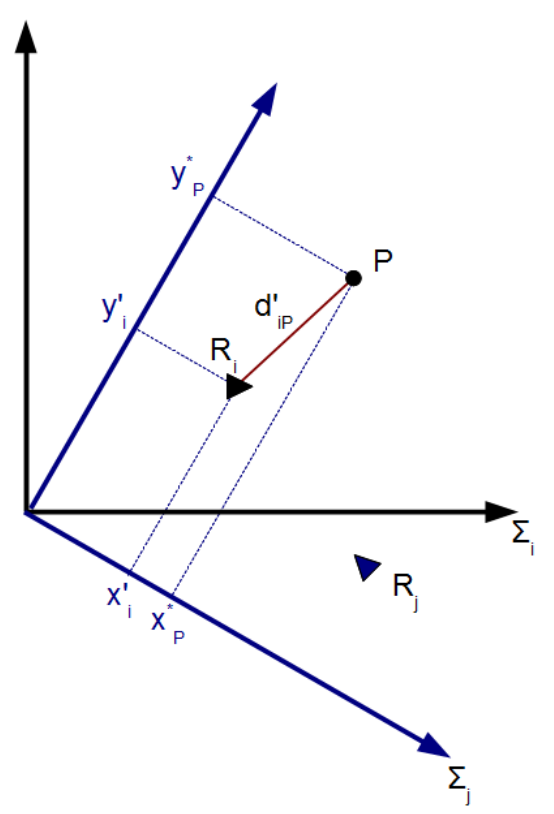

(b)

Figura 4.4 - Dados para a integração 
Uma vez que os cálculos de rotação sejam realizados e a relação do ponto $P$ ao robô $R_{i}$ no sistema de coordenadas rotacionado seja definida, a próxima etapa a ser realizada é a translação do ponto $P^{\prime}$ para o sistema de coordenadas do mapa $M p_{j}$, como apresentado na Equação 4.5. O ponto $P^{*}$, oriundo desta translação, resulta em uma coordenada de $M p_{j}$ que deve ser integrada com a coordenada do ponto $P$ pertencente à $M p_{i}$.

$$
\begin{aligned}
& x_{P}^{*}=x_{j}+d_{i j} \cos \alpha_{j i}+x_{i}^{P} \\
& y_{P}^{*}=y_{j}+d_{i j} \operatorname{sen} \alpha_{j i}+y_{i}^{P}
\end{aligned}
$$

Pela definição anterior, o ponto $P^{*}$ é estabelecido segundo a posição do robô $R_{j}$ em seu próprio sistema de coordenadas, assim como pela percepção de distância entre os dois robôs e pela relação de distância entre o ponto $P$ e a posição do robô $R_{i}$ no sistema de coordenadas rotacionado de $M p_{i}$, como ilustrado na Figura 4.5. É importante notar que por esta definição, a posição do robô $R_{j}$ é considerada durante o processo de translação das coordenadas do robô $R_{i}$, o que difere a técnica proposta do método de compartilhamento de informação adotado por Tan et al. (TAN et al., 2004).

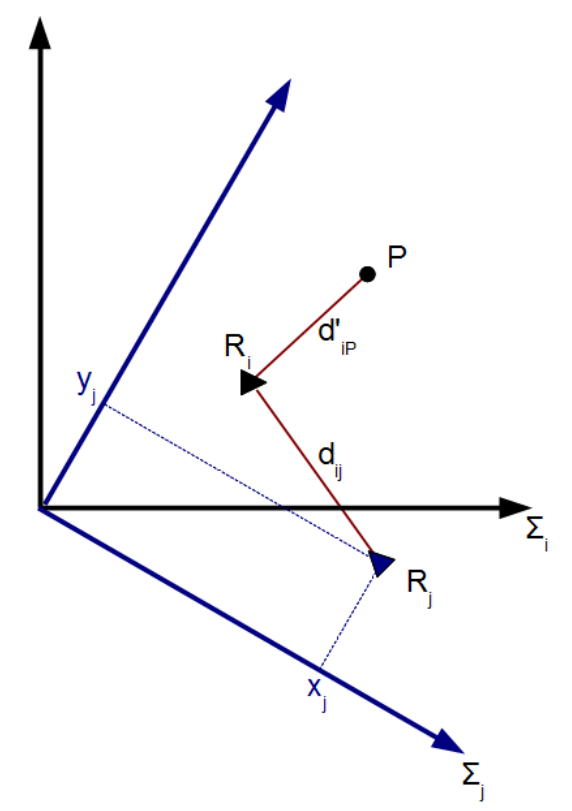

Figura 4.5 - Rastreamento do ponto $P^{*}$ 
O processo de integração de mapas locais entre dois robôs $R_{i}$ e $R_{j}$ pode ser visualizado no Algoritmo 4.1, representado pela função denominada integrar. A variável itInicio controle $_{\text {a }}$ indica um parâmetro de controle que define uma quantidade inicial de iterações para que o processo de integração seja inicializado. Esta variável visa garantir que os robôs adquiram uma quantidade mínima de informação sobre o ambiente no qual estão inseridos antes de compartilhar seus mapas com os demais robôs.

Inspirado na estratégia proposta por Burgard et al. (BURGARD et al., 2005), cujo trabalho apresenta uma estrutura de dados que armazena o tempo decorrido desde a última transferência de dados entre um determinado par de robôs, outro importante parâmetro de controle é representado pela variável $i t_{\text {intervalo }}$ Esta variável é responsável por determinar o menor intervalo de iterações para que uma nova integração seja realizada entre um mesmo par de robôs. Assim como no trabalho de Burgard et al., este parâmetro visa reduzir a troca redundante de informação entre os robôs, garantindo um método de mapeamento com múltiplos robôs mais eficiente.

Algoritmo 4.1 - Algoritmo do método de integração

Integrar( it $_{\text {atual }}$, posicao $\left._{R j}, \operatorname{mapa}_{R j}, i d_{R j}\right)$

\title{
VARIAVÉIS
}

itInicio $_{\text {controle }}$, it $_{\text {intervalo, }}$ intervalo, ultimaIntegracao ${ }_{\text {RiRj: }}$ Inteiro;

\section{INÍCIO}

\author{
SE $\left(\right.$ it $_{\text {atual }}>=$ itInicio $\left._{\text {controle }}\right)$ ENTÃO \\ intervalo $\leftarrow i t_{\text {atual }}-$ ultimaIntegracao $_{R i R j}$; \\ SE (intervalo $\left.>i t_{\text {intervalo }}\right)$ ENTÃO \\ ultimaIntegracao ${ }_{R i R j} \leftarrow i t_{\text {atual }}$; \\ rotacionarMapa $\left(\right.$ posicao $_{R j}$, mapa $\left._{R j}\right)$; \\ transladarMapa $\left(\right.$ posicao $_{R j}$, mapa $\left._{R j}\right)$; \\ calcularIntegracao $\left(\right.$ mapa $\left._{R i}, \operatorname{mapa}_{R j}\right)$;
}

FIM-SE

\section{FIM-SE}

Assumindo que as restrições impostas pelas variáveis itInicio $_{\text {controle }}$ e it $_{\text {intervalo }}$ são satisfeitas, o cálculo da transformação do sistema de coordenadas do robô $R_{j}$ é iniciado. As 
funções rotacionarMapa e transladarMapa são responsáveis por rotacionar e transladar, respectivamente, a grade de ocupação do robô $R_{j}$ para o sistema de coordenadas do robô $R_{i}$, segundo as equações de rotação e translação descritas previamente nesta seção. Uma vez que ambos os mapas são descritos em sistemas de coordenadas compatíveis, a grade de ocupação do robô $R_{j}$ é integrada com a grade de ocupação do robô $R_{i}$ por meio da função calcularIntegração. No presente trabalho, o cálculo da integração é realizado determinandose a média aritmética das probabilidades de ocupação das células dos mapas locais dos robôs $R_{i}$ e $R_{j}$

Outras restrições poderiam ser definidas para o processo de exploração de acordo com as especificações da tarefa de navegação de interesse, tal como uma restrição de ativação que consiste na especificação de um evento desencadeador para realizar a integração. Por exemplo, realizar o processo de junção de mapas apenas quando uma nova informação espacial é obtida pelo robô. Contudo, uma vez que a estratégia de navegação adotada neste trabalho é orientada a tarefas de exploração e vigilância, deve-se observar que tal restrição de integração baseada em novas informações espaciais não é apropriada.

Para melhor compreender tal observação, considere uma situação na qual esta última restrição de integração é ativada e que um determinado par de robôs, $R_{i}$ e $R_{j}$, se encontre apenas em dois instantes distintos durante todo o processo de exploração do ambiente, sendo uma vez na iteração $i t_{1}$ e outra na iteração $i t_{2}$. Em seu primeiro encontro, na iteração $i t_{1}$, o robô $R_{i}$ compartilha o seu mapa local com $R_{j}$. Em seu segundo encontro, na iteração $i t_{2}$, o mapa local de $R_{i}$ não foi atualizado com nenhuma nova informação espacial desde a última integração e portanto, segundo a restrição de integração baseada em novas informações espaciais, não é compartilhado com $R_{j}$. Nesta situação, uma desvantagem evidente é a perda de informação temporal. Em tarefas de vigilância, que são um dos focos da estratégia IAS-SS, a informação de que o estado do ambiente não se alterou nos últimos momentos é um dado relevante e crucial. Sendo assim, uma vez que o IAS-SS é idealizado tanto para tarefas de exploração quanto para problemas de vigilância, a restrição de integração baseada em novas informações espaciais não é adotada no método de integração desenvolvido neste trabalho, embora esta possa ser aplicada em outras abordagens que utilizem o método de integração proposto.

Inspirada na metodologia de comunicação utilizada por Calvo (CALVO, 2012) na estratégia SAFS, orientada para problemas de formação e descrita na Seção 4.4, adota-se no presente trabalho um mecanismo de comunicação similar ao empregado pelo referido autor. 
Sendo assim, no método proposto de integração de mapas locais os robôs se comunicam entre si por meio de uma antena. Tal dispositivo de comunicação emite e detecta informações, ou mensagens, em torno dos robôs dentro de um raio de comunicação $R C>0$. Dois tipos de mensagens são emitidos e detectados pela antena no método proposto, sendo as mesmas modeladas na forma: (msg_id) e (msg_id, msg_dados).

A primeira mensagem - $\left(m s g \_i d\right)$ - indica o identificador de um determinado robô $R_{k}$, informação esta utilizada pelos demais robôs localizados dentro do raio de comunicação de $R_{k}$ na decisão relacionada ao compartilhamento de dados com o robô em questão, segundo a restrição imposta pelo parâmetro $i t_{\text {intervalo }}$. Caso o intervalo mínimo para uma nova integração de dados seja satisfeito, os robôs então emitem a segunda mensagem - (msg_id, msg_dados) responsável por carregar os dados utilizados na integração (grade de inferência e posição do robô dentro do mapa métrico). A primeira mensagem é emitida de forma contínua por todos os robôs, enquanto que a segunda só é transmitida quando a restrição de $i t_{\text {intervalo }}$ é satisfeita para um determinado par de robôs.

É importante observar que o compartilhamento de informações entre os robôs ocorre apenas entre pares de robôs. Mesmo que existam outros agentes dentro do raio de comunicação de um determinado robô, este último realiza o processamento de compartilhamento de dados apenas com um destes agentes a cada instante, visando minimizar o congestionamento do canal de comunicação dos robôs.

Considerando a situação na qual dois ou mais robôs estão localizados dentro do raio de comunicação de um determinado robô $R_{i}$ e estes satisfazem simultaneamente todas as restrições de integração no instante $t$, impostas pelas variáveis itInicio $_{\text {controle }}$ e $i_{\text {intervalo, a }}$ prioridade com a qual o robô $R_{i}$ compartilha seus dados espaciais é definida segundo o maior intervalo de tempo sem integrações entre tais robôs e o robô $R_{i}$. Ou seja, o robô $R_{i}$ compartilha preferencialmente, no instante $t$, seu mapa local com aquele robô, localizado dentro de seu raio de comunicação, cuja última integração de dados ocorreu há mais tempo.

\subsection{ESTRATÉGIA DE EXPLORAÇÃO}

Para que um sistema de navegação seja efetivamente autônomo é necessário que o mesmo possua a capacidade de construir e manter uma representação espacial do ambiente no 
qual os robôs se encontram. Para criar esta representação espacial, ou mapa, um robô deve explorar o ambiente. A exploração do ambiente pode ser realizada de duas formas diferentes: manualmente, quando um ser humano controla ativamente o processo de locomoção do robô; ou autonomamente, quando o robô se locomove no ambiente independentemente de um controlador externo. Dada a natureza de mapeamento distribuído do presente trabalho, uma metodologia autônoma sugere ser mais adequada, pois o controle manual de cada um dos agentes que compõe o sistema é pouco viável neste cenário. A seguir, nesta seção, é apresentada a estratégia de exploração IAS-SS para coordenação de sistemas com múltiplos robôs móveis proposta por Calvo et al. (CALVO et al., 2011a; CALVO et al., 2011b; CALVO et al., 2011c).

Como elucidado anteriormente, a estratégia IAS-SS aborda o problema de exploração e vigilância de ambientes desconhecidos por sistemas multi-robóticos, seguindo as principais ideias relacionadas ao paradigma de sistemas de formigas artificiais. Essencialmente, um sistema multi-robótico no presente contexto é um grupo de agentes artificiais que se locomovem independentemente, de maneira que o ajuste na direção de movimento em tais agentes é realizado considerando-se alguns estímulos percebidos diretamente do ambiente.

Um robô é capaz de receber estímulos a partir da detecção da concentração do feromônio depositado em uma determinada área do ambiente, ajustando assim sua direção de navegação de acordo com a concentração detectada. Deve-se notar que enquanto os robôs se locomovem pelo ambiente esta mesma substância é liberada em torno das trajetórias percorridas pelos mesmos. É importante destacar que, nesta estratégia, o único critério utilizado pelos robôs para explorar completamente o ambiente no qual se encontram é precisamente a concentração de feromônio.

A lógica de decisão do IAS-SS é oposta àquela adotada pela teoria tradicional de sistemas de formigas, de modo que os robôs são impelidos para regiões com baixas concentrações de feromônio. Especificamente, quanto menor a quantidade detectada de feromônio em uma área do ambiente, maior é a probabilidade que o robô defina uma direção de navegação orientada para a área em questão. O diagrama de blocos apresentado na Figura 4.6 representa a sequência das principais ações realizadas por um robô do sistema a cada iteração da estratégia de exploração. 


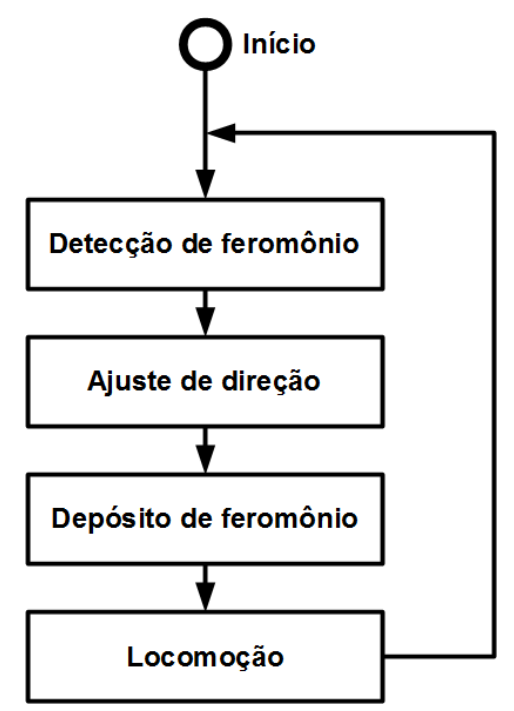

Figura 4.6 - Diagrama de blocos do IAS-SS

Uma importante característica da estratégia IAS-SS é o seu comportamento de desvio de obstáculos, obtido como uma consequência da natureza repulsiva do feromônio. Na estratégia, quando um robô está próximo a um obstáculo, a concentração de feromônio na área em questão é aumentada. Uma vez que a concentração de feromônio nesta área é maior, o robô apresenta naturalmente um comportamento de desvio de obstáculos. Sendo assim, as trajetórias geradas pela estratégia IAS-SS guia o sistema multi-robótico para um cenário livre de colisões, mantendo uma distância segura dos robôs aos obstáculos e dos robôs entre si.

Vale ressaltar que há alguns casos específicos em que o desvio de obstáculos oferecido pelo IAS-SS não é suficiente para uma navegação livre de colisões, tais casos são apresentados e tratados em (CALVO et al., 2012). De modo geral, tais casos específicos são tratados por meio de um mecanismo para desvio de obstáculos baseado em lógica fuzzy (ZADEH, 1965; LEE et al., 2012), sendo que os mesmos são ocasionados devido às próprias características físicas dos robôs. Tal mecanismo é ativado quando a distância do robô a um obstáculo é menor do que uma constante pré-definida.

Uma descrição detalhada da estratégia IAS-SS é elucidada a seguir. Considere um grupo de $N$ robôs $R_{k}, k=1, \ldots, N$. Cada robô $R_{k}$ pertencente ao grupo realiza duas operações básicas: ajuste na direção de movimento e depósito de feromônio. Como ilustrado na Figura 4.7, o modelo sensorial adotado na estratégia IAS-SS é tal que são detectados todos os estímulos de feromônio a uma distância específica $R D$ do robô, a partir de 90 graus a esquerda do centro do robô até 90 graus a direita de seu centro. Tais estímulos correspondem à média 
da quantidade de feromônio depositado em um determinado intervalo angular. O total de 180 graus é dividido em intervalos angulares idênticos, de modo que o sensor detecta estímulos correspondentes a diferentes ângulos $A_{s}$, tal que: $(2 S+1) \alpha=180$ e $A_{s}=s \alpha$, em que $s \in[-S$, $S]$ e $s \in \mathbb{N}$.

É importante notar que o modelo sensorial descrito na Figura 4.7 se refere apenas ao modelo de percepção de feromônio utilizado por cada robô. O modelo sensorial completo empregado no método proposto nesta tese consta ainda com as seguintes características, além das descritas previamente: (1) um dispositivo de comunicação, ou antena, que permite que os robôs identifiquem uns aos outros e que compartilhem suas correspondentes grades de inferência, de modo que tal dispositivo é delimitado por um raio de comunicação $R C$; e (2) um sensor de distância de obstáculos para construção da grade de ocupação do ambiente. Para efeitos de simplificação os limites de detecção dos sensores de feromônio e de distância de obstáculos são considerados iguais.

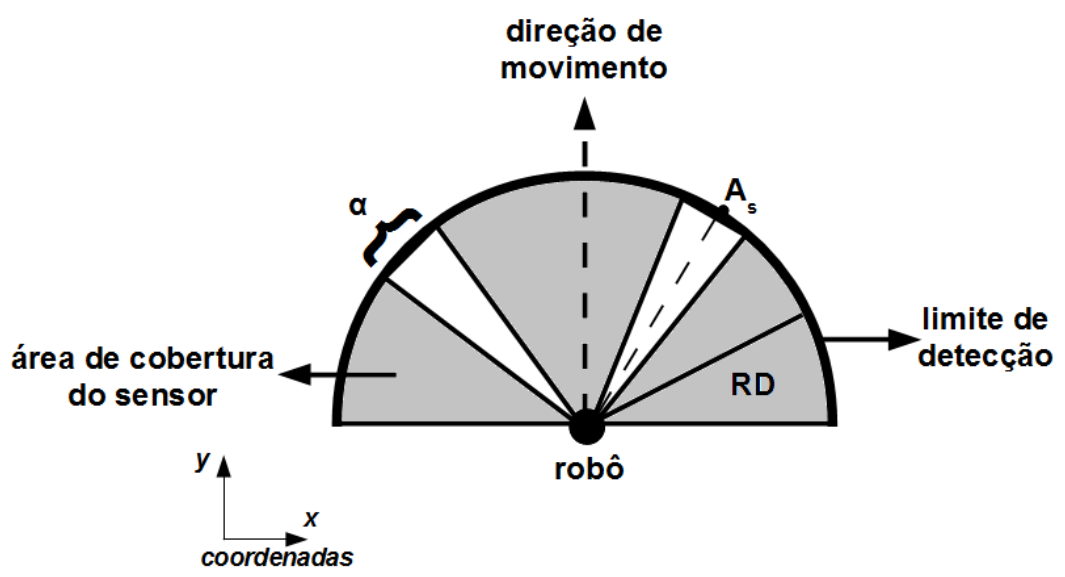

Figura 4.7 - Modelo sensorial do robô

Considerando novamente as operações básicas realizadas pelos robôs, o ajuste na direção de movimento dos mesmos segue o seguinte princípio fundamental. Assumindo um conjunto de estímulos proveniente dos feromônios detectados, a probabilidade que um determinado intervalo angular seja definido como a nova direção a ser seguida é inversamente proporcional à concentração de feromônio depositada no respectivo intervalo angular. Desta forma, o comportamento geral do sistema multi-robótico adotando o IAS-SS como estratégia 
de exploração é que os robôs se orientem para áreas desconhecidas ou ainda para áreas esparsamente visitadas ao longo do tempo pelos mesmos.

O depósito de feromônio ocorre por meio da liberação do mesmo em toda a região compreendida dentro da área de cobertura do sensor, de modo que tal depósito é inversamente proporcional à distância da área de liberação ao centro do robô. Assim, quanto maior a distância em relação ao robô, menor será a quantidade de feromônio a ser depositada na área em questão.

$\mathrm{Na}$ estratégia IAS-SS há dois métodos diferentes para definir o ajuste na direção de movimento dos robôs. O primeiro, denominado Amostragem Estocástica e abreviado neste trabalho como AE, considera todos os possíveis estímulos de feromônio observados no limite de detecção do sensor do robô. O segundo, denominado Amostragem Estocástica Elitista e abreviado como AEE, determina o ajuste na direção de movimento considerando um subconjunto bem definido das concentrações de feromônio encontradas nos limites de detecção do sensor. Ambos os métodos são elucidados a seguir:

\section{- Amostragem Estocástica}

Um estímulo de feromônio é definido pela quantidade de feromônio depositado em um determinado intervalo angular. A probabilidade de que um intervalo angular $A_{s}$ seja selecionado como a nova direção de movimento é inversamente proporcional à quantidade de feromônio no intervalo em questão. De maneira que, quanto menor a quantidade de feromônio detectado em intervalo angular específico, maior é a probabilidade associado ao mesmo. Especificamente, a probabilidade $P\left(A_{s}\right)$ atribuída ao ângulo $A_{s}$ é:

$$
P\left(A_{s}\right)=\frac{1-\tau_{s}}{\sum_{i=-S}^{S}\left(1-\tau_{i}\right)}
$$

em que $\tau_{s}$ é a quantidade de feromônio no intervalo angular $A_{s}$.

O ajuste na direção de movimento é determinado por meio de uma variável aleatória discreta definida de acordo com a probabilidade $P\left(A_{s}\right)$, assumindo valores no conjunto $\left\{A_{s} \mid s\right.$ $=-S, \ldots-1,0,1, \ldots, S\}$. A cada iteração $t$, o ajuste na direção de movimento é definido por: 
Capítulo 4 - Método Proposto

$$
\Theta_{R_{k}}(\mathrm{t})=\Theta_{R_{k}}(\mathrm{t}-1)+\gamma A_{s}^{*}
$$

em que: $\Theta_{R k}(t)$ é a direção de movimento do robô $R_{k}$ no instante $t ; \gamma \in[0,1]$ é uma constante de suavização para o ajuste na direção de movimento; e $A_{s}{ }^{*}$ é a direção estabelecida pela probabilidade definida na Equação 4.6.

Uma limitação relevante do método AE é elucidada em (CALVO et al., 2012). O método em questão não é eficiente para ambientes com grandes dimensões, uma vez que a quantidade de feromônio depositado nos diferentes intervalos angulares é similar em todos os pontos do ambiente. Neste cenário, a quantidade de feromônio dos intervalos angulares difere pouco entre os mesmos, fazendo com que a definição do ajuste na direção de movimento conduza o robô para direções desfavoráveis. Deve-se ressaltar que tal definição desfavorável é ocasionada pela própria natureza estocástica da estratégia de exploração. Uma solução alternativa para esta limitação é o método AEE descrito a seguir.

\section{- Amostragem Estocástica Elitista}

Neste método, diferentemente do $\mathrm{AE}$, nem todos os ângulos $A_{s}$ são considerados para definir a direção de movimento dos robôs. No método AEE dois subconjuntos formados pelos ângulos $A_{s}$ são considerados no processo de ajuste de direção. $\mathrm{O}$ primeiro, denominado subconjunto $U$, é constituído pelos intervalos angulares com as menores quantidades de feromônio detectadas entre todas as concentrações de feromônio em um determinado instante t. O segundo, denominado subconjunto $V$, é formado por intervalos angulares escolhidos aleatoriamente, de acordo com uma distribuição uniforme, dentre os ângulos $A_{s}$ não pertencentes ao subconjunto $U$. O subconjunto $V$ é construído para garantir a representatividade dos intervalos angulares observados pelo robô. As regras para construção dos subconjuntos $U$ e $V$ são:

- Subconjunto $U$ se $A_{s} \in U$ e $A_{z} \notin U$, então $\tau_{s} \leq \tau_{z}$

- Subconjunto $V$ se $A_{s} \in V$, então $A_{s} \notin U$ e $A_{s}$ é escolhido aleatoriamente em que: $\tau_{s}$ e $\tau_{z}$ são as quantidades de feromônio nos intervalos angulares $A_{s}$ e $A_{z}$, respectivamente; e s, $\mathrm{z}=-\mathrm{S}, \ldots,-1,0,1, \ldots, \mathrm{S}$. 
A probabilidade de escolha de um determinado intervalo angular, em ambos os conjuntos $U$ e $V$, é calculada de modo similar. Como no método AE, a probabilidade atribuída ao ângulo $A_{s}$ é inversamente proporcional a quantidade de feromônio depositado no respectivo intervalo angular. Especificamente, a probabilidade $P\left(A_{s}\right)$ é dada por:

$$
P\left(A_{s}\right)=\frac{1-\tau_{s}}{\sum_{i \in\left\{s \mid A_{s} \in\{U \cup V\}\right\}}\left(1-\tau_{i}\right)}
$$

em que $\tau_{s}$ é a quantidade de feromônio no intervalo angular $A_{s}$.

Os robôs na estratégia IAS-SS depositam feromônio dentro da área de cobertura de seu sensor, delimitada pelo limite de detecção do mesmo. A quantidade de feromônio liberada diminui a medida que a distância em relação ao centro do robô aumenta. Considere que $L_{k}{ }^{t}$ seja a área de cobertura do sensor do robô $R_{k}$ na iteração $t$ e que $Q$ denote o espaço inteiro do ambiente, de modo que $L_{k}{ }^{t} \subset Q \subset \mathbb{R}^{2}$. A quantidade de feromônio $\Delta_{q}^{k}(t)$, depositado pelo robô $R_{k}$ na posição $q$ durante a iteração $t$ é definida por:

$$
\begin{aligned}
& \Delta_{q}^{k}(t)=\left(1-\tau_{q}(t-1)\right) \Gamma_{q}^{k}(t) \\
& \Gamma_{q}^{k}(t)=\left\{\begin{array}{c}
\delta e^{\frac{-\left(q-q_{k}\right)^{2}}{\sigma^{2}}}, \text { se } \mathrm{X} \in L_{t} \\
0, \text { caso contrário }
\end{array}\right.
\end{aligned}
$$

em que: $q_{k}$ é a posição do robô $R_{k}$; $\sigma$ é a dispersão; e $\delta \in[0,1]$. Analisando-se esta formulação matemática em relação à técnica de mapeamento métrico OG, utilizada no presente trabalho, deve-se notar que a posição $q \in Q$ é diretamente relacionada a uma determinada célula $C_{i}$ da grade de inferência.

Além do processo de liberação de feromônio no ambiente, o mesmo evapora de acordo com uma taxa específica. A quantidade total de feromônio que evapora na posição $q$ durante o instante $t$ é modelada por meio da variável $\Phi_{q}(t)$ e é definida pela Equação 4.11.

$$
\Phi_{q}(t)=\rho \tau_{q}(t)
$$

em que: $\rho$ é a taxa de evaporação; e $\tau_{q}(t)$ é a quantidade total de feromônio na posição $q$ durante o instante $t$.

A quantidade total de feromônio na posição $q$ durante o instante $t$ é dada por: 


$$
\tau_{q}(t)=\left(\tau_{q}(t-1)-\Phi_{q}(t-1)\right)+\sum_{k=1}^{N} \Delta_{q}^{k}(t)
$$

O Algoritmo 4.2 ilustra o funcionamento geral da combinação do processo de exploração e mapeamento com múltiplos robôs, considerando como referência um robô $R_{i}$ qualquer. A variável iteracoes indica a quantidade total de iterações que a estratégia é executada. As variáveis $i d_{R i}$ e $i d_{R j}$ indicam os identificadores dos robôs $R_{i}$ e $R_{j}$, respectivamente. Similarmente, os mapas dos robôs $R_{i}$ e $R_{j}$ são representados pelas variáveis $\operatorname{mapa}_{R i}$ e $\operatorname{mapa}_{R j}$, respectivamente, assim como suas posições são denotadas por posicao pi $\mathrm{e}$ posicação $_{R j}$. É importante observar que a posicao $_{R i}$ indica a posição do robô $R_{i}$ em seu mapa $m a p a_{R i}$. A mesma observação também é válida para a variável posicação $o_{R j}$.

A função atualizarMapa é responsável por atualizar a grade de ocupação do robô por meio das leituras obtidas diretamente de seus sensores. As funções enviarDados e receberDados são responsáveis por enviar e receber, respectivamente, os dados referentes ao mapa local do robô e a posição do mesmo dentro deste. Caso um robô $R_{i}$ identifique um robô $R_{j}$ dentro de seu raio de comunicação e receba os dados espaciais deste último, a função integrar, responsável pela integração dos mapas locais e apresentada no Algoritmo 4.1, é chamada.

Algoritmo 4.2 - Algoritmo de controle do sistema

controle()

\section{VARIAVÉIS}

iteracoes: Inteiro;

\section{INÍCIO}

PARA $i_{\text {atual }} \leftarrow 1$ ATÉ iteracoes FAÇA

atualizarMapa();

enviarDados $\left(\right.$ posicao $_{R i}$, mapa $\left._{R i}, i d_{R i}\right)$;

SE $\left(\right.$ receberDados $\left(\right.$ posicao $\left._{R j}, \operatorname{mapa}_{R j}, i d_{R j}\right)==$ VERDADEIRO $)$ ENTÃO

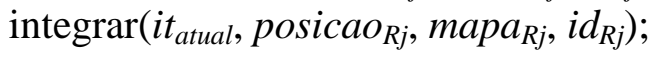

\section{FIM-SE}

detectarFeromonio();

ajustarDirecaoMovimento();

liberarFeromonio();

mover(); 


\section{FIM-PARA \\ FIM}

A função detectarFeromonio identifica as concentrações de feromônio nos limites de alcance do sensor do robô, de modo que o ajuste de direção de movimento do mesmo possa ser determinado de acordo com estas concentrações pela função ajustarDirecaoMovimento. Uma descrição detalhada de como as concentrações de feromônio são utilizadas como critérios de decisão sobre a direção de movimento a ser tomada por um determinado robô é elucidada na Seção 4.2. Uma vez que a direção de movimento é definida, o robô deposita feromônio sobre a área coberta pelos seus sensores por meio da função liberarFeromonio e se locomove para a direção definida previamente, por meio da função mover.

Uma importante questão que deve ser analisada ao se considerar o uso de feromônios na estratégia de exploração é a aplicabilidade do mesmo em ambientes reais utilizando-se robôs reais. Especificamente, o principal ponto a ser discutido é como os robôs devem realizar a interação do feromônio com o ambiente no qual os mesmos se encontram. A seguir, na Seção 4.3, uma breve discussão sobre o tópico em questão é realizada, apresentando-se uma solução para o problema, oriunda da união da estratégia de exploração IAS-SS com o método de integração de mapas proposto na presente tese de doutorado.

\subsection{FEROMÔNIO VIRTUAL}

Inicialmente, a opção mais evidente para a aplicação dos conceitos de feromônio em ambientes reais é a utilização tanto de dispositivos físicos capazes de liberar uma determinada substância a ser detectada quanto de sensores capazes de quantificar a concentração da mesma nos ambientes nos quais os robôs se encontram.

Diversos trabalhos na literatura (LILIENTHAL; DUCKETT, 2004; FERRI et al., 2011; RODRÍGUEZ et al., 2012) exploram o problema de se criar uma representação espacial do ambiente a partir de dados coletados por robôs móveis equipados com sensores de gás. Em contraste aos mapas métricos tradicionais obtidos a partir de sensores de distância dos tipos sonar e laser, uma única medida de um sensor baseado na detecção de gás fornece 
Capítulo 4 - Método Proposto

informações sobre uma área pequena, quando comparadas às informações provenientes dos sensores previamente mencionados.

De acordo com Lilienthal e Duckett (LILIENTHAL; DUCKETT, 2004) em um mapa de concentração de gás baseado em grades, cada célula do mapa contém uma estimativa da concentração relativa do gás detectado em uma área particular do ambiente. Contudo, segundo os autores, há vários problemas que devem ser considerados e tratados ao se criar tal representação.

O principal deles é que a distribuição das moléculas de gás em um ambiente que não é adequadamente ventilado tende a ser dominada por fluxos de convecção, em vez de difusão. Isso normalmente resulta em um padrão irregular de turbilhões temporalmente flutuantes. Em outras palavras, a distribuição das moléculas de gás gera diversas regiões com máxima concentração local, de maneira que, o valor máximo absoluto detectado é frequentemente identificado a certa distância da localização real da fonte de gás, se a mesma estiver operante durante algum tempo.

Como salientado anteriormente, outro problema relacionado aos sensores de gás, quando comparados aos sensores dos tipos sonar e laser, é que uma única medida de um sensor eletrônico de gás fornece informações acerca apenas de uma pequena área. Este problema é agravado pelo fato de que estes mesmos sensores, usualmente, não fornecem medidas instantâneas das concentrações de gás. Em vez disso, tais sensores são afetados por um longo tempo de resposta e de recuperação. É importante observar que tal característica é consideravelmente problemática para aplicações cujo tempo de resposta deve ser obtido em tempo real, como por exemplo, a estratégia de mapeamento elucidada nesta tese.

A construção autônoma de uma grade de ocupação cujas células identificam múltiplas fontes de gás, ou odor, em um ambiente interno sem um adequado fluxo de ar é proposta por Ferri et al. (FERRI et al., 2011). Esta abordagem é baseada em uma adaptação do tradicional método de mapeamento Bayesiano de grades de ocupação aplicado ao problema de localização de fontes químicas. Cada célula da grade de ocupação modificada contém uma estimativa para a concentração do gás detectado na correspondente área do ambiente. No trabalho em questão, as fontes espalhadas pelo ambiente emitem uma substância baseada em etanol. Um robô, dotado de um sensor de óxido de metal, se locomove autonomamente pelo ambiente mensurando a concentração desta substância enquanto constrói a grade de ocupação modificada do ambiente. 
Embora a concretização da questão do feromônio na estratégia IAS-SS possa ser realizada com dispositivos físicos reais, utilizando-se princípios similares aos apresentados por Ferri et al. (FERRI et al., 2011), a aplicação do mesmo pode se demonstrar desvantajosa para o cenário do presente trabalho. Uma vez que a estratégia IAS-SS visa tratar do problema de vigilância e exploração de ambientes internos, a emissão de substâncias por um robô durante a sua navegação pode ser considerada inadequada dependendo do ambiente no qual o mesmo se encontra, por exemplo, um escritório. Uma alternativa mais adequada e que não sofre dos problemas elucidados por Lilienthal e Duckett (LILIENTHAL; DUCKETT, 2004) é a utilização de feromônios virtuais integrados.

$\mathrm{Na}$ abordagem proposta baseada em feromônio virtual, cada robô é responsável por gerenciar o seu próprio mapa de concentração de feromônio, realizando as operações de depósito e evaporação da substância quando apropriado. Uma vez que cada robô mantém um mapa local de concentração de feromônio, deve-se realizar um processo de integração destas informações de maneira similar àquela realizada com o método de integração de mapas elucidado neste trabalho. Tal integração deve ser realizada de modo que os robôs tenham acesso não apenas aos dados de seu próprio processo de depósito de feromônio, mas também aos resultados da exploração dos demais robôs que compõem o sistema de vigilância.

Em uma situação ideal, em que o custo computacional não é relevante, a integração do feromônio pode ser realizada assumindo um raio de comunicação infinito entre os robôs e que os mesmos trocam informações entre si a cada iteração. Sendo assim, se os robôs compartilham as informações sobre o feromônio com todos os demais a cada instante, as grades de feromônio dos mesmos correspondem ao mapa global das concentrações de feromônio do ambiente.

Dadas as características dos dispositivos de comunicação atuais, a suposição de um raio de comunicação infinito, ou melhor, de um raio de comunicação capaz de conectar entre si todos os robôs (TONG et al., 2008), pode ser implementada por meio de dispositivos baseados em comunicação Wireless, como apresentado por Yun et al. (YUN et al., 2005). Na abordagem proposta de feromônio virtual integrado descrita acima, o principal problema é o tempo computacional de se compartilhar os dados referentes aos mapas locais de feromônio entre todos os robôs a cada iteração.

Uma solução para este problema é a inserção de uma restrição que garanta que os robôs troquem informações apenas após um intervalo mínimo de iterações. Além de reduzir o tempo computacional do sistema, tal restrição reduz também a troca redundante de 
Capítulo 4 - Método Proposto

informação entre os robôs. Deve-se notar que tal restrição é diretamente relacionada à variável $i t_{\text {intervalo }}$ descrita no Algoritmo 4.1, elucidado no início do presente capítulo.

Outro fator relevante que pode ser considerado para reduzir o custo computacional da abordagem é garantir que os robôs compartilhem seus mapas de feromônio apenas com aqueles robôs compreendidos dentro de um raio de comunicação $R C$. Uma vez que o processo de ajuste de direção de um robô $R_{k}$ considera apenas as concentrações de feromônio nos limites de alcance de seu próprio sensor de feromônio, apenas os robôs próximos à $R_{k}$ interferem de forma mais impactante no ajuste da direção de movimento do mesmo, por meio da liberação de feromônio.

Para garantir uma representatividade do real estado das concentrações de feromônio presentes no ambiente, os robôs poderiam ainda compartilhar seus mapas de feromônio com todos os demais segundo um limite de tempo pré-estabelecido. Garantindo que os mesmos possuam dados referentes a regiões distantes de suas atuais localizações no ambiente. Contudo, analisando-se os resultados obtidos com o presente trabalho, descritos no Capítulo 5, tal definição de limite de tempo não se mostrou necessária para garantir uma exploração eficiente do ambiente e, portanto, não foi utilizada na execução dos experimentos realizados em simulação.

A seguir, na Seção 4.4, é apresentada uma extensão da estratégia IAS-SS elucidada em (CALVO, 2012) que visa a aplicação da mesma considerando o problema de formação de robôs. Neste tipo de problema, a organização espacial dos robôs no ambiente enquanto os mesmos se locomovem é uma característica crucial a ser garantida. Sendo assim, deve-se ressaltar que o método proposto de integração de mapas locais baseado em observações interrobôs também é analisado e avaliado sob a ótica dos problemas de formação, empregando-se para tal a extensão do IAS-SS denominada SAFS.

\subsection{SISTEMA DE FORMAÇÃO}

As formas nas quais indivíduos se integram autonomamente em um grupo dinâmico e complexo têm atraído a atenção da comunidade cientifica, de modo que um importante ponto de estudo é o motivo pelo qual agentes biológicos de uma mesma espécie tendem a ser mover próximos uns dos outros. Por meio de observações de situações reais e simuladas de agentes 
biológicos, Partridge (PARTRIDGE, 1982) afirma que os animais são capazes de realizar tarefas mais complexas, aumentando suas habilidades de defesa, assim como suas chances de sobrevivência, quando se movem em um grupo.

No presente trabalho, a organização espacial relativa entre os robôs é denominada formação. A formação dos robôs implica na organização e na manutenção de uma forma geométrica pelo grupo de robôs. Tal organização estrutural pode ser estática ou dinâmica. Sistemas com múltiplos agentes utilizam estratégias de formação tanto para estabelecer a forma geométrica do grupo de agentes quanto para maximizar a cobertura da área de sensoriamento dos robôs (GAGE, 1992). É importante observar que a maximização da área de cobertura permite que os robôs adquiram uma melhor e mais completa representação do ambiente no qual estão inseridos.

Como uma extensão da estratégia IAS-SS, é apresentada em (CALVO, 2012) uma modificação na estratégia de coordenação de múltiplos robôs móveis considerando-se o problema de formação. Tal extensão é denominada SAFS - do inglês Self-Adaptative Formation System. Uma vez que a tarefa de formação requer uma maior interação entre os agentes, a estrutura dos robôs é mais complexa em relação àquela proposta no IAS-SS. A topologia da formação é determinada considerando fundamentos baseados em diagramas de Voronoi e triangularização de Delaunay (GUIBAS; STOLFI, 1985; SHEWCHUCK, 1997; KALLMANN et al., 2003; DE BERG et al., 2008).

$\mathrm{Na}$ estratégia SAFS, os robôs depositam feromônio com propriedades repulsivas e atrativas para realizar comportamentos de exploração e formação, respectivamente. A estratégia segue uma política baseada em uma abordagem líder-seguidor, de maneira que a função do líder é indicar o caminho a ser percorrido pelos seguidores. Os seguidores são responsáveis por manter a coesão do grupo. O líder é o único robô a liberar feromônio repulsivo, para indicar áreas exploradas, e feromônio atrativo, para denotar o trajeto a ser percorrido pelos seguidores. O líder detecta apenas o feromônio repulsivo, guiando os robôs para áreas com baixas concentrações deste tipo de feromônio. Os seguidores, em contrapartida, depositam apenas o feromônio repulsivo, demarcando áreas exploradas, e detectam apenas o feromônio atrativo, visando seguir a trajetória adotada pelo líder.

Diferentemente do IAS-SS, na estratégia SAFS os robôs se comunicam tanto indiretamente, por meio do feromônio, quanto diretamente, por meio de uma antena. Tal dispositivo emite e detecta informações, ou mensagens, em torno dos robôs dentro de um raio de comunicação $R C>0$. Há dois tipos de mensagens que são emitidas e detectadas pela 
Capítulo 4 - Método Proposto

antena no SAFS, sendo que as mesmas são modeladas como pares do tipo: (msg_id, msg_nivel) e (msg_id, msg_feromonio). O primeiro termo em ambos os tipos, msg_id, corresponde ao identificador de um determinado robô $R_{k}$. O segundo termo de cada tipo de mensagem, msg_nivel e msg_feromonio, indica o nível hierárquico de cada robô na topologia da formação dos mesmos e a concentração de feromônio repulsivo detectada pelo robô, respectivamente. O primeiro par é emitido de forma contínua, enquanto que o segundo é transmitido apenas quando um novo líder precisa ser definido.

Considerando a união da estratégia SAFS com o método de integração de mapas proposto, deve-se salientar que, assim como na estratégia IAS-SS, os robôs também compartilham por meio das antenas suas respectivas grades de inferência. $\mathrm{O}$ compartilhamento desta informação permite a integração dos mapas métricos obtidos por cada robô e a aplicação da estratégia de exploração baseada em feromônios virtuais. Para efeitos de simplificação, o raio de comunicação da estratégia SAFS é definido como sendo igual ao raio de comunicação elucidado no método de integração.

A formação dos robôs é estabelecida enquanto os mesmos se locomovem pelo ambiente, de modo que a mesma é representada por meio de uma topologia na qual cada robô é associado a um nível hierárquico dentro desta. Assume-se que o robô líder é representado pelo nível zero, enquanto que os níveis hierárquicos dos seguidores são gradualmente incrementados em uma unidade a medida que a distância em relação ao líder aumenta, segundo a amplitude do caminho do grafo que descreve a topologia da formação. Na Figura 4.8, é apresentado um exemplo dos níveis hierárquicos de um grupo de 10 robôs organizados em uma formação ilustrativa.

O sistema de coordenação dos robôs na estratégia SAFS é composto por sete componentes: Núcleo de Decisão, Módulo de Hierarquia, Módulo de Inicialização, Módulo Líder, Módulo Seguidor, Módulo de Desvio de Obstáculos e Módulo de Feromônio.

A cada instante, os robôs recebem estímulos do ambiente por meio de seus sensores de feromônio e de distância a obstáculos, além das informações provenientes da antena. Estes sinais são interpretados no Núcleo de Decisão, que é responsável por atualizar o estado do robô. As funções do Núcleo de Decisão de um robô são: identificar sua vizinhança, o instante em que o grupo necessita de um líder e o momento exato em que o robô deve desviar de um obstáculo. 


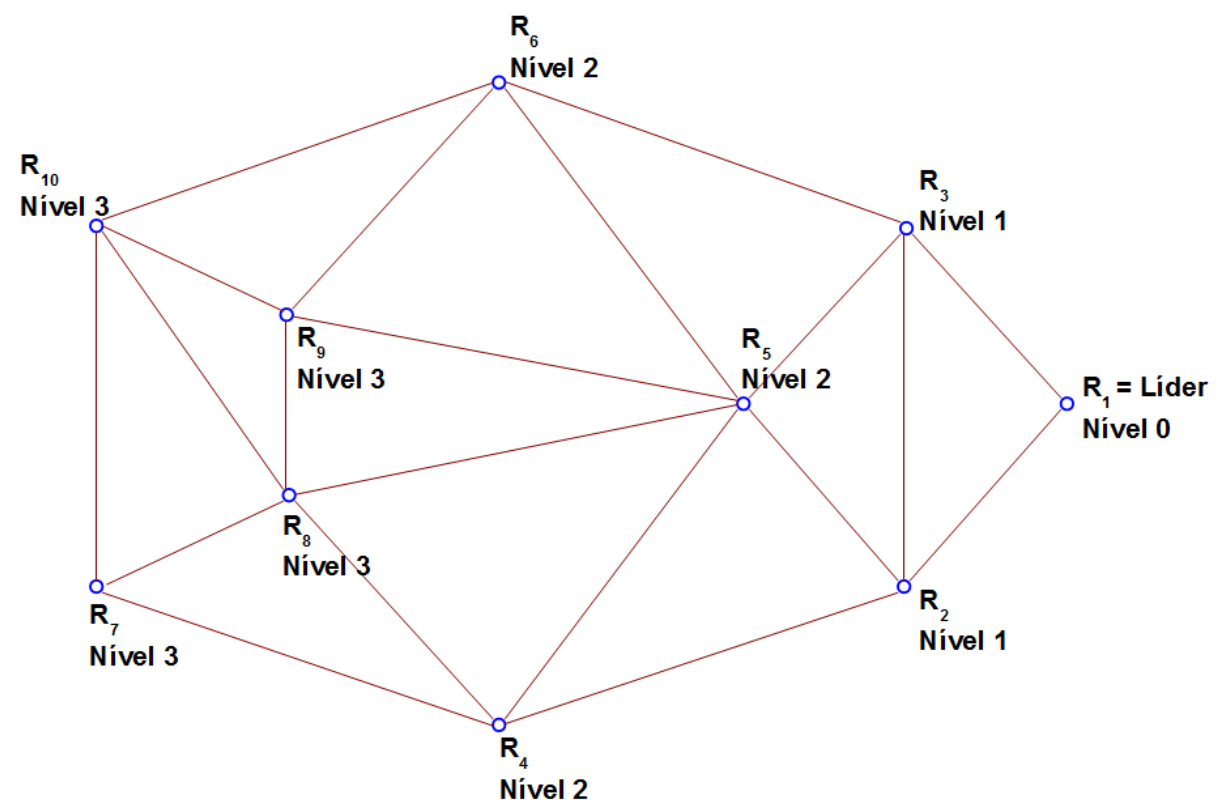

Figura 4.8 - Nível hierárquico dos robôs em formação

Considerando a primeira função do Núcleo de Decisão, um robô $R_{k}$ é capaz de detectar seus vizinhos por meio de mensagens recebidas pela antena. Se um robô não possui vizinhos, então o Núcleo de Decisão deduz que o mesmo é um líder de um grupo com um único robô. Neste contexto, o módulo Líder é ativado e o Módulo Seguidor é desativado. De acordo com a segunda função, um robô recebe informação sobre o nível de seus vizinhos continuamente. Se o robô é um seguidor, a informação detectada é útil para que o mesmo possa determinar seu próprio nível na topologia do grupo.

Se o robô não recebe informação sobre os níveis hierárquicos de seus vizinhos por um longo período, é possível deduzir que o mesmo está disperso do grupo ou está em um grupo que ainda não possui líder. Neste último caso, o Módulo de Inicialização é ativado para se eleger um novo líder. Considerando a terceira função, para detectar o instante em que um robô deve desviar de um obstáculo, o Núcleo de Decisão analisa todas as leituras do sensor de distância a obstáculos. Se pelo menos uma destas leituras indica que a distância entre o robô e o obstáculo mais próximo é menor do que uma constante pré-definida, então o Módulo de Desvio de Obstáculos é ativado, assim como ocorre na estratégia IAS-SS.

O único módulo que é ativado independentemente do estado do robô é o Módulo de Hierarquia, no qual a topologia do grupo de robôs é estabelecida. Níveis hierárquicos são propagados entre as conexões do grafo que representa a topologia do grupo. Dentre os $N_{k}$ vizinhos do robô $R_{k}$, determinados pelo Núcleo de Decisão, apenas aqueles diretamente 
conectados são considerados. Para este propósito, a triangularização de Delaunay é aplicada. Os vizinhos diretamente conectados ao robô $R_{k}$ são denotados como vizinhos adjacentes a $R_{k}$.

No Módulo de Inicialização, um novo líder é definido. Uma vez que o líder é guiado para regiões com baixa concentração de feromônio repulsivo, o novo líder é aquele que detecta a menor concentração desta substância. O líder é definido utilizando-se o fluxo de informação entre os robôs referente às concentrações de feromônio repulsivo que cada um destes detecta no ambiente durante o instante $t$.

As funções atribuídas ao líder são especificadas no Módulo Líder, sendo estas: (1) atrair seguidores, por meio da liberação de uma trilha de feromônio atrativo; (2) iniciar o processo que define os níveis hierárquicos do grupo; e (3) estimular o deslocamento do grupo para regiões com baixa concentração de feromônio repulsivo. Embora este módulo seja fundamental para a estratégia SAFS, uma vez que a mesma é baseada em uma abordagem líder-seguidor, a formação não é prejudicada se o líder do grupo falha. Neste caso, o Núcleo de Decisão detecta a interrupção da transmissão da informação de nível e ativa o Módulo de Inicialização para determinar um novo líder.

Na estratégia SAFS, os seguidores são responsáveis por manter a formação. De modo que os mesmos são orientados segundo três comportamentos: (1) seguir a trilha de feromônio atrativo liberada pelo líder; (2) seguir os vizinhos, visando manter a coesão do grupo enquanto o mesmo de locomove; e (3) dispersar dos vizinhos, garantindo uma distância segura entre os robôs para que os mesmos não colidam entre si. O terceiro comportamento dos seguidores é representado por meio de uma força de atração exercida pelos centroides formados pelas células de um diagrama de Voronoi obtido por meio da topologia do grupo de robôs.

No Módulo de Feromônio, dois tipos diferentes de feromônio são liberados. Se um robô é líder, então o mesmo deposita tanto o feromônio repulsivo quanto o atrativo. Caso contrário, o robô libera apenas o feromônio repulsivo. A dinâmica para liberação e evaporação de ambos os tipos de feromônio é similar àquela apresentada na Seção 4.2.

Considerando a grade de inferência adotada nesta tese e apresentada no início do presente capítulo, deve-se observar que a mesma apresenta uma alteração em seu último nível quando aplicada às abordagens envolvendo a união da estratégia SAFS com o método de integração de mapas proposto. Tal alteração consiste na divisão do Nível 4, representado pela matriz de feromônios, em duas camadas. A primeira camada é destinada a armazenar as concentrações de feromônio do tipo repulsivo, enquanto a segunda é identificada pelo controle do feromônio do tipo atrativo presente no ambiente. 
É importante notar também que diferentes mecanismos de integração poderiam ser aplicados ao sistema de exploração e vigilância neste cenário, considerando a abordagem líder-seguidor adotada na estratégia SAFS. Por exemplo, a integração de dados poderia ocorrer apenas entre líderes de grupos diferentes de robôs, ou ainda, apenas entre o líder e seus respectivos seguidores. No presente trabalho, considerando as avaliações referentes ao problema de formação, adota-se um mecanismo de integração no qual os robôs compartilham seus mapas locais apenas com seus respectivos robôs vizinhos adjacentes, localizados dentro de seus respectivos raios de comunicação, independentemente se os mesmos são seguidores ou líderes.

\subsection{CONSIDERAÇÕES PARCIAIS}

Neste capítulo, foi apresentado o método de integração de mapas locais proposto na presente tese. Tal método de integração é baseado em observações inter-robôs e realiza a junção de dados por meio de uma modificação na técnica de compartilhamento de informação proposta por Tan et al. (TAN et al., 2004). Especificamente, a modificação que torna o modelo de compartilhamento proposto por Tan et al. (TAN et al., 2004) apto a realizar tarefas de mapeamento, está relacionada a centralização do sistema de coordenadas de cada robô. Diferentemente do modelo de compartilhamento tradicional, no método proposto neste trabalho os sistemas de coordenadas dos robôs não são centralizados em suas respectivas posições durante o processo de exploração do ambiente, caso este que é empregado na abordagem original, mas sim em suas posições iniciais.

Além disso, também foi elucidada uma estratégia bio-inspirada de coordenação de múltiplos robôs móveis para tarefas de exploração e vigilância de ambientes proposta por Calvo et al. (CALVO et al., 2011a; CALVO et al., 2011b; CALVO et al., 2011c), denominada IAS-SS. A estratégia é baseada em uma modificação do algoritmo de otimização por colônia de formigas e é empregada para definir as direções de movimentos dos robôs. Uma importante contribuição do presente trabalho é discutida neste capítulo, por meio da proposta de utilização do conceito de feromônio virtual integrado. Tal conceito emerge da união da estratégia IAS-SS com o método de integração de mapas proposto. Finalmente, no final do capítulo, é apresentada uma extensão da estratégia de exploração que visa a coordenação de múltiplos robôs considerando o problema de formação. 
Capítulo 4 - Método Proposto

A seguir, no Capítulo 5, são apresentados os resultados obtidos com o presente trabalho, analisando-se o mesmo por meio de uma série de experimentos realizados em simulação. 
Capítulo 4 - Método Proposto 
Os experimentos foram executados na plataforma Player/Stage, desenvolvida por pesquisadores da Universidade do Sul da Califórnia, que modela vários robôs e sensores, simulando simultaneamente suas dinâmicas, incluindo modelos que representam erros de odometria. Embora a plataforma inclua mecanismos de navegação para desvio de obstáculos, tal comportamento emerge naturalmente do IAS-SS como uma consequência da característica repulsiva do feromônio. Para propósitos experimentais foi utilizado o modelo do robô Pioneer 2DX equipado com o sensor laser SICK LMS 200 capaz de mapear o ambiente e os obstáculos presentes no mesmo, tal como, por exemplo, paredes e objetos.

É importante salientar que o presente trabalho se concentra no processo de integração de dados e mapeamento do ambiente, sendo assim, as questões referentes à localização dos robôs móveis e ao tratamento dos erros de odometria não foram abordados no trabalho, embora as mesmas tenham um impacto significativo no desenvolvimento da abordagem proposta considerando-se aplicações em ambientes reais.

As simulações foram realizadas visando avaliar o desempenho do método de integração de mapas proposto considerando diferentes condições iniciais. Sendo assim, foram executados experimentos variando: (1) o método de ajuste na direção de movimento dos robôs; (2) a estrutura física dos ambientes simulados; (3) o tamanho do raio de comunicação adotado pelos robôs; (4) os valores atribuídos a variável it intervalo; (5) o número de robôs empregados; e (6) a dimensão do ambiente simulado. Além dos experimentos variando tais 
características, o método proposto é avaliado analisando-se três abordagens distintas, sendo estas: (1) comparação com outro método de mapeamento, especificamente é realizada uma análise de desempenho em relação ao método de mapeamento topológico Thinning; (2) comparação de desempenho de mapeamento realizando também a integração dos dados de feromônio, avaliando desta forma a eficiência da abordagem de feromônios virtuais descrita no Capítulo 4; e (3) análise de desempenho do método de mapeamento quando este é utilizado em uma aplicação que lida com o problema de formação de robôs móveis, utilizando para tal a estratégia SAFS.

\subsection{CONFIGURAÇÃO DOS EXPERIMENTOS}

A seguir, são apresentados os valores paramétricos que correspondem ao melhor desempenho do sistema de coordenação de múltiplos robôs, considerando os experimentos prévios realizados em (CALVO et al., 2011a; CALVO et al., 2011b), os quais avaliaram o desempenho do IAS-SS considerando diferentes valores para tais parâmetros. Os parâmetros do sistema utilizados nos experimentos são: $\sigma=0.4 R D$ (dispersão do feromônio); $\rho=10^{-4}$ (taxa de evaporação); $\tau_{q}(0)=0.5$ (quantidade de feromônio na posição $q$ na iteração $t=0$ ); $R D=8$ metros (raio do semicírculo no qual o feromônio é depositado); $\gamma=0.5$ (constante de suavização do ajuste na direção de movimento); velocidade de cada robô $=0.5$ metros por segundo; $S=360$ (número de intervalos angulares); número de elementos dos subconjuntos $U$ e $V$ correspondem a $30 \%$ e $10 \%$ da quantidade total de elementos do conjunto $S$, respectivamente; $R C_{k} \in\{4,8,16,24,32,40\}$ metros (raio de comunicação do robô $R_{k}, k=1$, ..., $N$, em que $N$ é o número de robôs empregados); número máximo de iterações da simulação $=1000$.

Os valores atribuídos aos parâmetros $\sigma$ e $\rho$ foram definidos por meio de análises de desempenho realizadas em (CALVO et al., 2011c). É importante salientar que os critérios de desempenho adotados nos experimentos realizados por Calvo et al. (CALVO et al., 2011a; CALVO et al., 2011b; CALVO et al., 2011c) foram: (1) o tempo necessário para concluir a tarefa de exploração de um determinado ambiente; e (2) o intervalo de tempo máximo entre dois ciclos consecutivos de sensoriamento, de maneira que este último critério visa avaliar o desempenho do sistema nas tarefas de vigilância do ambiente.

Uma importante observação sobre a estratégia IAS-SS proposta por Calvo (CALVO, 2012) é que a mesma se utiliza de uma abordagem de acesso aos feromônios baseada em uma 
estrutura de dados global, denominada no presente trabalho como mapa global de feromônios. Tal estrutura visa simular as concentrações do feromônio presente no ambiente, de modo que todos os robôs tenham acesso a uma mesma estrutura de dados. Contudo deve-se notar que, na prática, esta estrutura de dados não é aplicável a cenários envolvendo robôs reais, uma vez que os mesmos teriam acesso apenas aos seus dados locais de feromônio. Portanto, deve se salientar que nos experimentos iniciais apresentados na presente tese é utilizado o mesmo conceito de mapa global de feromônios empregado nos trabalhos descritos em (CALVO et al., 2011a; CALVO et al., 2011b; CALVO et al., 2011c; CALVO, 2012). Por outro lado, nos experimentos descritos no final deste capítulo, é avaliada a abordagem de feromônios virtuais integrados elucidada na presente tese. Abordagem esta que visa propor um mecanismo de acesso aos feromônios aplicável a ambientes reais, baseando-se no método de integração de mapas locais proposto.

Considerando o processo de integração, a junção de mapas locais foi inicializada apenas a partir da iteração $t \geq 100$, ou seja, itInicio controle $=100$. Tal restrição garante que os robôs obtenham uma quantidade mínima de informação acerca do ambiente antes de iniciar o processo de integração. Além disso, de modo geral, o parâmetro $i t_{\text {intervalo }}$ foi definido como sendo igual a 50. Deve-se lembrar de que tal parâmetro define o intervalo mínimo de iterações para que dois robôs $R_{i}$ e $R_{j}$ compartilhem novamente entre si seus respectivos mapas locais, reduzindo dessa forma a troca redundante de informação entre os mesmos. Na Seção 5.2, é apresentado um conjunto de experimentos específicos que avaliam a variação do parâmetro $i t_{\text {intervalo }}$, para os demais experimentos deve-se assumir que o mesmo é configurado como um intervalo de 50 iterações.

Cada configuração dos experimentos foi executada 10 vezes. De maneira que a média dos desempenhos foi calculada para avaliar os mesmos. O tempo discreto foi adotado nos experimentos e é equivalente ao número máximo de iterações da simulação. O número máximo de iterações gasta aproximadamente 90 min para ser simulado em um computador com um processador Intel Core i7-2630QM, CPU 2.00 GHz e 4GB de memória RAM. Logo, cada iteração da simulação gasta em torno de 5.4 segundos para ser realizada.

Na Figura 5.1, são apresentados os modelos de ambientes empregados no presente trabalho. De modo geral, os ambientes simulados foram configurados com uma dimensão de $30 \mathrm{~m}$ X 20m, totalizando uma área de $600 \mathrm{~m}^{2}$. Tal área foi representada por meio de uma matriz de dimensão 375 X 375. Os ambientes nos quais o sistema de coordenação de múltiplos robôs realizou a tarefa de exploração foram divididos em pequenas regiões denominadas setores. Sendo assim, os modelos de ambientes adotados foram divididos em 24 
setores de tamanhos iguais. Uma exceção para tal divisão foi aplicada em uma configuração de experimentos que visa avaliar o desempenho do sistema em ambientes de diferentes dimensões, de modo que, tal configuração de experimentos é discutida quando apresentada na Seção 5.2.

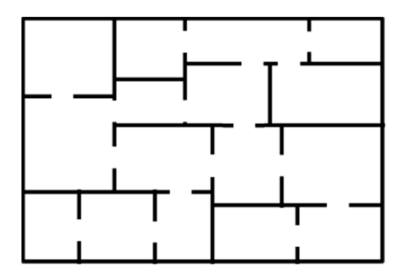

(a)

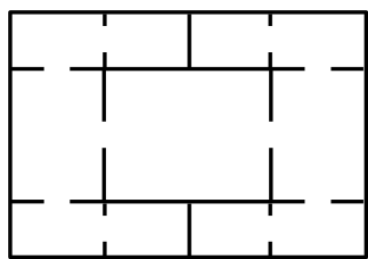

(e)

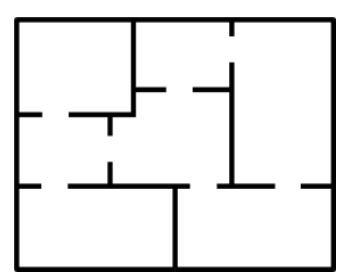

(b)

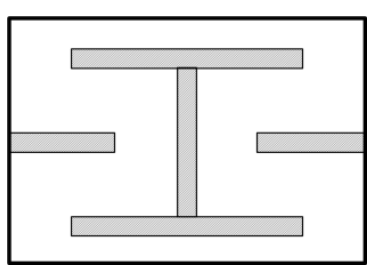

(c)

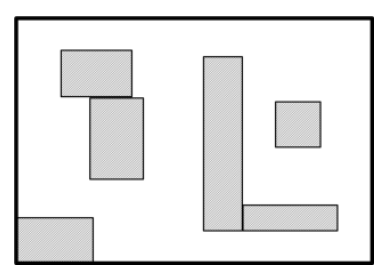

(d)

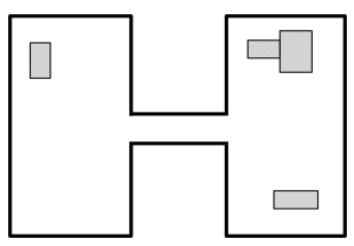

(g)

Figura 5.1 - Modelos de ambiente

Os setores são apenas uma divisão abstrata do ambiente em subáreas e, portanto, são utilizados apenas como uma ferramenta para análise de desempenho do processo de mapeamento. É importante observar que neste caso os mesmos não representam obstáculos presentes no ambiente. Na Figura 5.2, é apresentado a divisão em 24 setores de um ambiente composto por cinco salas ligadas por um único corredor. Esta divisão é representada pelas linhas tracejadas que dividem o ambiente em subáreas. Deve-se notar que tal divisão não é utilizada de forma alguma pelos robôs que compõem o sistema de exploração.

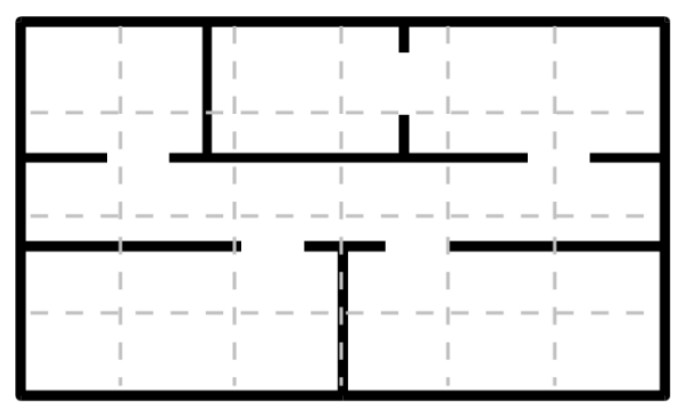

Figura 5.2 - Exemplo de setores

A divisão do ambiente em setores foi utilizada para avaliar a quantidade de regiões exploradas, e consequentemente mapeadas, pelo método proposto. Um determinado setor é 
Capítulo 5 - Resultados Experimentais

considerado como visitado se o mesmo é alcançado por um robô qualquer. É importante notar que se um robô está fisicamente em um setor $S C_{i}$ e seus sensores atingem tanto os setores $S C_{i}$ quanto $S C_{j}$, considera-se que o robô visitou apenas o setor $S C_{i}$. Tal definição visa garantir que a análise de desempenho realizada seja mais criteriosa.

\subsection{RESULTADOS DE SIMULAÇÃO}

Inicialmente, apresenta-se um exemplo de simulação no qual é ilustrado o efeito da integração de mapas na tarefa de mapeamento. Na Figura 5.3, são apresentados os mapas métricos locais obtidos por três diferentes robôs $-R_{1}, R_{2}$ e $R_{3}$ - alocados no ambiente da Figura 5.1(a), assim como também são apresentados os mapas obtidos com a integração das grades de ocupação entre os robôs. Todos os mapas apresentados correspondem aos resultados finais de mapeamento de cada um dos robôs após o número máximo de iterações da simulação.

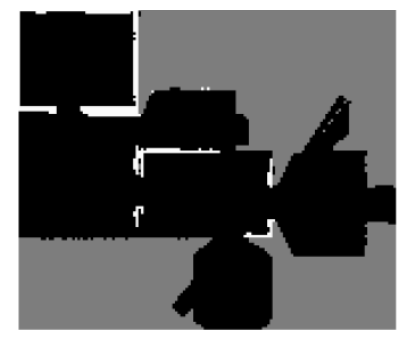

(a)

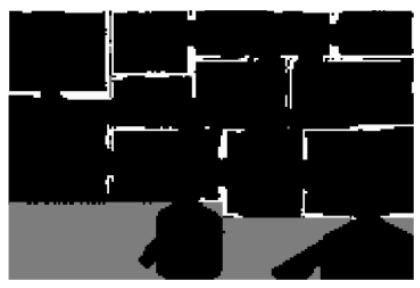

(d)

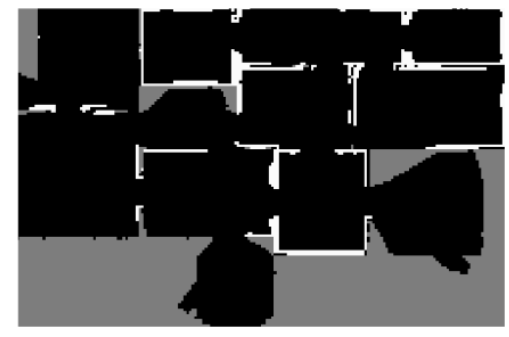

(b)

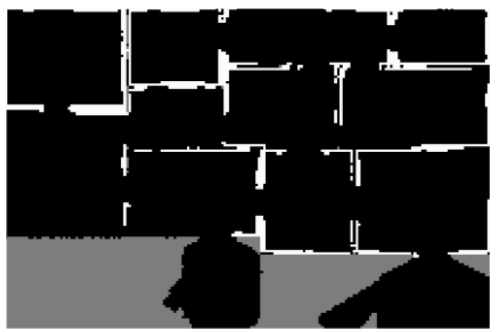

(e)

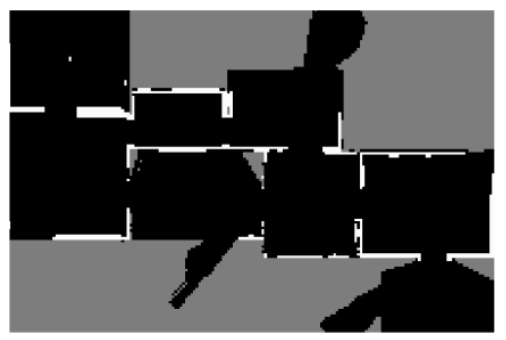

(c)

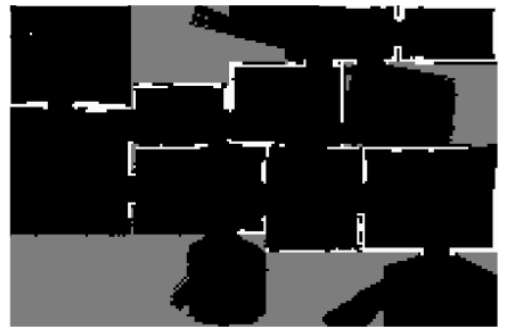

(f)

Figura 5.3 - Exemplo de mapeamento: (a), (b) e (c) Mapas métricos locais dos robôs $R_{1}, R_{2}$ e $R_{3}$, respectivamente; (d), (e) e (f) Mapas métricos integrados dos robôs $R_{l}, R_{2}$ e $R_{3}$, respectivamente

No experimento em questão, os robôs inicializaram o processo de exploração a partir de posições aleatórias na área superior esquerda do ambiente. Na primeira linha da Figura 5.3, os mapas métricos locais de cada robô são apresentados. Tais mapas são construídos 
considerando apenas a informação adquirida pelos próprios sensores de distância a obstáculos de cada robô. Na segunda linha da figura, os mapas obtidos por meio do processo de integração de mapas, realizado entre os robôs, são ilustrados para os mesmos. Os mapas integrados demonstram o ganho de informação obtido pela junção dos mapas métricos locais de cada robô. Deve-se destacar que os mapas apresentados na Figura 5.3(d), (e) e (f) são distintos, uma vez que o processo de integração depende dos encontros realizados pelos robôs durante a exploração do ambiente, de maneira que tal exploração é definida pela natureza estocástica da estratégia IAS-SS.

As trajetórias realizadas por cada robô durante o processo de exploração do ambiente no experimento em questão são apresentadas na Figura 5.4. Estas trajetórias estão representadas por linhas brancas no interior das áreas livres dos mapas métricos apresentados. Por meio da visualização de tais trajetórias, é possível identificar quais áreas foram visitadas por cada robô e quais regiões foram obtidas pelo mesmo por meio do compartilhamento de dados entre os robôs.

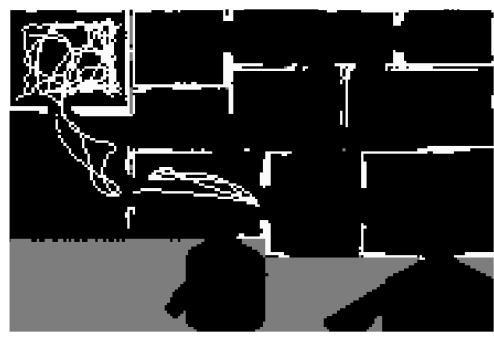

(a)

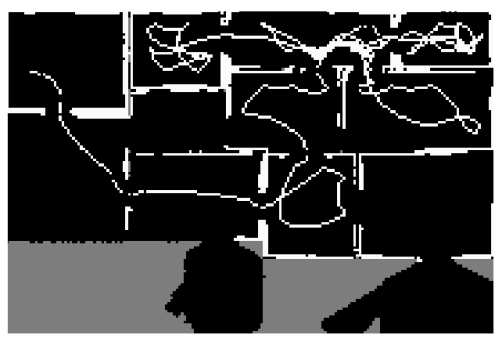

(b)

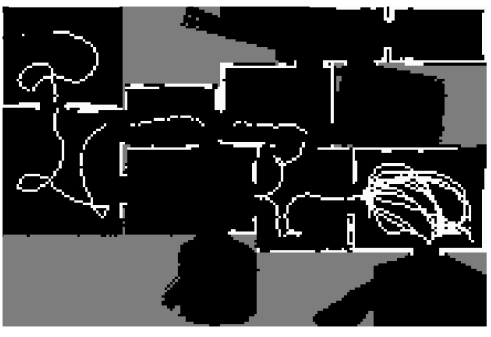

(c)

Figura 5.4 - Trajetórias de exploração: (a) $R_{1}$; (b) $R_{2}$; (c) $R_{3}$

Na Figura 5.4(a), torna-se evidente o ganho de informação obtido pelo robô $R_{l}$. Analisando-se a trajetória do mesmo é possível inferir que tal robô explorou fisicamente apenas três salas do ambiente simulado. Contudo, o mesmo robô possui informações em sua grade de ocupação que descrevem o estado das salas na região superior do ambiente, as quais não foram efetivamente exploradas pelo robô $R_{l}$. Informações estas provenientes da integração de mapas com os robôs $R_{2}$ e $R_{3}$.

Avaliando: variação do raio de comunicação

O primeiro conjunto de experimentos realizado visa avaliar a influência do raio de comunicação no método de integração de mapas proposto. Nestes experimentos são utilizados 
cinco robôs alocados em um ambiente sem obstáculos internos, a fim de melhor avaliar o impacto do alcance do raio de comunicação entre os robôs. Os raios de comunicação testados foram: 4, 8, 16, 24, 32 e 40 metros. Deve-se notar que o raio de 32 metros é um valor próximo a maior distância encontrada dentro de um ambiente de dimensão 30m X 20m. Sendo assim, as configurações dos experimentos com raios de comunicação iguais, ou superiores, a 32 metros correspondem a um cenário no qual os robôs podem compartilhar dados entre si independentemente da distância entre os mesmos.

Na Tabela 5.1, são apresentadas as porcentagens de exploração do ambiente, de modo que as mesmas correspondem a uma variável compreendida no intervalo [0,1] que descreve a relação da quantidade de setores representados pelo mapa de um determinado robô e a quantidade total de setores do ambiente. Deve-se lembrar de que, de modo geral, os ambientes foram divididos em 24 setores. É importante notar também que a quantidade de setores representados pelo mapa de cada robô indica tanto os setores visitados pelo mesmo quanto os setores transferidos a este por meio do método de integração de mapas proposto.

Neste experimento, um conjunto de 10 simulações foi realizado para cada variação do raio de comunicação. Portanto, os valores apresentados na tabela correspondem à média da porcentagem de exploração do ambiente, aplicando-se o método de integração de mapas proposto conjuntamente com a estratégia de exploração IAS-SS, considerando cada robô empregado e cada raio de comunicação testado.

Inicialmente, no experimento proposto, o aumento do raio de comunicação induz uma melhoria na porcentagem de exploração do ambiente. Obtendo-se o melhor resultado quando o raio de comunicação é igual a 16 metros. Contudo, para raios de comunicação maiores do que 24 metros há um suave decaimento na porcentagem de exploração do ambiente. Tal comportamento é provocado pelo aumento do número de integrações entre os robôs. Com o aumento no número de integrações os robôs requerem um tempo maior para o compartilhamento e o processamento da integração dos mapas locais, reduzindo consequentemente o tempo destinado à exploração do ambiente em si.

Tabela 5.1 - Média e desvio padrão do desempenho do método de mapeamento variando o raio de comunicação

\begin{tabular}{cccccc}
\hline $\begin{array}{c}\text { Raio de } \\
\text { comunicação }\end{array}$ & $\mathbf{R}_{\mathbf{1}}$ & $\mathbf{R}_{\mathbf{2}}$ & $\mathbf{R}_{\mathbf{3}}$ & $\mathbf{R}_{\mathbf{4}}$ & $\mathbf{R}_{\mathbf{5}}$ \\
\hline 4 & $0.92 \pm 0.11$ & $0.91 \pm 0.11$ & $0.95 \pm 0.06$ & $0.92 \pm 0.11$ & $0.94 \pm 0.09$ \\
8 & $0.97 \pm 0.06$ & $0.97 \pm 0.05$ & $0.97 \pm 0.06$ & $0.96 \pm 0.06$ & $0.96 \pm 0.06$ \\
16 & $0.99 \pm 0.01$ & $0.99 \pm 0.01$ & $0.99 \pm 0.01$ & $0.99 \pm 0.01$ & $0.99 \pm 0.01$ \\
24 & $0.98 \pm 0.02$ & $0.98 \pm 0.02$ & $0.98 \pm 0.02$ & $0.98 \pm 0.02$ & $0.98 \pm 0.02$ \\
32 & $0.96 \pm 0.04$ & $0.94 \pm 0.04$ & $0.97 \pm 0.03$ & $0.94 \pm 0.05$ & $0.95 \pm 0.05$ \\
40 & $0.94 \pm 0.06$ & $0.90 \pm 0.13$ & $0.93 \pm 0.08$ & $0.88 \pm 0.12$ & $0.88 \pm 0.12$ \\
\hline
\end{tabular}


Considerando os casos nos quais o raio de comunicação é igual a 32 ou 40 metros, os robôs sempre compartilham seus mapas locais com os demais, independentemente da distância entre os mesmos, pois esta sempre é menor do que o raio de comunicação em questão. Uma vez que a comunicação entre os robôs é maior, o processo de exploração do ambiente se torna mais lento, pois um maior tempo é gasto no compartilhamento dos dados.

Avaliando: estratégias de ajuste de direção de movimento

Nos experimentos de variação do raio de comunicação, foi utilizada como técnica de ajuste da direção de movimento dos robôs o método AEE da estratégia IAS-SS. Para avaliar o desempenho da estratégia de exploração IAS-SS, um novo de conjunto de experimentos foi realizado visando demonstrar que o desempenho do método de mapeamento baseado no IASSS não é uma consequência arbitrária de um comportamento aleatório.

Para tais experimentos foi avaliado o desempenho do método considerando três técnicas distintas de ajuste da direção, sendo estas: (1) método AE; (2) método AEE; e (3) estratégia uniforme de exploração, abreviada como UNI. De acordo com a estratégia uniforme, uma variável aleatória discreta, definida por uma distribuição uniforme no espaço de ângulos $A_{s}$, determina os ajustes na direção de movimento durante o processo de exploração.

Novamente, um conjunto de 10 ensaios foi realizado para cada método, considerando três robôs alocados no ambiente da Figura 5.1(a). Além disso, deve-se salientar que em todos os experimentos descritos a partir deste ponto, o raio de comunicação adotado nas simulações é aquele que obteve o melhor resultado no conjunto anterior de experimentos, ou seja, o raio de comunicação em todos os experimentos elucidados a seguir foi definido como 16 metros.

Os gráficos do processo de exploração do ambiente, utilizando os métodos AE e AEE, assim como a estratégia uniforme, são apresentados na Figura 5.5 (a), (b) e (c), respectivamente. Tais gráficos apresentam a média do desempenho obtido com cada mecanismo de ajuste de direção durante toda a exploração do ambiente. No eixo $x$, têm-se as iterações do processo de exploração, enquanto que, no eixo $y$, apresentam-se as médias da porcentagem de exploração do ambiente. 


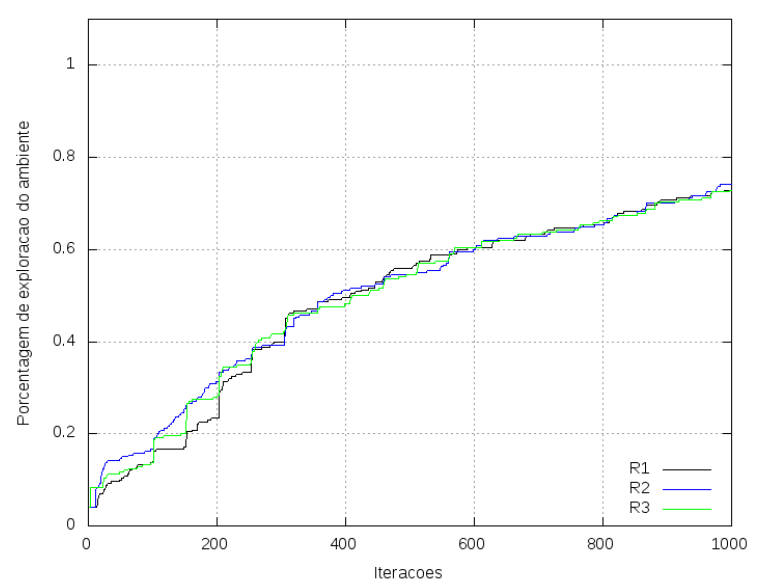

(a)

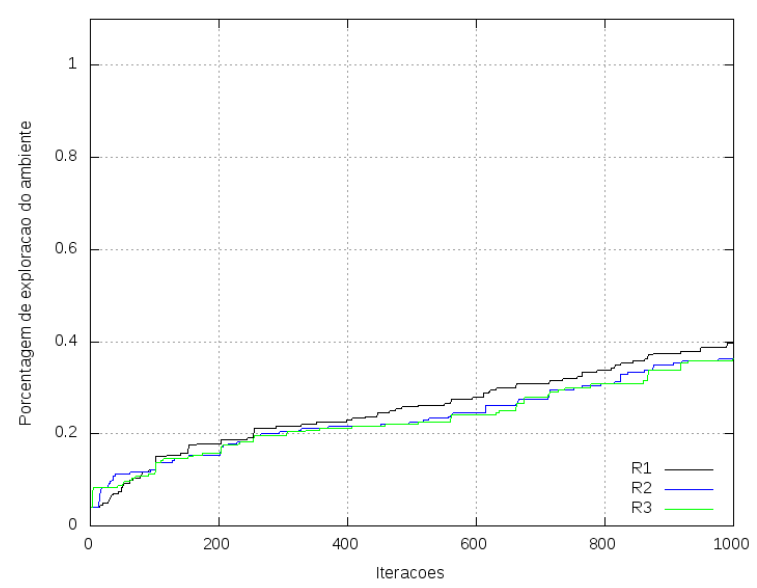

(b)

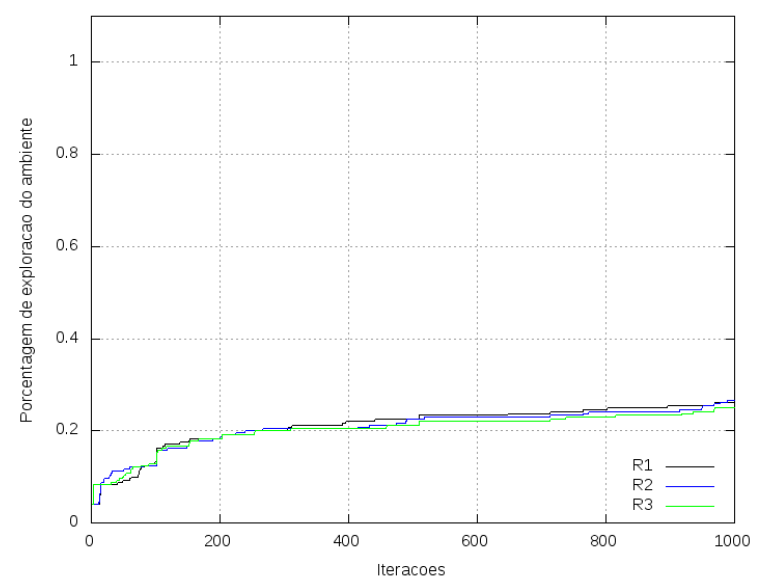

(c)

Figura 5.5 - Desempenho do mapeamento variando o método de ajuste de direção: (a) AEE; (b) AE; (c) UNI

Como pode ser observado pelos gráficos em análise, os robôs empregando a estratégia IAS-SS com o método de ajuste de direção AEE apresentam um desempenho de mapeamento superior àqueles apresentados pelos robôs utilizando os demais mecanismos de ajuste da direção de movimento. Na Tabela 5.2, são apresentadas as médias e desvios padrões, considerando os três robôs do referido experimento, dos valores finais dos gráficos da porcentagem de exploração do ambiente de cada método de ajuste de direção.

Tabela 5.2 - Média e desvio padrão dos métodos de ajuste de direção

\begin{tabular}{ccc}
\hline Método de ajuste & Média $(\mu)$ & Desvio Padrão $(\sigma)$ \\
\hline AEE & 0.73 & 0.07 \\
AE & 0.37 & 0.15 \\
UNI & 0.25 & 0.06 \\
\hline
\end{tabular}


No presente trabalho, são realizadas análises estatísticas entre os experimentos executados utilizando-se o teste t de Student para validar, ou rejeitar, hipóteses de que um determinado conjunto de experimentos possui um desempenho melhor quando comparado a outro conjunto com configurações diferentes. Na Tabela 5.3, são sumarizadas as informações estatísticas referentes a comparação dos desempenhos dos métodos de ajuste de direção apresentados na Tabela 5.2. O nível de significância adotado em todas as análises estatísticas realizadas nesta tese foi igual a 5\%. Além disso, a identificação de similaridade das variâncias entre dois grupos distintos de experimentos foi realizada por meio do teste $F$, adotando-se o mesmo nível de significância empregado no teste $t$. $\mathrm{O}$ valor tabelado do teste $t$ é expresso na forma $t_{\operatorname{tab}(X, Y \text { g.l. })}=$ valor, em que $X$ é o nível de significância e $Y$ é o número de graus de liberdade. A hipótese nula das análises realizadas é definida como $H_{o}: \mu_{A}=\mu_{B}$. Em que, $\mu_{A} \mathrm{e}$ $\mu_{B}$ são as médias dos desempenhos dos conjuntos de experimentos $A$ e $B$, respectivamente. $\mathrm{Ou}$ seja, dois conjuntos de experimentos com configurações distintas possuem em média um desempenho equivalente. Em contrapartida, a hipótese alternativa é definida como $H_{a}: \mu_{A} \neq$ $\mu_{B}$. Neste caso, as médias de desempenho são distintas e, consequentemente, um dos conjuntos de experimentos possui um desempenho melhor do que o outro.

Tabela 5.3 - Comparação dos métodos de ajuste de direção

\begin{tabular}{|c|c|c|c|c|}
\hline $\begin{array}{c}\text { Métodos } \\
\text { comparados }\end{array}$ & Variâncias & Valor t calculado & Valor t tabelado & $\begin{array}{c}\text { Relação entre os } \\
\text { valores }\end{array}$ \\
\hline $\mathrm{AEE} / \mathrm{AE}$ & Diferentes & $t_{c a l}=6.52$ & $\begin{array}{c}t_{t a b}(0.05,14 \text { g.1. })= \\
1.76\end{array}$ & $>$ \\
\hline AEE/UNI & Iguais & $t_{c a l}=14.56$ & $\begin{array}{c}t_{t a b}(0.05,18 \text { g.1. })= \\
1.73\end{array}$ & $>$ \\
\hline AE/UNI & Diferente & $t_{c a l}=2.11$ & $\begin{array}{c}t_{t a b}(0.05,12 \text { g.1. })= \\
1.78\end{array}$ & $>$ \\
\hline
\end{tabular}

Na última coluna da Tabela 5.3, são apresentadas as relações dos valores calculados e tabelados para $t$, considerando-se os métodos de ajuste de direção organizados em pares. Nos casos em que o valor calculado $t_{c a l}$ é maior do que o valor tabelado $t_{t a b}$, a hipótese nula é rejeitada para o par de métodos em análise. Como pode ser observado na tabela em questão, todos os pares de métodos apresentam diferença estatística entre si, indicando que o método AEE possui um melhor desempenho do que o $\mathrm{AE}$ e que ambos os métodos anteriores apresentam desempenhos melhores do que a estratégia uniforme UNI. Desta forma, 
Capítulo 5 - Resultados Experimentais

comprova-se que o desempenho do método de mapeamento baseado no IAS-SS não é uma consequência arbitrária de um comportamento aleatório.

Avaliando: variação do número de robôs

O próximo conjunto de experimentos visou verificar o desempenho do método de integração de mapas variando-se a quantidade de robôs utilizados no processo de exploração do ambiente. Novamente, nestes experimentos, foi simulado o ambiente ilustrado na Figura 5.1(a). Para uma análise mais completa, todos os métodos de ajuste na direção de movimento comparados anteriormente foram utilizados nos experimentos.

A quantidade de robôs empregada variou no intervalo [1,5]. A variação da quantidade de robôs no referido intervalo foi escolhida devido a dois fatores, a saber: (1) a própria dimensão do ambiente simulado; e (2) uniformidade com os experimentos descritos e simulados por Calvo et al. (CALVO et al., 2011a; CALVO et al., 2011b; CALVO et al., 2011c) para o IAS-SS.

As médias das porcentagens de exploração do ambiente para os métodos de ajuste da direção AEE, AE e UNI são apresentadas nas Tabelas 5.4, 5.5 e 5.6, respectivamente, considerando cada variação da quantidade de robôs utilizada na exploração. Todos os robôs iniciaram o processo de navegação a partir da sala localizada na região superior esquerda do ambiente.

Como pode ser observado nas tabelas em questão, o aumento da quantidade de robôs gerou um aumento significativo no desempenho do método de mapeamento, considerando o AEE como estratégia de exploração. Uma vez que tal estratégia gera uma exploração do ambiente mais eficiente, o aumento do número de robôs permite um maior compartilhamento de informação entre os mesmos, por meio do método de integração de mapas proposto, aumentando consequentemente a média da porcentagem de exploração do ambiente. No caso em que foi empregado cinco robôs para explorar o ambiente, as médias das porcentagens de exploração atingiram o valor de $80 \%$.

A melhoria gradativa no desempenho de mapeamento, à medida que o número de robôs aumenta, também é observada em menor escala no método UNI. Uma vez que a estratégia uniforme possui um comportamento essencialmente aleatório, o aumento da média da porcentagem de exploração do ambiente, causado pelo incremento da quantidade de robôs, é induzido pelo próprio processo de integração de mapas quando o mesmo é realizado por um 
robô que se dispersa substancialmente dos outros robôs, permitindo que tal robô compartilhe informações espaciais significativas com os demais.

Tabela 5.4 - Desempenho do método de mapeamento variando a quantidade de robôs - AEE

\begin{tabular}{cccccc}
\hline $\begin{array}{c}\text { Quantidade de } \\
\text { robôs }\end{array}$ & $\boldsymbol{R}_{\boldsymbol{1}}$ & $\boldsymbol{R}_{\boldsymbol{2}}$ & $\boldsymbol{R}_{\mathbf{3}}$ & $\boldsymbol{R}_{\boldsymbol{4}}$ & $\boldsymbol{R}_{\boldsymbol{5}}$ \\
\hline 1 & $0.44 \pm 0.08$ & - & - & - & - \\
2 & $0.62 \pm 0.09$ & $0.63 \pm 0.09$ & - & - & - \\
3 & $0.72 \pm 0.08$ & $0.74 \pm 0.07$ & $0.72 \pm 0.07$ & - & - \\
4 & $0.70 \pm 0.10$ & $0.70 \pm 0.10$ & $0.70 \pm 0.10$ & $0.70 \pm 0.10$ & - \\
5 & $0.79 \pm 0.11$ & $0.80 \pm 0.11$ & $0.80 \pm 0.11$ & $0.80 \pm 0.12$ & $0.79 \pm 0.11$ \\
\hline
\end{tabular}

Tabela 5.5 - Desempenho do método de mapeamento variando a quantidade de robôs - AE

\begin{tabular}{|c|c|c|c|c|c|}
\hline \multirow{2}{*}{$\begin{array}{c}\text { Quantidade de } \\
\text { robôs }\end{array}$} & \multicolumn{5}{|c|}{ Média e desvio padrão do mapeamento } \\
\hline & $R_{1}$ & $\boldsymbol{R}_{2}$ & $R_{3}$ & $\boldsymbol{R}_{4}$ & $\boldsymbol{R}_{5}$ \\
\hline 1 & $0.40 \pm 0.10$ & - & - & - & - \\
\hline 2 & $0.40 \pm 0.11$ & $0.37 \pm 0.07$ & - & - & - \\
\hline 3 & $0.39 \pm 0.14$ & $0.36 \pm 0.16$ & $0.36 \pm 0.16$ & - & - \\
\hline 4 & $0.37 \pm 0.13$ & $0.34 \pm 0.14$ & $0.34 \pm 0.14$ & $0.35 \pm 0.15$ & - \\
\hline 5 & $0.51 \pm 0.17$ & $0.50 \pm 0.20$ & $0.50 \pm 0.20$ & $0.50 \pm 0.19$ & $0.51 \pm 0.18$ \\
\hline
\end{tabular}

Tabela 5.6 - Desempenho do método de mapeamento variando a quantidade de robôs - UNI

\begin{tabular}{cccccc}
\hline $\begin{array}{c}\text { Quantidade de } \\
\text { robôs }\end{array}$ & $\boldsymbol{R}_{\boldsymbol{1}}$ & $\boldsymbol{R}_{\mathbf{2}}$ & $\boldsymbol{R}_{\mathbf{3}}$ & $\boldsymbol{R}_{\boldsymbol{4}}$ & $\boldsymbol{R}_{\boldsymbol{5}}$ \\
\hline 1 & $0.20 \pm 0.05$ & - & - & - & - \\
2 & $0.24 \pm 0.07$ & $0.24 \pm 0.07$ & - & - & - \\
3 & $0.26 \pm 0.05$ & $0.26 \pm 0.08$ & $0.25 \pm 0.05$ & - & - \\
4 & $0.29 \pm 0.12$ & $0.30 \pm 0.12$ & $0.28 \pm 0.13$ & $0.28 \pm 0.13$ & - \\
5 & $0.39 \pm 0.17$ & $0.38 \pm 0.17$ & $0.38 \pm 0.18$ & $0.36 \pm 0.16$ & $0.36 \pm 0.16$ \\
\hline
\end{tabular}

É importante destacar o comportamento peculiar do método AE nestes experimentos, o qual apresentou uma melhora no desempenho de seu mapeamento apenas com a utilização de cinco robôs. Nos demais casos de teste, o método AE apresentou um desempenho quase constante, sofrendo apenas pequenas oscilações. Tal comportamento corrobora a limitação do método AE elucidada por Calvo et al. (CALVO et al., 2012) e discutida no Capítulo 4.

A limitação elucidada pelos autores indica que o método em questão não é eficiente para ambientes com grandes dimensões, uma vez que a quantidade de feromônio depositado 
nos diferentes intervalos angulares é similar em todos os pontos do ambiente, fazendo com que a definição do ajuste na direção de movimento conduza o robô para direções desfavoráveis. Independentemente do tamanho do ambiente simulado e considerando que todos os robôs iniciam o processo de exploração a partir de uma mesma sala, o aumento da quantidade de robôs utilizados ocasiona uma saturação de feromônio na sala em questão, fazendo com que os robôs tenham uma inicialização desfavorável neste cenário e gastem muito tempo para se dispersar uns dos outros.

\section{Avaliando: mapeamento com e sem integração de dados}

Uma interessante análise a ser realizada sobre os desempenhos do método de mapeamento do experimento em questão é a verificação da eficiência do sistema de exploração quando o mesmo não realiza a integração de mapas entre os robôs. Nesta situação, o método de integração proposto é desativado e os robôs adquirem informação espacial apenas por meio de seus próprios sensores de distância a obstáculos. Sendo assim, apenas os setores visitados diretamente por um determinado robô são considerados para o cálculo da porcentagem de exploração do ambiente realizada pelo mesmo.

Nas Tabelas 5.7, 5.8 e 5.9, são apresentadas as médias do desempenho do método de mapeamento sem a integração de mapas, considerando a variação da quantidade de robôs nos métodos AEE, AE e UNI, respectivamente.

Deve-se destacar que para o cálculo do desempenho do método de mapeamento sem a integração de mapas foram empregadas as mesmas simulações executadas para o cálculo de desempenho com a integração de mapas ativada. Contudo, nesta nova abordagem, foram considerados apenas os dados métricos obtidos diretamente por cada robô, sem o compartilhamento de informações.

Uma importante consideração a ser feita com esta nova abordagem é observar que o desempenho do método de mapeamento apresentou um comportamento padrão para os três métodos de ajuste de direção. Analisando-se os métodos de ajuste separadamente, as médias das porcentagens de exploração mantiveram valores similares nos ensaios variando-se a quantidade de robôs utilizada.

Uma vez que os experimentos foram realizados com uma mesma quantidade de iterações, os robôs tenderam a visitar uma quantidade de setores com uma mesma área, de acordo com o método de ajuste de direção empregado. Dessa forma, é possível inferir que a 
média de exploração quando a integração de mapas é desativada não depende do número de robôs utilizados, mas sim, apenas do método de exploração empregado.

Tabela 5.7 - Desempenho do método de mapeamento sem integração variando a quantidade de robôs - AEE

\begin{tabular}{cccccc}
\hline $\begin{array}{c}\text { Quantidade de } \\
\text { robôs }\end{array}$ & $\boldsymbol{R}_{\boldsymbol{I}}$ & $\boldsymbol{R}_{\boldsymbol{2}}$ & $\boldsymbol{R}_{\mathbf{3}}$ & $\boldsymbol{R}_{\boldsymbol{4}}$ & $\boldsymbol{R}_{\boldsymbol{5}}$ \\
\hline 1 & $0.44 \pm 0.08$ & - & - & - & - \\
2 & $0.46 \pm 0.13$ & $0.52 \pm 0.09$ & - & - & - \\
3 & $0.43 \pm 0.17$ & $0.51 \pm 0.13$ & $0.44 \pm 0.12$ & - & - \\
4 & $0.42 \pm 0.14$ & $0.42 \pm 0.16$ & $0.38 \pm 0.18$ & $0.37 \pm 0.16$ & - \\
5 & $0.42 \pm 0.11$ & $0.45 \pm 0.15$ & $0.44 \pm 0.14$ & $0.42 \pm 0.12$ & $0.44 \pm 0.17$ \\
\hline
\end{tabular}

Tabela 5.8 - Desempenho do método de mapeamento sem integração variando a quantidade de robôs - AE

\begin{tabular}{|c|c|c|c|c|c|}
\hline \multirow{2}{*}{$\begin{array}{c}\text { Quantidade de } \\
\text { robôs }\end{array}$} & \multicolumn{5}{|c|}{ Média e desvio padrão do mapeamento } \\
\hline & $R_{1}$ & $\boldsymbol{R}_{2}$ & $R_{3}$ & $\boldsymbol{R}_{4}$ & $\boldsymbol{R}_{5}$ \\
\hline 1 & $0.40 \pm 0.10$ & - & - & - & - \\
\hline 2 & $0.35 \pm 0.10$ & $0.27 \pm 0.10$ & - & - & - \\
\hline 3 & $0.32 \pm 0.11$ & $0.25 \pm 0.13$ & $0.20 \pm 0.08$ & - & - \\
\hline 4 & $0.30 \pm 0.10$ & $0.21 \pm 0.07$ & $0.22 \pm 0.07$ & $0.27 \pm 0.13$ & - \\
\hline 5 & $0.35 \pm 0.14$ & $0.30 \pm 0.14$ & $0.26 \pm 0.07$ & $0.27 \pm 0.13$ & $0.28 \pm 0.13$ \\
\hline
\end{tabular}

Tabela 5.9 - Desempenho do método de mapeamento sem integração variando a quantidade de robôs - UNI

\begin{tabular}{cccccc}
\hline $\begin{array}{c}\text { Quantidade de } \\
\text { robôs }\end{array}$ & $\boldsymbol{R}_{\boldsymbol{1}}$ & $\boldsymbol{R}_{\mathbf{2}}$ & $\boldsymbol{R}_{\mathbf{3}}$ & $\boldsymbol{R}_{\boldsymbol{4}}$ & $\boldsymbol{R}_{\boldsymbol{5}}$ \\
\hline 1 & $0.20 \pm 0.05$ & - & - & - & - \\
2 & $0.20 \pm 0.05$ & $0.20 \pm 0.08$ & - & - & - \\
3 & $0.20 \pm 0.05$ & $0.25 \pm 0.09$ & $0.19 \pm 0.04$ & - & - \\
4 & $0.24 \pm 0.12$ & $0.23 \pm 0.08$ & $0.20 \pm 0.04$ & $0.18 \pm 0.02$ & - \\
5 & $0.30 \pm 0.14$ & $0.20 \pm 0.07$ & $0.25 \pm 0.13$ & $0.22 \pm 0.10$ & $0.20 \pm 0.08$ \\
\hline
\end{tabular}

Além disso, é evidenciada mais uma vez a relevância do método de integração de mapas locais, por meio da observação do ganho de informação obtido com a aplicação do mesmo durante a exploração do ambiente. Na Figura 5.6(a), é apresentado o mapa métrico de um dos cinco robôs empregados em uma das simulações realizadas, considerando o mapeamento sem a integração de mapas.

Em contrapartida, na Figura 5.6(b), é ilustrado o mapa métrico do mesmo robô quando este realizou integrações de mapas locais com os demais robôs presentes no ambiente. De 
acordo com a trajetória do robô, é possível notar que o mesmo não explorou efetivamente todo o ambiente, mas graças ao processo de integração de mapas o robô em questão possui informações espaciais sobre todo o ambiente no qual foi inserido.

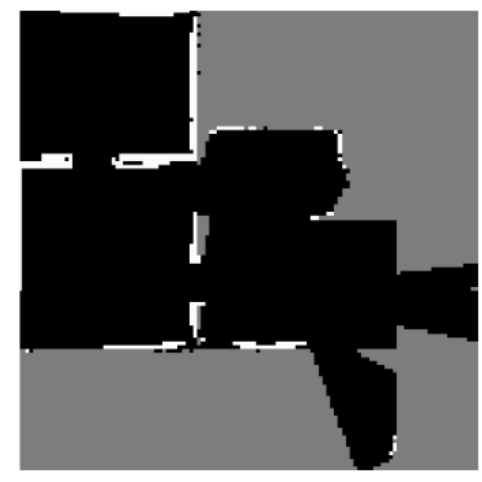

(a)

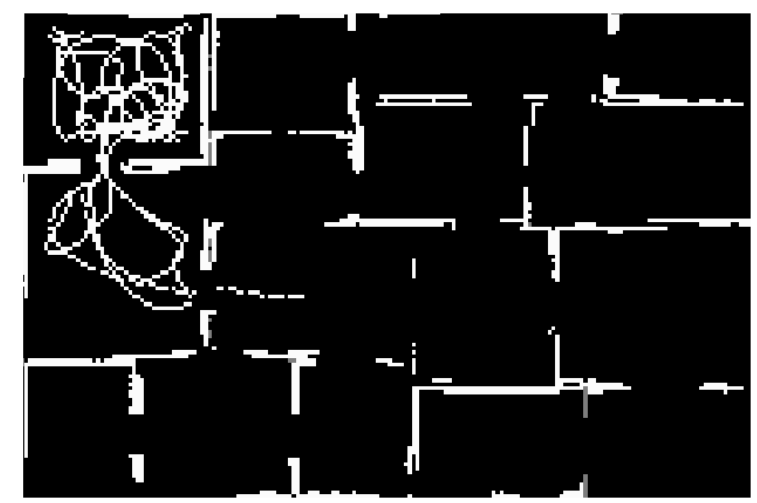

(b)

Figura 5.6 - Mapa de um robô: (a) Sem integração; (b) Com integração

Para validar a constatação de que o método de integração proposto melhora o desempenho da tarefa de mapeamento foi realizado um teste $t$ pareado entre os resultados apresentados nos experimentos anteriores, os quais variaram a quantidade de robôs empregada no processo de exploração.

Nas Tabelas 5.10 e 5.11, são apresentadas as médias e desvios padrões gerais para cada quantidade de robôs, utilizando-se os métodos AEE e UNI, respectivamente. Assim como são apresentados os valores calculados e tabelados para o teste $t$. Uma vez que o método AE é naturalmente similar ao AEE e possui um desempenho inferior a este último, os dados referentes à comparação do mapeamento com e sem integração utilizando o método AE foram omitidos. É importante notar que se utilizando apenas um único robô, independentemente do método de ajuste de direção, é impossível realizar um processo de integração de mapas e, portanto, não há comparação do método de mapeamento com e sem integração de dados neste caso específico.

Considerando agora o desempenho do método de mapeamento empregando-se o método UNI e variando-se a quantidade de robôs no intervalo [2,5] é possível observar que $t_{c a l}>t_{\text {tab }}$ para todos os demais conjuntos de experimentos. Sendo assim, a hipótese nula é rejeitada em todos os referidos casos, indicando que a média do desempenho de mapeamento utilizando o método de integração de mapas é maior do que a média do desempenho sem a integração na estratégia uniforme. Similarmente, a mesma conclusão é obtida ao se comparar o desempenho do método de mapeamento com e sem integração de mapas locais, utilizando- 
se o método AEE. Validando, dessa forma, a suposição de que o processo de integração de mapas locais aumenta o desempenho da tarefa de mapeamento realizada pelos robôs pertencentes ao sistema de exploração e vigilância de ambientes.

Tabela 5.10 - Comparação do método de mapeamento com e sem integração de mapas - AEE

\begin{tabular}{|c|c|c|c|c|c|}
\hline $\begin{array}{c}\text { Quantidade de } \\
\text { robôs }\end{array}$ & Integração & Média $(\mu)$ & $\begin{array}{c}\text { Desvio } \\
\text { Padrão }(\sigma)\end{array}$ & $\begin{array}{c}\text { Valores do teste } \boldsymbol{t} \\
t_{t a b}(0.05,9 \text { g.1. })=1.83\end{array}$ & $\begin{array}{c}\text { Relação entre } \\
\text { os valores }\end{array}$ \\
\hline \multirow{2}{*}{1} & Sim & 0.44 & 0.08 & \multirow{2}{*}{ - } & \multirow{2}{*}{ Inexistente } \\
\hline & Não & 0.44 & 0.08 & & \\
\hline \multirow{2}{*}{2} & Sim & 0.62 & 0.09 & \multirow{2}{*}{$t_{c a l}=7.93$} & \multirow{2}{*}{$>$} \\
\hline & Não & 0.49 & 0.11 & & \\
\hline \multirow[b]{2}{*}{3} & Sim & 0.72 & 0.07 & \multirow{2}{*}{$t_{c a l}=16.30$} & \multirow[b]{2}{*}{$>$} \\
\hline & Não & 0.46 & 0.14 & & \\
\hline \multirow{2}{*}{4} & Sim & 0.70 & 0.10 & \multirow{2}{*}{$t_{c a l}=15.47$} & \multirow{2}{*}{$>$} \\
\hline & Não & 0.39 & 0.16 & & \\
\hline \multirow{2}{*}{5} & Sim & 0.79 & 0.11 & \multirow{2}{*}{$t_{c a l}=9.80$} & \multirow[b]{2}{*}{$>$} \\
\hline & Não & 0.43 & 0.13 & & \\
\hline
\end{tabular}

Tabela 5.11 - Comparação do método de mapeamento com e sem integração de mapas - UNI

\begin{tabular}{|c|c|c|c|c|c|}
\hline $\begin{array}{c}\text { Quantidade de } \\
\text { robôs }\end{array}$ & Integração & Média $(\mu)$ & $\begin{array}{c}\text { Desvio } \\
\text { Padrão }(\sigma)\end{array}$ & $\begin{array}{c}\text { Valores do teste } \boldsymbol{t} \\
t_{t a b}(0.05,9 \mathrm{~g} .1 .)=1.83\end{array}$ & $\begin{array}{c}\text { Relação entre } \\
\text { os valores }\end{array}$ \\
\hline \multirow{2}{*}{1} & Sim & 0.20 & 0.05 & \multirow{2}{*}{ - } & \multirow{2}{*}{ Inexistente } \\
\hline & Não & 0.20 & 0.05 & & \\
\hline \multirow{2}{*}{2} & Sim & 0.24 & 0.07 & \multirow{2}{*}{$t_{c a l}=3.43$} & \multirow{2}{*}{$>$} \\
\hline & Não & 0.20 & 0.06 & & \\
\hline \multirow{2}{*}{3} & Sim & 0.25 & 0.06 & \multirow{2}{*}{$t_{c a l}=3.49$} & \multirow{2}{*}{$>$} \\
\hline & Não & 0.21 & 0.06 & & \\
\hline \multirow{2}{*}{4} & Sim & 0.28 & 0.12 & \multirow{2}{*}{$t_{c a l}=2.54$} & \multirow{2}{*}{$>$} \\
\hline & Não & 0.21 & 0.06 & & \\
\hline \multirow{2}{*}{5} & Sim & 0.37 & 0.16 & \multirow{2}{*}{$t_{c a l}=3.80$} & \multirow{2}{*}{$>$} \\
\hline & Não & 0.23 & 0.10 & & \\
\hline
\end{tabular}

Na Figura 5.7, são apresentados os gráficos de exploração do ambiente utilizando-se o método AEE com e sem integração de mapas, variando-se a quantidade de robôs empregados. $\mathrm{Na}$ coluna da esquerda, são visualizados os gráficos sem a integração de mapas, e na coluna da direita, os gráficos correspondentes com o método de integração ativado. 


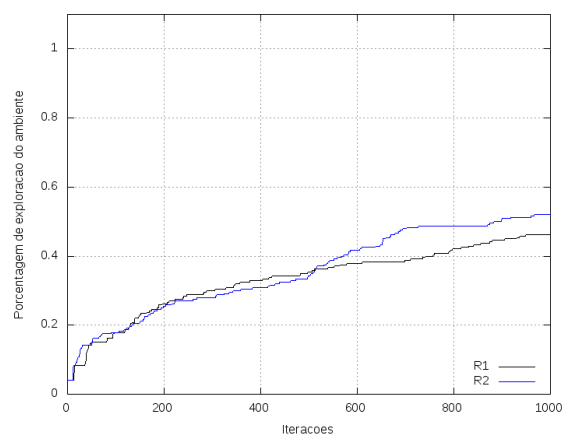

(a)

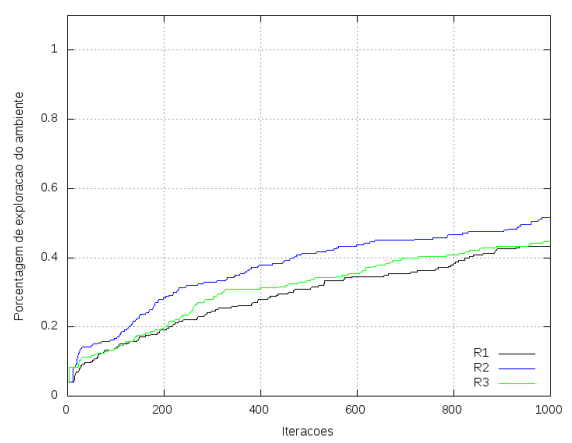

(c)

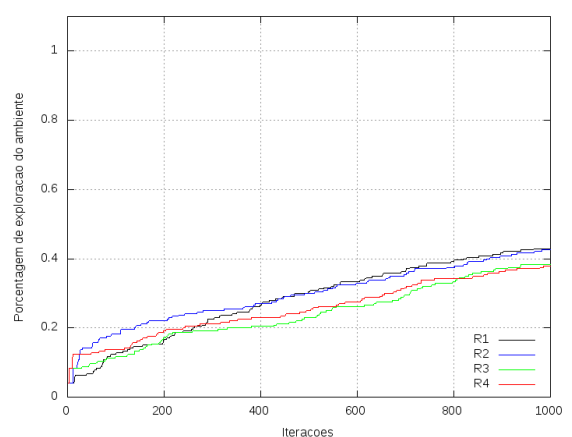

(e)

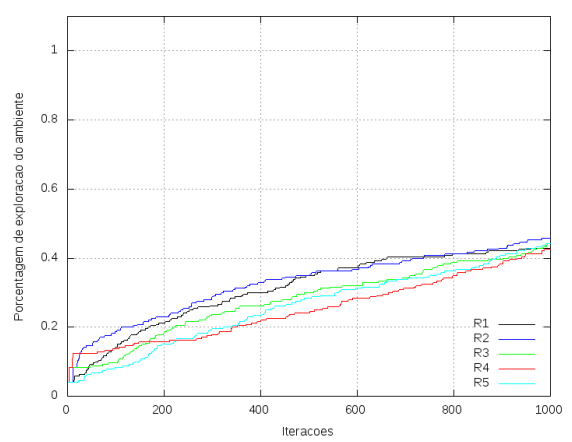

(g)

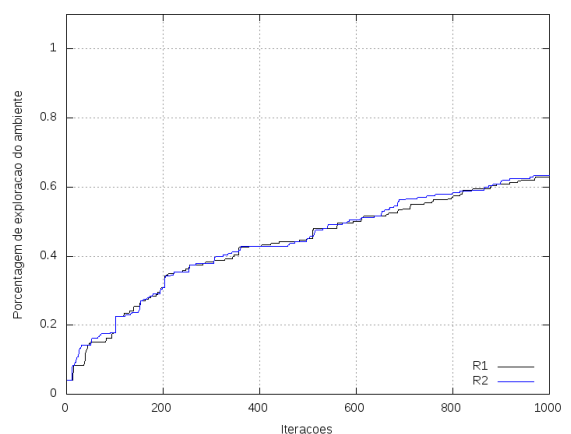

(b)

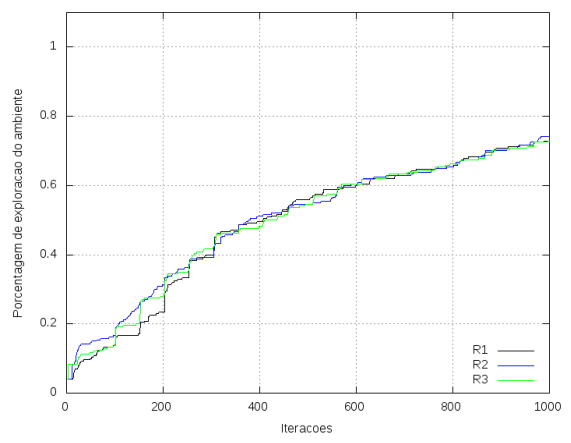

(d)

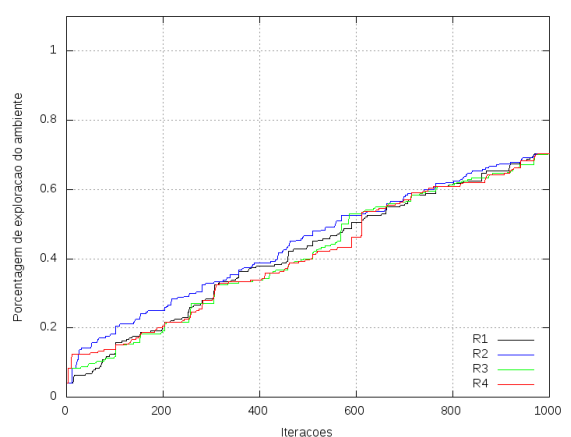

(f)

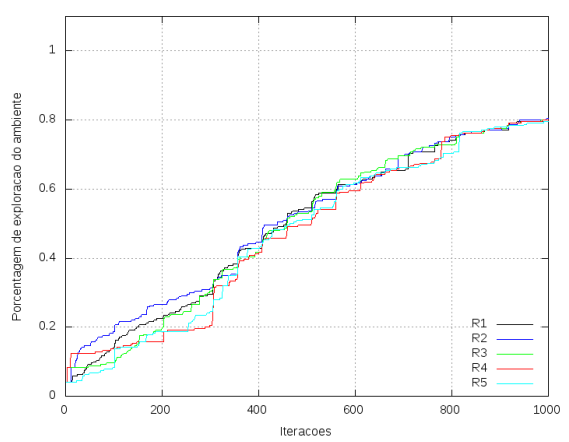

(h)

Figura 5.7 - Gráficos de exploração variando-se a quantidade de robôs empregados no método AEE. Na coluna da esquerda, têm-se os gráficos sem a utilização da integração de mapas. Na coluna da direita, os gráficos correspondentes com a integração de mapas. 
Como pode ser observado na figura em questão, as curvas dos gráficos sem integração, na coluna da esquerda, crescem de forma menos acentuada, indicando um processo de mapeamento mais lento. Além disso, os pontos máximos atingidos pelas curvas dos gráficos com integração, na coluna da direita, são maiores do que seus correspondentes sem a integração de mapas. O que permite inferir que o método proposto de integração de mapas locais não apenas torna a tarefa de mapeamento do ambiente mais rápida, como também a torna mais eficiente.

Avaliando: variação do tamanho do ambiente

Visando validar o método proposto para diversos tipos de ambientes, o conjunto de experimentos a seguir analisa o desempenho do mapeamento considerando diferentes tamanhos de ambiente. No conjunto de experimentos em questão, foi utilizado o ambiente ilustrado na Figura 5.1(b). Vale lembrar que nos ensaios experimentais anteriores, os ambientes foram simulados com uma área de $600 \mathrm{~m}^{2}$ e cada setor do mesmo como um quadrado de $25 \mathrm{~m}^{2}$.

No conjunto de experimentos em questão, três robôs $\left(R_{1}, R_{2}\right.$ e $\left.R_{3}\right)$ foram alocados na região superior esquerda do ambiente da Figura 5.1(b). Foi empregado o método de ajuste de direção AEE com um raio de comunicação de 16 metros para o compartilhamento dos mapas métricos locais entre os robôs. O tamanho do ambiente variou nas dimensões: $20 \mathrm{~m} \mathrm{X} \mathrm{10m,} 20$ X 20m, 30m X 20m, 30m X 30m e 40 X 30. O tamanho dos setores em todas as simulações executadas foi igual àquele utilizado nos experimentos anteriores.

$\mathrm{Na}$ Tabela 5.12, são apresentadas as médias e desvios padrões das porcentagens de exploração para cada dimensão do ambiente, considerando que os robôs compartilham informações espaciais entre si. Em contrapartida, na Tabela 5.13, são apresentas as médias e desvios padrões das porcentagens de exploração para o mesmo conjunto de dados, porém considerando apenas as informações métricas obtidas diretamente pelos sensores de cada robô, ou seja, com o método de integração de mapas desativado.

Como pode ser observados pelas Tabelas 5.11 e 5.12, há um declínio na porcentagem de exploração quando o tamanho do ambiente aumenta, situação denotada pelos casos $30 \mathrm{~m} \mathrm{X}$ 30m (36 setores) e 40m X 30m (48 setores). Uma vez que em tais casos a área a ser explorada é maior e a quantidade de iterações entre as configurações testadas é mantida constante, o declínio na porcentagem de exploração pode ser visto como uma consequência natural e 
esperada. Contudo, vale ressaltar que mesmo um ambiente com o dobro do tamanho dos experimentos anteriores, o método de mapeamento com a integração de mapas ativada atingiu uma porcentagem de exploração próxima a $85 \%$ para todos os robôs empregados nestas simulações.

Tabela 5.12 - Desempenho do método de mapeamento com integração variando a dimensão do ambiente - AEE

\begin{tabular}{lccc}
\hline Dimensão do ambiente & \multicolumn{3}{c}{ Média e desvio padrão do mapeamento } \\
& $\boldsymbol{R}_{\boldsymbol{I}}$ & $\boldsymbol{R}_{\mathbf{2}}$ & $\boldsymbol{R}_{\mathbf{3}}$ \\
\hline 20m X 10m (8 setores) & $0.77 \pm 0.11$ & $0.60 \pm 0.27$ & $0.58 \pm 0.27$ \\
20m X 20m (16 setores) & $0.89 \pm 0.11$ & $0.88 \pm 0.10$ & $0.88 \pm 0.10$ \\
30m X 20m (24 setores) & $0.91 \pm 0.07$ & $0.91 \pm 0.07$ & $0.92 \pm 0.07$ \\
30m X 30m (36 setores) & $0.89 \pm 0.11$ & $0.89 \pm 0.08$ & $0.89 \pm 0.11$ \\
40m X 30m (48 setores) & $0.85 \pm 0.08$ & $0.86 \pm 0.08$ & $0.85 \pm 0.08$ \\
\hline
\end{tabular}

Tabela 5.13 - Desempenho do método de mapeamento sem integração variando a dimensão do ambiente - AEE

\begin{tabular}{cccc}
\hline \multirow{2}{*}{ Dimensão do ambiente } & \multicolumn{3}{c}{ Média e desvio padrão do mapeamento } \\
& $\boldsymbol{R}_{\boldsymbol{I}}$ & $\boldsymbol{R}_{\mathbf{2}}$ & $\boldsymbol{R}_{\mathbf{3}}$ \\
\hline 20m X 10m (8 setores) & $0.52 \pm 0.21$ & $0.48 \pm 0.26$ & $0.43 \pm 0.25$ \\
20m X 20m (16 setores) & $0.58 \pm 0.13$ & $0.70 \pm 0.17$ & $0.58 \pm 0.15$ \\
30m X 20m (24 setores) & $0.71 \pm 0.11$ & $0.62 \pm 0.23$ & $0.65 \pm 0.17$ \\
30m X 30m (36 setores) & $0.57 \pm 0.18$ & $0.56 \pm 0.11$ & $0.58 \pm 0.11$ \\
40m X 30m (48 setores) & $0.44 \pm 015$ & $0.53 \pm 0.12$ & $0.46 \pm 0.17$ \\
\hline
\end{tabular}

Deve-se destacar que as porcentagens de exploração nos ambientes 20 X 10 (8 setores) e 20 X 20 (16 setores) foram menores do que àquela apresentada no ambiente $30 \times 20$ (24 setores) devido principalmente as próprias dimensões dos ambientes. Uma vez que, nestes casos, as áreas que separam uma sala do ambiente das outras são menores, os robôs demandaram um tempo maior para se desviarem dos obstáculos presentes no ambiente paredes e demais robôs - e, consequentemente, levaram um tempo maior para atravessarem de uma sala para a próxima.

Considerando a utilização do método proposto de integração de mapas locais baseado em observações inter-robôs, outra importante observação a ser realizada referente aos dados em análise é o fato de que não apenas as porcentagens de exploração e mapeamento do ambiente dos robôs aumentam com a utilização do método proposto, como também, os desvios padrões dos experimentos executados diminuem à medida que os robôs compartilham entre si informações espaciais acerca do ambiente no qual se encontram. 
Avaliando: métodos de mapeamento - OG com integração de dados e Thinning

No próximo conjunto de experimentos, visa-se comparar o método de mapeamento com integração de dados com outra abordagem de mapeamento. Sendo assim, avalia-se o método proposto em relação à técnica de mapeamento topológico Thinning. Ambas as técnicas de mapeamento são aplicadas simultaneamente nos ambientes ilustrados nas Figuras 5.1(c) e (d), denotados para simplificação como $A M B_{C}$ e $A M B_{D}$, respectivamente. Uma vez que ambas utilizam a mesma estratégia de exploração - IAS-SS (AEE) - a comparação entre as mesmas se torna mais objetiva, avaliando-se apenas a tarefa de mapeamento em si.

Nestes experimentos são utilizados três robôs $-R_{1}, R_{2}$ e $R_{3}$ - em um ambiente simulado de dimensão $30 \mathrm{~m}$ X 20m. Na Figura 5.8(a), é apresentado o gráfico da porcentagem de exploração do método de mapeamento métrico com integração de dados, empregando-se um raio de comunicação de 16 metros. Na Figura 5.8(b), é apresentado o gráfico de exploração empregando-se a técnica Thinning. Ambos os gráficos se referem à exploração do ambiente $A M B_{C}$.

Na Figura 5.9, são ilustrados exemplos dos mapas gerados com cada uma das abordagens mencionadas em uma das simulações executadas. Os mapas métricos baseados em grades de ocupação com integração de mapas dos robôs $R_{1}, R_{2}$ e $R_{3}$ são apresentados nas Figuras 5.9(a), (b) e (c), respectivamente.

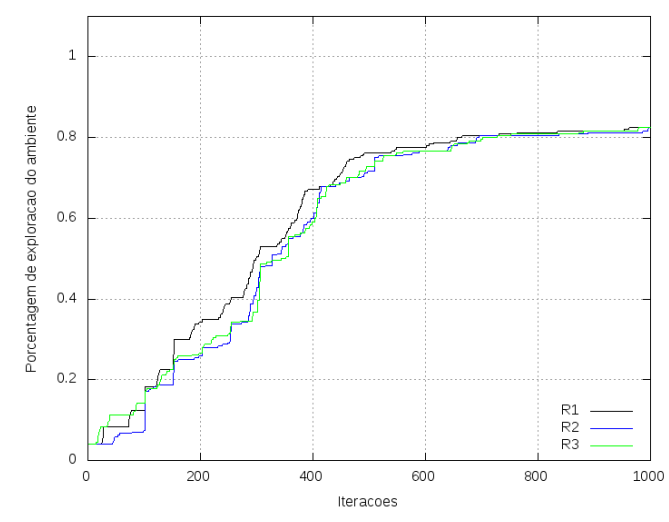

(a)

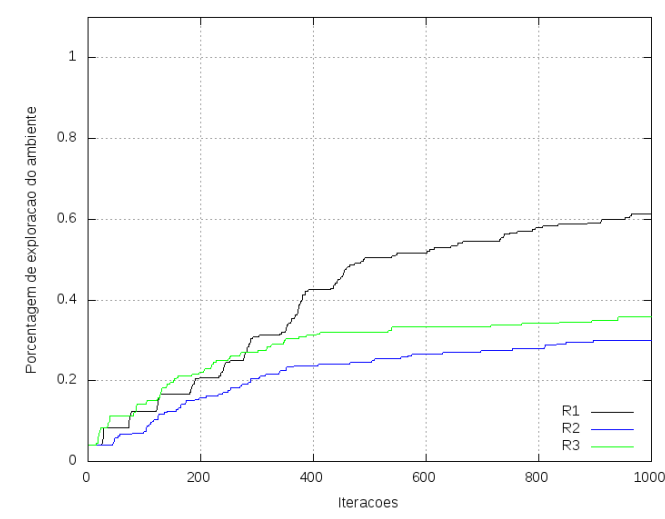

(b)

Figura 5.8 - Gráficos de exploração variando-se o método de mapeamento no ambiente $A M B_{C}$ (a) Grade de Ocupação com integração de mapas; (b) Thinning 
Uma vez que os mapas topológicos obtidos com a técnica Thinning são gerados a partir de representações métricas, os mesmos são apresentados sobrepostos aos mapas métricos utilizados em suas respectivas construções, visando assim uma melhor visualização e entendimento dos mapas em questão. Nas Figuras 5.9(d), (e) e (f), os mapas topológicos são denotados pelas linhas verdes, considerando-se os robôs $R_{1}, R_{2}$ e $R_{3}$, respectivamente.

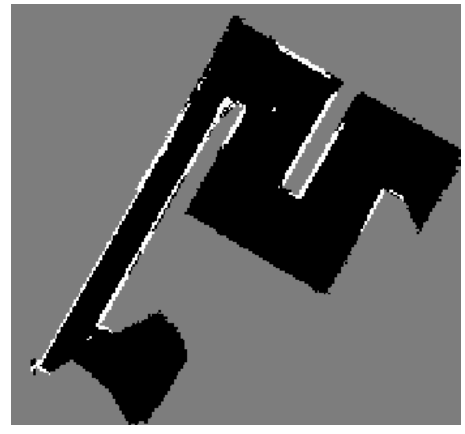

(a)

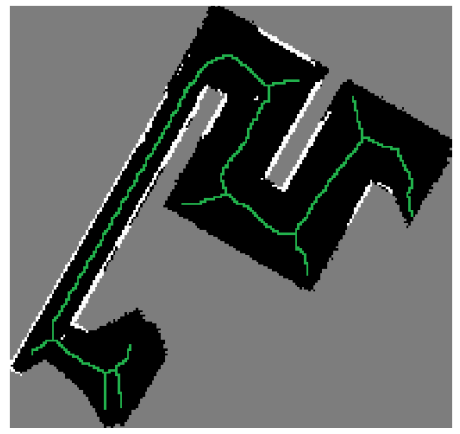

(d)

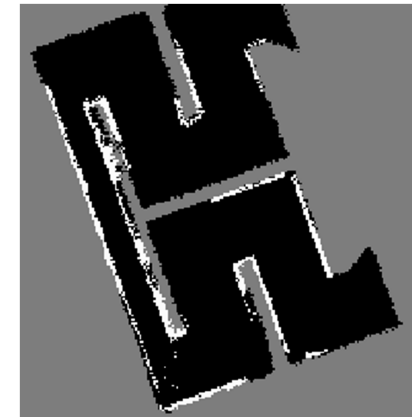

(b)

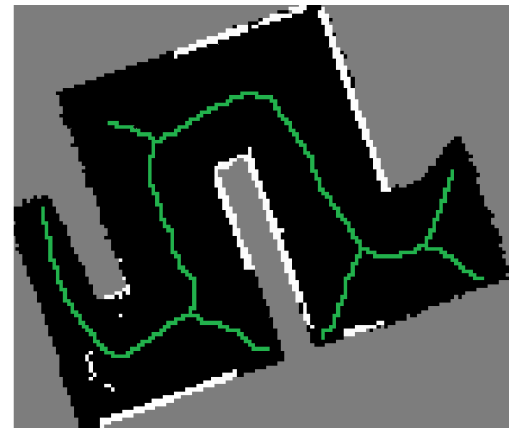

(e)

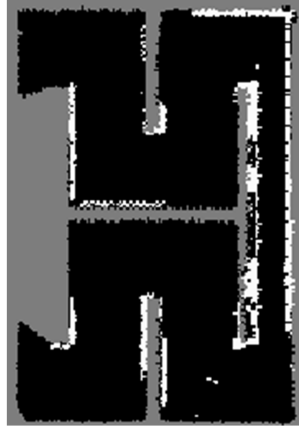

(c)

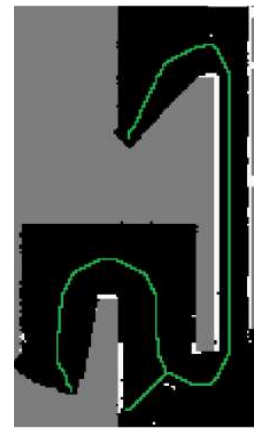

(f)

Figura 5.9 - Mapeamento do ambiente $A M B_{C}$. Mapas métricos com integração de dados: (a) $R_{I}$; (b) $R_{2}$; (c) $R_{3}$. Mapas topológicos: (d) $R_{1}$; (e) $R_{2}$; (f) $R_{3}$

Considerando-se agora a exploração do ambiente $A M B_{D}$, apresenta-se na Figura 5.10(a) o gráfico da porcentagem de exploração do método de mapeamento métrico com integração de dados, mantendo-se o raio de comunicação em 16 metros. Na Figura 5.10(b), é apresentado o gráfico de exploração empregando-se a técnica Thinning. Os exemplos dos mapas gerados com cada uma das abordagens mencionadas são ilustrados na Figura 5.11. Os mapas métricos baseados em grades de ocupação com integração de mapas dos robôs $R_{1}, R_{2} \mathrm{e}$ $R_{3}$ são apresentados nas Figuras 5.11(a), (b) e (c), respectivamente. Em contrapartida, nas Figuras 5.11(d), (e) e (f), são denotados os mapas topológicos dos robôs $R_{1}, R_{2}$ e $R_{3}$, respectivamente.

Em ambos ambientes testados, $A M B_{C}$ e $A M B_{D}$, o método de mapeamento métrico com integração de dados demonstra possuir um desempenho melhor do que o método de 
mapeamento topológico Thinning, considerando-se como critério de avaliação a porcentagem de exploração do ambiente em questão. Na Tabela 5.14, são apresentadas as médias e desvios padrões de cada abordagem de mapeamento empregada, assim como também são apresentados os valores obtidos com o teste $t$ pareado, referente à comparação dos métodos de mapeamento testados.

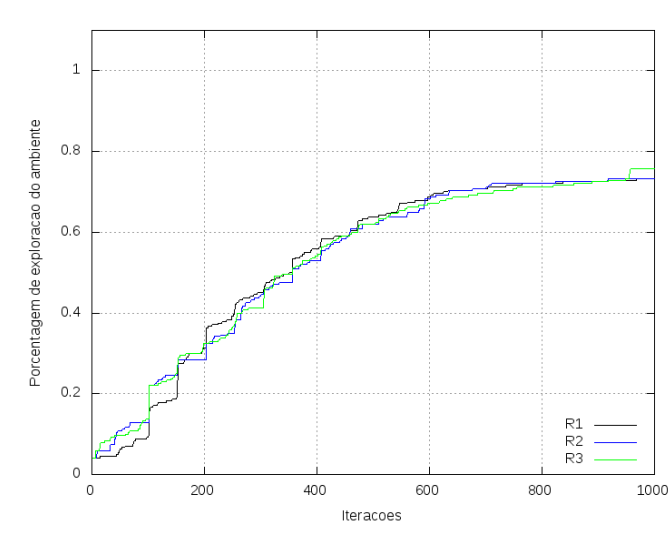

(a)

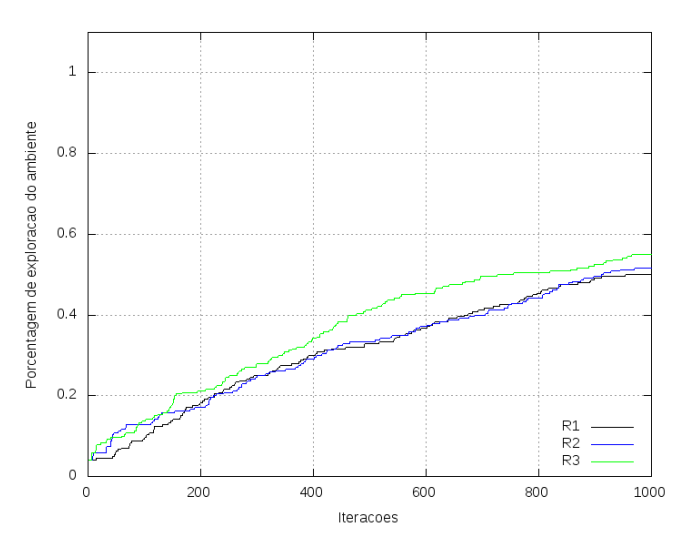

(b)

Figura 5.10 - Gráficos de exploração variando-se o método de mapeamento no ambiente $A M B_{D}$ (a) Grade de Ocupação com integração de mapas; (b) Thinning

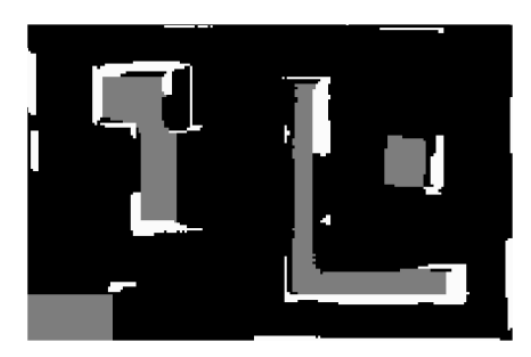

(a)

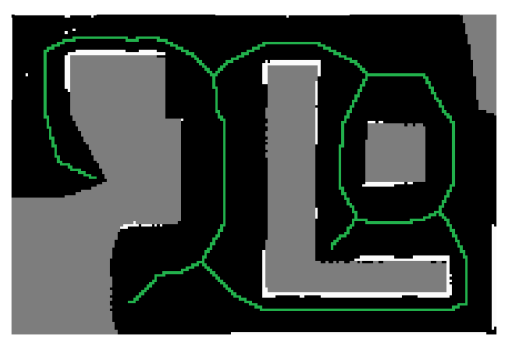

(d)

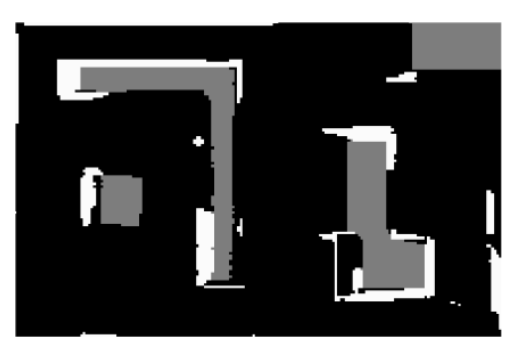

(b)

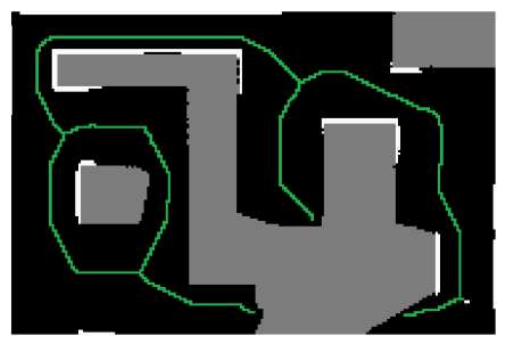

(e)

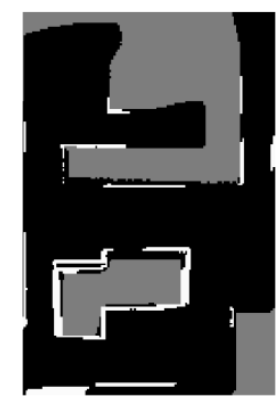

(c)

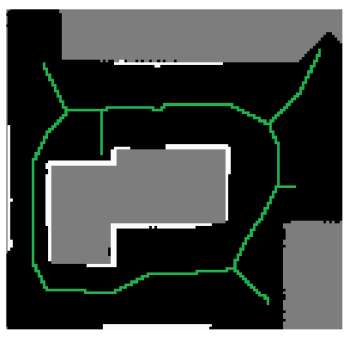

(f)

Figura 5.11 - Mapeamento do ambiente $A M B_{D}$. Mapas métricos com integração de dados: (a) $R_{1}$; (b) $R_{2}$; (c) $R_{3}$. Mapas topológicos: (d) $R_{1}$; (e) $R_{2}$; (f) $R_{3}$ 
Como pode ser observado na Tabela 5.14, a relação entre os valores do teste $t$ é $t_{c a l}>$ $t_{\text {tab }}$ para ambos os ambientes $A M B_{C}$ e $A M B_{D}$. Rejeitando, portanto, a hipótese nula nos casos em questão. Uma vez que a hipótese nula é rejeitada, pode-se inferir que a abordagem de mapeamento utilizando o método proposto de integração de mapas possui um desempenho médio, referente à porcentagem de exploração do ambiente, melhor do que o método Thinning.

Tabela 5.14 - Comparação entre métodos de mapeamento - Grade de Ocupação com integração de mapas e mapas topológicos Thinning

\begin{tabular}{cccccc}
\hline Ambiente & $\begin{array}{c}\text { Método de } \\
\text { mapeamento }\end{array}$ & Média $(\mu)$ & $\begin{array}{c}\text { Desvio } \\
\text { Padrão }(\sigma)\end{array}$ & $\begin{array}{c}\text { Valores do teste } t \\
t_{\text {tab }}(0.05,18 \mathrm{~g} .1 .)=1.73\end{array}$ & $\begin{array}{c}\text { Relação entre } \\
\text { os valores }\end{array}$ \\
\hline \multirow{2}{*}{$A M B_{C}$} & $\begin{array}{c}\text { Métrico com } \\
\text { integração } \\
\text { Topológico } \\
\text { Thinning }\end{array}$ & 0.82 & 0.09 & $t_{\text {cal }}=8.58$ & \\
& 0.42 & 0.11 & & \\
\hline \multirow{2}{*}{$\begin{array}{c}\text { Métrico com } \\
\text { integração }\end{array}$} & 0.73 & 0.21 & & $>$ \\
& $\begin{array}{c}\text { Topológico } \\
\text { Thinning }\end{array}$ & 0.52 & 0.25 & $t_{\text {cal }}=2.05$ & \\
\hline
\end{tabular}

Avaliando: feromônio virtual integrado

É importante lembrar que em todos os experimentos descritos até então foi empregado o conceito de mapa de feromônio global. Ou seja, todos os robôs possuíam acesso a uma grade de feromônio global, na qual os mesmos realizavam os processos de liberação e detecção de feromônio. Contudo, tal abordagem não é aplicável em robôs reais, uma vez que na estratégia de exploração IAS-SS não há uma central de processamento na qual os robôs teriam acesso a este tipo de estrutura de dados. Para solucionar este problema, é proposta nesta tese uma alternativa que emprega o conceito de feromônio virtual integrado. $\mathrm{Na}$ abordagem de feromônio virtual, cada robô mantém uma grade de feromônio local que é acessada apenas pelo próprio robô, de forma que a mesma pode ser compartilhada com os demais e integrada com estes por meio do método de integração proposto.

Para avaliar a eficiência da abordagem de feromônio virtual os experimentos variandose a quantidade de robôs, utilizando o método de ajuste de direção IAS-SS (AEE) no 
ambiente da Figura 5.1(a), foram replicados com este novo conceito. Todas as condições iniciais do referido experimento foram mantidas, apenas o processo de acesso a grade de feromônios foi alterado, permitindo assim uma avaliação objetiva que mensura apenas o impacto da alteração do conceito de mapa global de feromônio para o conceito de feromônios virtuais integrados.

Na Tabela 5.15, são apresentadas as médias e desvios padrões das porcentagens de exploração para cada robô empregado, considerando a aplicação da abordagem de feromônios virtuais integrados. De maneira análoga aos experimentos descritos anteriormente, na Tabela 5.16, são apresentados os desempenhos de exploração considerando apenas os resultados obtidos diretamente pelos sensores dos robôs, ou seja, com o método de integração desativado. Os resultados dos experimentos originais, utilizando mapas globais de feromônio, foram descritos nas Tabelas 5.4 e 5.7.

Tabela 5.15 - Desempenho do método de mapeamento empregando feromônios virtuais integrados - AEE

\begin{tabular}{cccccc}
\hline $\begin{array}{c}\text { Quantidade de } \\
\text { robôs }\end{array}$ & $\boldsymbol{R}_{\boldsymbol{I}}$ & $\boldsymbol{R}_{\mathbf{2}}$ & $\boldsymbol{R}_{\mathbf{3}}$ & $\boldsymbol{R}_{\boldsymbol{4}}$ & $\boldsymbol{R}_{\boldsymbol{5}}$ \\
\hline 1 & $0.40 \pm 0.11$ & - & - & - & - \\
2 & $0.48 \pm 0.14$ & $0.50 \pm 0.14$ & - & - & - \\
3 & $0.58 \pm 0.10$ & $0.59 \pm 0.11$ & $0.60 \pm 0.11$ & - & - \\
4 & $0.60 \pm 0.08$ & $0.60 \pm 0.08$ & $0.60 \pm 0.08$ & $0.58 \pm 0.08$ & - \\
5 & $0.63 \pm 0.11$ & $0.62 \pm 0.10$ & $0.62 \pm 0.13$ & $0.62 \pm 0.10$ & $0.62 \pm 0.11$ \\
\hline
\end{tabular}

Tabela 5.16 - Desempenho do método de mapeamento com a integração de mapas desativada - AEE

\begin{tabular}{cccccc}
\hline $\begin{array}{c}\text { Quantidade de } \\
\text { robôs }\end{array}$ & $\boldsymbol{R}_{\boldsymbol{I}}$ & $\boldsymbol{R}_{\boldsymbol{2}}$ & $\boldsymbol{R}_{\mathbf{3}}$ & $\boldsymbol{R}_{\boldsymbol{4}}$ & $\boldsymbol{R}_{\boldsymbol{5}}$ \\
\hline 1 & $0.40 \pm 0.11$ & - & - & - & - \\
2 & $0.37 \pm 0.17$ & $0.41 \pm 0.14$ & - & - & - \\
3 & $0.36 \pm 0.15$ & $0.42 \pm 0.11$ & $0.45 \pm 0.17$ & - & - \\
4 & $0.39 \pm 0.12$ & $0.41 \pm 0.10$ & $0.38 \pm 0.14$ & $0.34 \pm 0.13$ & - \\
5 & $0.41 \pm 0.11$ & $0.39 \pm 0.13$ & $0.38 \pm 0.16$ & $0.32 \pm 0.12$ & $0.41 \pm 0.13$ \\
\hline
\end{tabular}

Como pode ser observado nas tabelas em questão, o aumento da quantidade de robôs gerou um aumento significativo no desempenho do método de mapeamento, considerando o método de mapeamento empregando feromônios virtuais integrados. De modo similar aos resultados exibidos na Tabela 5.4, o aumento do número de robôs permite um maior compartilhamento de informação entre os mesmos, por meio do método de integração de 
mapas proposto, aumentando consequentemente a média da porcentagem de exploração do ambiente.

Para validar a suposição de que o método de mapeamento empregando feromônios virtuais é melhor do que a sua contrapartida sem integração de informações espaciais e de feromônios - os resultados das Tabelas 5.15 e 5.16 foram comparados por meio de um teste $t$ pareado. Na Tabela 5.17, são apresentados os dados dos valores do teste $t$ referentes a tal análise.

Tabela 5.17 - Comparação do método de mapeamento com e sem integração de mapas - Feromônios virtuais

\begin{tabular}{|c|c|c|c|c|c|}
\hline $\begin{array}{c}\text { Quantidade de } \\
\text { robôs }\end{array}$ & $\begin{array}{c}\text { Feromônios } \\
\text { virtuais }\end{array}$ & Média $(\mu)$ & $\begin{array}{c}\text { Desvio } \\
\text { Padrão }(\sigma)\end{array}$ & $\begin{array}{c}\text { Valores do teste } t \\
t_{t a b}(0.05,9 \mathrm{~g} .1 .)=1.83\end{array}$ & $\begin{array}{c}\text { Relação entre } \\
\text { os valores }\end{array}$ \\
\hline \multirow{2}{*}{1} & Sim & 0.40 & 0.11 & \multirow{2}{*}{-} & \multirow{2}{*}{ Inexistente } \\
\hline & Não & 0.40 & 0.11 & & \\
\hline \multirow{2}{*}{2} & Sim & 0.49 & 0.14 & \multirow{2}{*}{$t_{c a l}=8.66$} & \multirow{2}{*}{$>$} \\
\hline & Não & 0.39 & 0.15 & & \\
\hline \multirow{2}{*}{3} & Sim & 0.59 & 0.10 & \multirow{2}{*}{$t_{c a l}=7.07$} & \multirow{2}{*}{$>$} \\
\hline & Não & 0.41 & 0.14 & & \\
\hline \multirow{2}{*}{4} & Sim & 0.59 & 0.08 & \multirow{2}{*}{$t_{c a l}=9.81$} & \multirow{2}{*}{$>$} \\
\hline & Não & 0.38 & 0.12 & & \\
\hline \multirow{2}{*}{5} & Sim & 0.62 & 0.11 & \multirow{2}{*}{$t_{c a l}=9.03$} & \multirow{2}{*}{$>$} \\
\hline & Não & 0.38 & 0.12 & & \\
\hline
\end{tabular}

Como pode ser observado pela relação entre os valores de $t_{t a b}$ e $t_{c a l}$, em todas as configurações dos experimentos, com exceção do caso no qual a relação é inexistente, o desempenho do desempenho do mapeamento sem a aplicação da abordagem de feromônios virtuais se mostrou inferior ao método de mapeamento com a abordagem de feromônios virtuais, esta última inerentemente relacionada ao método de integração de mapas proposto. Tal resultado comprova a eficiência do método de mapeamento com feromônios virtuais, permitindo dessa forma que tal abordagem seja explorada em trabalhos futuros empregandose robôs reais.

Uma importante análise de desempenho a ser discutida é a comparação do método de mapeamento com integração de dados utilizando o conceito de mapa global de feromônio e sua contrapartida empregando a abordagem de feromônios virtuais. Na Tabela 5.18, são apresentados os dados estatísticos referentes ao teste $t$ não pareado realizado para tal análise. 
Como se era esperado, o desempenho médio entre as duas abordagens apresentou uma relação $t_{c a l}>t_{\text {tab }}$ para uma quantidade de robôs variando no intervalo [2,5]. Tal resultado indica que o método de mapeamento com integração de dados utilizando o mapa global de feromônios possui um desempenho melhor do que o mapeamento empregando o conceito de feromônios virtuais.

Uma vez que no mapa global de feromônios os robôs possuem acesso a uma mesma estrutura de dados para processamento do feromônio é natural que tal abordagem apresente uma melhor eficiência em relação a sua contrapartida baseada em feromônios virtuais. Contudo, tal comportamento, não deteriora o fato de que, entre as duas abordagens, apenas o método empregando feromônios virtuais pode ser empregado em ambientes reais. Além disso, deve-se lembrar de que o mapeamento utilizando feromônios virtuais também apresentou um desempenho comprovado melhor do que o simples mapeamento sem integração de dados, sendo portanto, uma solução viável para a tarefa de mapeamento distribuído de ambientes internos.

Tabela 5.18 - Comparação do método de mapeamento - Mapa global de feromônio versus Feromônios virtuais integrados

\begin{tabular}{|c|c|c|c|c|c|}
\hline $\begin{array}{l}\text { Quantidade } \\
\text { de robôs }\end{array}$ & $\begin{array}{c}\text { Abordagem de } \\
\text { feromônio }\end{array}$ & Média $(\mu)$ & $\begin{array}{c}\text { Desvio } \\
\text { Padrão }(\sigma)\end{array}$ & $\begin{array}{c}\text { Valores do teste } t \\
t_{\text {tab }}(0.05,18 \mathrm{~g} .1 .)=1.73\end{array}$ & $\begin{array}{c}\text { Relação entre } \\
\text { os valores }\end{array}$ \\
\hline \multirow{2}{*}{1} & Mapa Global & 0.44 & 0.08 & \multirow{2}{*}{$t_{c a l}=0.92$} & \multirow{2}{*}{$<$} \\
\hline & Fer. Virtual & 0.40 & 0.11 & & \\
\hline \multirow{2}{*}{2} & Mapa Global & 0.62 & 0.09 & \multirow{2}{*}{$t_{c a l}=2.47$} & \multirow{2}{*}{$>$} \\
\hline & Fer. Virtual & 0.49 & 0.14 & & \\
\hline \multirow{2}{*}{3} & Mapa Global & 0.72 & 0.07 & \multirow{2}{*}{$t_{c a l}=3.86$} & \multirow{2}{*}{$>$} \\
\hline & Fer. Virtual & 0.59 & 0.08 & & \\
\hline \multirow{2}{*}{4} & Mapa Global & 0.70 & 0.10 & \multirow{2}{*}{$t_{c a l}=2.71$} & \multirow{2}{*}{$>$} \\
\hline & Fer. Virtual & 0.59 & 0.08 & & \\
\hline \multirow{2}{*}{5} & Mapa Global & 0.79 & 0.11 & \multirow{2}{*}{$t_{c a l}=3.45$} & \multirow{2}{*}{$>$} \\
\hline & Fer. Virtual & 0.62 & 0.11 & & \\
\hline
\end{tabular}

Uma característica interessante a ser observada é a relação $t_{c a l}<t_{t a b}$ nos experimentos em que se empregou apenas um único robô para exploração do ambiente. Neste caso especifico, deve-se notar que não há integração de dados, independentemente da abordagem de feromônios utilizada - mapa global ou feromônios virtuais - e, portanto, não há diferença estatística entre as duas abordagens analisadas. 
Avaliando: variação do parâmetro it intervalo

No método proposto de integração de mapas locais há um importante parâmetro que define com que frequência o compartilhamento de informações ocorre entre os robôs, definido

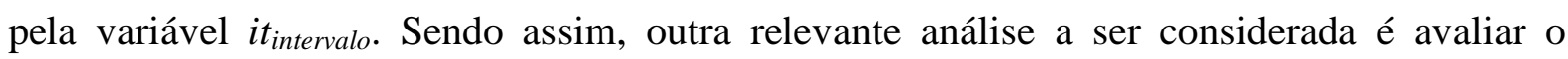
impacto da variação do parâmetro it intervalo no processo de integração. Para tal um novo conjunto de experimentos foi realizado, de maneira que, mensurou-se a média de exploração do ambiente quando o parâmetro em questão assume os seguintes valores $i t_{\text {intervalo }} \in\{1,10$, $20,30,40,50\}$.

No referido conjunto de experimentos, foram empregados cinco robôs alocados no centro do ambiente da Figura 5.1(e). Como estratégia de exploração utilizou-se o IAS-SS (AEE) com raio de comunicação de 16 metros e abordagem de acesso aos estímulos do ambiente baseado em feromônios virtuais integrados. Na Tabela 5.19, são apresentadas as médias e desvios padrões gerais para cada valor do parâmetro it $t_{\text {intervalo }}$ testado.

Tabela 5.19 - Desempenho do método de mapeamento variando-se o parâmetro $i t_{\text {intervalo }}$

\begin{tabular}{ccc}
\hline $\boldsymbol{i t}_{\text {intervalo }}$ & Média $(\mu)$ & Desvio Padrão $(\sigma)$ \\
\hline 1 & 0.59 & 0.14 \\
10 & 0.65 & 0.12 \\
20 & 0.64 & 0.10 \\
30 & 0.62 & 0.10 \\
40 & 0.62 & 0.07 \\
50 & 0.53 & 0.13 \\
\hline
\end{tabular}

Como pode ser observado na Tabela 5.19, os desempenhos médios em todos os casos de teste foram relativamente próximos. Para verificar se há diferença estatística em tais ensaios, foi realizado um teste $t$ não pareado entre os resultados mencionados. Visando a simplificação e melhor entendimento desta análise, foram omitidos na Tabela 5.20 os valores de $t_{t a b}$ e $t_{c a l}$ do teste $t$ realizado, apresentando-se apenas a relação entre tais valores para pares de configurações de experimentos.

Considerando os valores de $i t_{\text {intervalo }}$ iguais a 1, 10, 20, 30 e 40 não houve diferença estatística entre os experimentos realizados, o que permite inferir que em média o aumento da troca de informações entre os robôs, representando pela diminuição dos valores de $i t_{\text {intervalo }}$, é compensado pelo maior tempo necessário para compartilhar estes dados, provocando uma 
exploração mais lenta do ambiente. Dessa forma, o desempenho da tarefa de mapeamento com o método proposto de integração se mantem similar para os referidos casos de teste.

Tabela 5.20 - Comparação do desempenho entre os valores do parâmetro $i t_{\text {intervalo }}$

\begin{tabular}{cccccc}
\hline \multicolumn{7}{c}{ Relação entre os valores do teste t comparando variações do parâmetro it $_{\text {intervalo }}$} \\
\hline & 10 & 20 & 30 & 40 & 50 \\
1 & $<$ & $<$ & $<$ & $<$ & $<$ \\
10 & $<$ & $<$ & $<$ & $>$ \\
20 & & $<$ & $<$ & $>$ \\
30 & & & & $>$ \\
40 & & & & $>$ \\
\hline
\end{tabular}

O desempenho do mapeamento iniciou a se degradar apenas quando $i t_{\text {intervalo }}$ foi igual a 50. Este resultado indica que a partir de tal iteração a exploração do ambiente começa a se tornar menos objetiva, quando analisada sob a ótica dos estímulos de feromônio detectados no ambiente para ajuste na direção de movimento dos robôs. Uma vez que os robôs levam mais tempo para trocar seus mapas de feromônios locais, os mesmos tendem a se direcionar para áreas já exploradas pelos demais, reduzindo assim a eficiência da tarefa de exploração.

É importante observar que não existe um melhor valor para o parâmetro $i t_{\text {intervalo }}$. Um valor pequeno para o parâmetro aumenta a troca de informações entre os robôs, mas também aumenta o tempo gasto para tal compartilhamento, tornando o processo de locomoção mais lento. Em contrapartida, um valor alto para o parâmetro torna a movimentação mais rápida, contudo os robôs tendem a perder informações relevantes dos feromônios das áreas já exploradas pelos demais, conduzindo a um processo de exploração muitas vezes redundante.

\section{Avaliando: formação dos robôs}

Por fim, o último conjunto de experimentos visa avaliar o desempenho do método de mapeamento com integração de dados quando o mesmo é aplicado em um sistema cuja formação é uma característica crucial. Nestes experimentos é utilizada a extensão da estratégia IAS-SS denominada SAFS, mantendo como técnica de ajuste na direção de movimentos dos robôs o método AEE.

Em tais experimentos são simulados os ambientes ilustrados nas Figuras 5.1(f) e (g), abreviados para simplificação como $A M B_{F}$ e $A M B_{G}$. Diferentemente dos experimentos anteriores, optou-se por simular tais ambientes com dimensões 40m X 20m, totalizando uma 
área de $800 \mathrm{~m}^{2}$. Além disso, definiu-se também que os ambientes fossem divididos em 25 setores, de modo que 12 setores são localizados na sala à esquerda do ambiente e outros 12 na sala à direita, e um último setor compreendendo totalmente o corredor que liga as duas salas.

Para avaliar a tarefa de formação foram replicados os experimentos relacionados ao tema apresentados por Calvo (CALVO, 2012). Nos experimentos realizados pelo referido autor, foram empregados 10 robôs utilizando a estratégia SAFS no ambiente $A M B_{F}$. Sendo assim, no presente trabalho foi empregada a mesma quantidade de robôs, adotando-se um raio de comunicação de 16 metros. Vale lembrar que além da troca de informação pertinente à estratégia SAFS, os robôs nos experimentos realizados nesta tese compartilham também dados referentes aos seus respectivos mapas locais.

Na Tabela 5.21, são apresentados os desempenhos do método de mapeamento para os ambientes $A M B_{F}$ e $A M B_{G}$. Como nas análises anteriores, é apresentado tanto o desempenho da tarefa de mapeamento considerando que há o compartilhamento de mapas métricos entre os robôs, quanto o desempenho correspondente do mapeamento considerando que o mesmo é realizado com o método de integração de mapas desativado.

Tabela 5.21 - Média e desvio padrão do método de mapeamento com formação

\begin{tabular}{cccc}
\hline Ambiente & Integração de mapas & Média $(\mu)$ & Desvio Padrão $(\sigma)$ \\
\hline \multirow{2}{*}{$A M B_{F}$} & Sim & 0.53 & 0.04 \\
& Não & 0.36 & 0.03 \\
\hline \multirow{2}{*}{$A M B_{G}$} & Sim & 0.50 & 0.07 \\
& Não & 0.33 & 0.05 \\
\hline
\end{tabular}

Como pode ser observado pelos resultados apresentados, o mapeamento com formação empregando o método de integração de mapas proposto possui um desempenho melhor do que sua contrapartida sem a integração, para ambos os ambientes. Vale notar também que uma vez que os robôs realizam o processo de exploração adotando uma determinada formação, os mesmos não se dispersam no ambiente e, consequentemente, a média da porcentagem de exploração do ambiente atinge um valor não muito expressivo, ligeiramente superior a $50 \%$ no melhor caso.

Uma importante característica observada nos experimentos em questão foi que os mesmos apresentaram o mesmo comportamento descrito nas simulações realizadas por Calvo (CALVO, 2012). Inicialmente, uma vez que os robôs estavam próximos uns dos outros e distantes de seus respectivos centroides, notou-se que os mesmos tenderam a se dispersar até 
estabelecerem uma estrutura de formação. A partir do momento em que a formação foi estabelecida, a mesma foi mantida até que o líder do grupo de robôs atingiu o corredor que liga as duas salas do ambiente. Durante o tempo no qual o grupo de robôs atravessa o corredor, a topologia da formação foi reorganizada autonomamente, permitindo que o grupo se locomovesse sem colisões. Saindo do corredor, o grupo encontrou novamente uma área ampla e, devido novamente às forças de atração dos centroides, foram impulsionados a se dispersarem em uma nova formação, maximizando a área de cobertura de sensoriamento do grupo.

Deve-se lembrar de que na estratégia SAFS, os robôs detectam a cada instante seus vizinhos adjacentes, construindo constantemente as células de Voronoi correspondentes à topologia da formação e computando seus respectivos centroides. Se um robô está longe de seu centroide, então o mesmo está próximo ao limite de fronteira de sua célula. Isto significa que existe um risco de colisão e, neste caso, a força de atração exercida por seu centroide é maior. À medida que um robô se aproxima de seu centroide, a intensidade de tal força diminui gradativamente, de modo que o estado de equilíbrio é atingido no instante em que todos os robôs estão extremamente próximos de seus respectivos centroides.

\subsection{CONSIDERAÇÕES PARCIAIS}

Analisando a tarefa de mapeamento, uma importante vantagem do método proposto neste trabalho, comparado ao modelo de compartilhamento proposto por Tan et al. (TAN et al., 2004), é a capacidade que o mesmo possui de mapear o ambiente. Uma vez que o modelo descrito em (TAN et al., 2004) lida apenas com o problema de cobertura, o mesmo não constrói um mapa que representa o ambiente no qual os robôs estão inseridos. Além disso, é importante salientar que a capacidade de sensoriamento do ambiente em (TAN et al., 2004) depende fortemente do número de robôs empregados e do raio de comunicação entre os mesmos, de modo que não há garantia de que todo o ambiente é explorado. Em contrapartida, uma vez que o método proposto de mapeamento utiliza o IAS-SS como estratégia de exploração é possível esperar que o mesmo seja capaz de explorar o ambiente por completo, desde que iterações suficientes sejam empregadas pela estratégia de exploração.

Uma segunda diferença entre tais propostas é o fato de que o sistema com múltiplos robôs elucidado em (TAN et al., 2004) é testado apenas em ambientes sem obstáculos, tornando a tarefa de navegação mais simples. Na abordagem proposta nesta tese cada 
ambiente é divido em salas, de maneira que a movimentação dos robôs é limitada pelas paredes que separam as salas, tornando os experimentos realizados mais realísticos e próximos às aplicações em ambientes reais.

Outra importante vantagem da abordagem proposta é a capacidade de mapeamento contínuo do ambiente. A estratégia IAS-SS garante que o ambiente é continuamente explorado segundo os estímulos de feromônios detectados pelos robôs nas áreas visitadas pelos mesmos. Uma vez que o ambiente é periodicamente explorado, os mapas gerados pelos robôs são constantemente atualizados e qualquer mudança na estrutura do ambiente pode ser reconhecida e compartilhada com os demais robôs pertencentes ao sistema de exploração e vigilância.

Considerando o número de robôs empregados no processo de exploração, deve-se notar que quanto maior a quantidade de robôs utilizada maior é a área do ambiente mapeada pelo método proposto em um mesmo intervalo de tempo. Contudo, é importante observar que devido ao comportamento do IAS-SS mesmo que um único robô seja utilizado na tarefa de exploração, o mesmo ainda é capaz de mapear completamente um ambiente qualquer, desde que iterações suficientes sejam destinadas ao processo de exploração. De modo geral observase que o tempo necessário para se mapear uma determinada área diminui à medida que o número de robôs aumenta, ocasionando uma maior troca de informações entre os mesmos.

Analisando-se os resultados obtidos com o presente trabalho em relação aos resultados apresentados por Calvo et al. (CALVO et al., 2011a; CALVO et al., 2011b; CALVO et al., 2011c;), referentes ao desempenho da estratégia IAS-SS, deve-se salientar a melhor eficiência do método AEE como mecanismo de ajuste na direção de movimento dos robôs. Assim como nos trabalhos dos referidos autores, o método AEE também atingiu um desempenho superior do que os demais métodos analisados - AE e estratégia uniforme - contribuindo desta forma para validação do IAS-SS (AEE) como estratégia de exploração e vigilância de ambientes internos.

Um problema relevante detectado na área de mapeamento autônomo por meio de robôs móveis é a falta de métricas bem definidas para comparação com os demais métodos encontrados na literatura. De modo geral, tais métodos são avaliados considerando-se apenas a geração dos mapas em si, ou nos melhores casos, analisando-se medidas de desempenho inerentes à própria abordagem de mapeamento proposta. Uma interessante métrica aplicável a qualquer abordagem de mapeamento é a apresentada por Liu e Ma (LIU; MA., 2009), que define a porcentagem de exploração do ambiente e, consequentemente, de mapeamento do 
mesmo. Sendo assim, é interessante discutir os resultados obtidos por Liu e Ma em seu respectivo trabalho.

A abordagem proposta por Liu e Ma (LIU; MA, 2009), baseada em algoritmos de otimização por enxame de partículas e curvas de Hilbert, foi desenvolvida para mapas configurados em planos de coordenadas de dimensão 400 X 400, divididos em 16 subregiões. Nos experimentos realizados pelos autores em questão, foram empregados três robôs durante um processo de mapeamento com 3500 iterações. Na abordagem de Liu e Ma, um método de exploração aleatória baseado em curvas $S$-shaped é comparado com o algoritmo baseado em PSO e curvas de Hilbert proposto pelos autores. As porcentagens de exploração do ambiente utilizando o método de exploração aleatório e o algoritmo baseado no PSO/curvas de Hilbert foram aproximadamente de $30 \%$ e $70 \%$, respectivamente. Considerando os resultados reportados na presente tese de doutorado, o método de mapeamento proposto apresentou um desempenho superior em relação ao algoritmo proposto por Liu e Ma, atingindo em alguns casos médias de desempenho superiores a $90 \%$.

Uma importante observação a ser levada em consideração na comparação das duas abordagens é notar que cada sub-região do algoritmo proposto por Liu e Ma corresponde a $6,25 \%$ do tamanho total do ambiente. Enquanto que, cada setor do método de mapeamento proposto neste trabalho equivale aproximadamente a $4,16 \%$ da dimensão total do ambiente, considerando-se a divisão do ambiente mais comum realizada nas simulações executadas, ou seja, a divisão em 24 setores. Além disso, deve-se salientar também que há uma diferença significativa na estrutura dos ambientes utilizados em cada abordagem. Os ambientes empregados em (LIU; MA, 2009) são menos complexos do que aqueles utilizados no presente trabalho, uma vez que os ambientes simulados por Liu e Ma são formados por uma pequena quantidade de obstáculos dispostos em uma ampla área livre. 
Neste trabalho foi proposto um novo método de integração de mapas locais baseado em observações inter-robôs, considerando como estratégia de exploração de ambientes internos a abordagem elucidada por Calvo et al. (CALVO et al., 2011a; CALVO et al., 2011b; CALVO et al., 2011c), denominado Sistema de Vigilância baseado na Modificação do Sistema Colônias de Formigas (IAS-SS). No método proposto, a integração de mapas locais é realizada por meio de uma modificação do modelo de compartilhamento de informações proposto por Tan et al. (TAN et al., 2004), tornando o mesmo invariante em relação ao tempo por meio da alteração da centralização do sistema de coordenadas de cada robô. No método proposto, os sistemas de coordenadas dos robôs são centralizados nas respectivas posições iniciais de cada robô. Uma vez que os mesmos não possuem conhecimento prévio acerca do ambiente no qual estão inseridos, a posição inicial de todos os robôs é definida como a coordenada $(0,0)$ e orientação $0^{\circ}$ de seu próprio sistema de coordenadas.

O processo de integração de mapas é definido por meio de matrizes de transformação de sistemas de coordenadas, representadas pela distância entre pares de robôs e suas respectivas posições relativas. As contribuições do método proposto são: (1) extensão do modelo de compartilhamento de informação elucidado em (TAN et al., 2004), tornando-o capaz de transmitir mapas do ambiente entre os robôs de modo construtivo; (2) inserção de informações espaciais no sistema de exploração e vigilância IAS-SS; e (3) criação de uma abordagem baseada em feromônios virtuais para aplicações do IAS-SS em ambientes reais, 
sem a necessidade de sensores físicos para liberação e detecção de substâncias químicas, por meio da integração de mapas locais de feromônio. Os resultados obtidos com o desenvolvimento da presente tese foram publicados em fóruns nacionais e internacionais por meio de artigos científicos, a saber:

- CAlvo, R.; OliVEIRA, J. R.; FIGUEIREDO, M.; ROMERO, R. A. F.. Uma estratégia de coordenação distribuída e bio-inspirada para sistema multiagentes aplicada à tarefa de vigilância de ambientes desconhecidos. X Congresso Brasileiro de Inteligência Computacional (CBIC), Fortaleza/CE - Brasil, p. 1 - 9, 2011.

- CAlvo, R.; OliveirA, J. R.; FIGUEIREDO, M.; ROMERO, R. A. F.. A distributed, bio-inspired coordination strategy for multiple agent systems applied to surveillance tasks in unknown environments. International Joint Conference on Neural Networks (IJCNN), San Jose/CA - USA, Proceedings of IJCNN 2011. Los Alamos: IEEE Press, p. 3248 - 3255, 2011.

- CAlvo, R.; OliveirA, J. R.; FIGUEIREDO, M.; ROMERO, R. A. F.. Inverse ACO applied for unknown environment exploration. The Third International Conference on Advanced Cognitive Technologies and Applications (COGNITIVE), Rome - Italy, Proceedings of COGNITIVE 2011, p. 142 - 147, 2011.

- CAlVO, R.; OllVEIRA, J. R.; FIGUEIREDO, M.; ROMERO, R. A. F.. Bio-inspired coordination of multiple robots systems and stigmergy mechanisms to cooperative exploration and surveillance tasks. IEEE International Conference on Cybernetics and Intelligent Systems and on Robotics, Automation and Mechatronics (CISRAM), Qingdao - China, Proceedings of CIS-RAM 2011, p. 223 - 228, 2011.

- CAlVO, R.; OliveirA, J. R.; FIGUEIREDO, M.; ROMERO, R. A. F.. A bioinspired coordination strategy for controlling of multiple robots in surveillance tasks. International Journal on Advances in Software, vol. 5, p. 146 - 165, 2012.

- OllVEIRA, J. R.; CALVO, R.; ROMERO, R. A. F.. Estratégia de formação autoadaptativa baseada em uma modificação do algoritmo ACO. XI Congresso Brasileiro de Inteligência Computacional (CBIC), Porto de Galinhas/Pernambuco - Brasil, p. $1-6,2013$. 
- OliVEIRA, J. R.; CALVO, R.; ROMERO, R. A. F.. Robotic mapping using a distributed and bio-inspired coordination. Journal of Intelligent and Robotic Systems, 2013. (Submitted)

Uma série de experimentos em simulação foi realizada para analisar o desempenho do método proposto, sendo este avaliado segundo os seguintes fatores: (1) influência de três métodos distintos no processo de ajuste na direção de movimento dos robôs, considerando os estímulos provenientes das concentrações de feromônio; (2) diferentes estruturas físicas para os ambientes simulados; (3) variações no alcance do raio de comunicação entre os robôs; (4) variações no parâmetro que define o intervalo mínimo entre dois processos de integração consecutivos de um mesmo par de robôs; (5) o emprego de diferentes quantidades de robôs para se mapear um ambiente com área constante e tempo de exploração também constante; (6) variações no tamanho do ambiente simulado; (7) comparação do método de mapeamento com integração de dados com a abordagem de mapeamento topológico Thinning, baseada em algoritmos de esqueletização de imagens; (8) eficiência do processo de exploração quando se é aplicada também a integração dos mapas locais de feromônio de cada robô, gerando assim uma abordagem de navegação baseada em feromônios virtuais; e (9) eficiência do mapeamento quando este é realizado em aplicações nas quais os robôs devem manter uma determinada organização espacial, denominada formação, empregando-se para tal a estratégia SAFS proposta por Calvo (CALVO, 2012). Uma importante consideração a ser destacada sobre os experimentos é salientar que os mesmos demandaram um esforço de tempo substancial, uma vez que cada simulação exigia um tempo aproximado de 90 minutos e que cada configuração dos experimentos foi simulada 10 vezes. A realização total de todos os experimentos descritos no presente trabalho demandou um tempo aproximado de 1000 horas de simulação.

Os experimentos realizados demonstraram que o método de mapeamento proposto com integração de mapas locais apresentou um desempenho expressivo, principalmente quando comparado ao mapeamento sem integração de dados. Além disso, mesmo quando comparado com outra abordagem de mapeamento - técnica Thinning - o método proposto apresentou uma eficiência superior. É importante salientar que os desempenhos analisados se referem à porcentagem de exploração e mapeamento do ambiente, representada pela relação da área denotada no mapa de cada robô e a área total do ambiente. 
Um conjunto específico de experimentos que merece destaque foi a validação da abordagem de exploração baseada no conceito de feromônios virtuais, comprovando assim a eficácia do método de integração de mapas conjuntamente com o IAS-SS para aplicações em ambientes reais. Nesta abordagem cada robô constrói seu próprio mapa local de feromônio e o mesmo é integrado com os mapas dos demais robôs quando as restrições do método de integração são satisfeitas, eliminando a necessidade de sensores físicos reais.

Analisando-se o desempenho do método de mapeamento com integração de dados proposto em relação aos demais trabalhos encontrados na literatura, notou-se a falta de métricas bem definidas para uma comparação adequada. Entretanto, uma análise viável foi realizada em relação ao trabalho elucidado por Liu e Ma (LIU; MA, 2009), uma vez que ambos os trabalhos apresentam métricas de desempenhos similares. Nesta análise, o método proposto neste trabalho se mostrou superior em relação ao desempenho obtido com a aplicação da técnica de Liu e Ma (LIU; MA, 2009). Contudo, deve-se salientar que tal comparação foi realizada considerando-se apenas os resultados apresentados no artigo dos referidos autores.

Por fim, uma importante observação a ser considerada é notar que embora a abordagem proposta de mapeamento com integração de dados apresente um desempenho significante, o trabalho apresentado nesta tese de doutorado ainda apresenta limitações importantes. Dentre tais limitações, deve-se destacar: (1) falta de um protocolo de comunicação adequado, uma vez que o foco do presente trabalho é o processo de mapeamento em si, se assumiu para critérios de simplificação que a comunicação entre os robôs ocorre de forma ideal. Contudo, para aplicações envolvendo robôs reais, um protocolo de comunicação apropriado e uma política para tratar erros durante a comunicação precisam ser devidamente abordados; (2) durante as etapas de rotação e translação dos mapas locais no processo de integração se considerou que os robôs possuíam dados precisos de distância e orientação relativa entre os mesmos. Tal característica não deteriora o desempenho dos resultados obtidos com a presente proposta, contudo, em um ambiente real, esta característica poderia afetar de forma relevante a qualidade dos mapas gerados por meio da integração, dependendo dos possíveis ruídos detectados na distância relativa entre pares de robôs; e (3) os mapas métricos baseados em grades de ocupação foram escolhidos para serem integrados, pois os mesmos são representações bem definidas e reconhecidas na literatura, porém se deve ter em mente, como discutido no Capítulo 2, que os mesmos possuem um custo computacional 
elevado. Sendo assim, a eficácia do método proposto de mapeamento com integração de dados ainda precisa ser validada em plataformas com recursos computacionais limitados.

Além das limitações da proposta é importante ressaltar também algumas vantagens observadas com a aplicação da mesma, sendo estas: (1) o mapeamento dinâmico e contínuo do ambiente proveniente da colaboração do método de mapeamento proposto com o IAS-SS. Uma vez que a estratégia IAS-SS garante que o ambiente é continuamente explorado, baseando-se nos estímulos provocados pela detecção das concentrações de feromônio, observa-se que o ambiente é periodicamente explorado, de maneira que os mapas construídos pelos robôs são constantemente atualizados e qualquer mudança na estrutura do ambiente é reconhecida e compartilhada entre os mesmos; (2) extensibilidade do método de mapeamento proposto com integração de dados. É importante observar que embora se tenha utilizado mapas baseados em grades de ocupação para o processo de integração, a metodologia proveniente de tal modelo de compartilhamento de mapas não se limita apenas a tais representações, podendo ser adaptada a diferentes tipos de mapas, desde que estes empreguem representações espaciais baseadas em sistemas de coordenadas.

\subsection{TRABALHOS FUTUROS}

Como trabalhos futuros pretende-se realizar uma série de desenvolvimentos que visam adequar o sistema de exploração e vigilância IAS-SS com o método de mapeamento proposto de integração de dados para aplicações em ambientes reais. Uma vez que a abordagem de feromônios virtuais foi proposta e validada no presente trabalho, um fator crucial que ainda necessita ser abordado no sistema em questão é a implementação de uma técnica de localização autônoma para os robôs móveis.

Nos experimentos realizados até então as localizações dos robôs nos ambientes simulados são obtidas diretamente da plataforma Player/Stage sem o emprego de um método apropriado. Embora o sistema não possua uma técnica de localização, diversos trabalhos na

literatura abordam o problema em questão. Sendo assim, pretende-se realizar um levantamento das melhores técnicas de localização, visando selecionar e desenvolver aquelas mais adequadas para o sistema de exploração e vigilância.

Deve-se notar que o método de localização a ser desenvolvido terá um impacto significante na qualidade dos mapas gerados, tanto naqueles obtidos diretamente com os 
sensores dos próprios robôs quanto nos obtidos considerando o processo de integração. Prevendo o impacto negativo inerente a um método de localização naturalmente não preciso, aliado aos possíveis ruídos detectados na distância relativa entre pares de robôs quando o sistema for aplicado em ambientes reais, pretende-se também estudar uma abordagem híbrida de integração de mapas locais, baseada tanto nas observações inter-robôs quanto no alinhamento de landmarks presentes no ambiente.

$\mathrm{Na}$ abordagem híbrida em questão, os robôs deverão realizar o processo de integração de mapas locais inicialmente tal como descrito no presente trabalho. Uma vez que é esperado que ocorra um desalinhamento nas representações espaciais dos mapas, uma segunda etapa para ajuste do alinhamento deverá ser realizada. Tal etapa corresponderá ao alinhamento de landmarks representados pelas linhas topológicas obtidas com o método Thinning.

Deve-se notar que mesmo que ocorram variações nas representações espaciais dos mapas, devido tanto ao método de localização empregado quanto aos ruídos inerentes ao mesmo, a relação das linhas topológicas aos obstáculos presentes no ambiente não se altera e, portanto, pode ser utilizada para ajustar o alinhamento entre dois mapas locais. Uma vez que este alinhamento será executado após o processo de integração de mapas proposto, espera-se que o custo computacional do alinhamento dos landmarks seja reduzido, uma vez que não será necessário identificar todos os possíveis alinhamentos entre pares ou conjuntos de landmarks, concentrando o cálculo do ajuste necessário para o alinhamento apenas na área compreendida dentro do raio de comunicação formado por um par de robôs qualquer.

Por fim, pretende-se realizar também um estudo mais aprofundado do desempenho do mapeamento com integração de dados quando o mesmo é aplicado em sistemas multirobóticos em formação. Avaliando-se a capacidade da estratégia SAFS em mudar de líder e de se dividir em subgrupos. Resultados preliminares demonstraram que a estratégia suporta adaptações na topologia do grupo causadas pelas mudanças de direção de movimento dos robôs e pela divisão do grupo. Sendo assim, visa-se definir uma política de compartilhamento de informações mais adequada e pertinente para a estratégia em questão.

Nos experimentos realizados no presente trabalho, adotou-se a política de que os robôs integrariam seus mapas locais apenas com seus vizinhos adjacentes, localizados dentro de seus respectivos raios de comunicação. Outras políticas que poderiam ser definidas são, por exemplo: permitir o compartilhamento de dados apenas entre líderes de grupos diferentes de robôs ou apenas entre um líder e seus respectivos seguidores. 
Nos cenários envolvendo a abordagem líder-seguidor, outros pontos interessantes podem ser estudados, como o compartilhamento seletivo da informação, permitindo que apenas um determinado tipo de dado seja compartilhado entre tipos pré-definidos de robôs. Neste cenário, pode-se definir, por exemplo, a seguinte política de integração: permitir a integração de dados espaciais apenas entre líderes de grupos distintos, concentrando assim o processamento da integração em determinados agentes do sistema distribuído, e realizar a integração de dados de feromônio entre todos os robôs, independentemente se os mesmos são líderes ou seguidores, uma vez que tais informações são empregadas por todos os robôs como critérios de navegação. 
Capítulo 6-Conclusões Finais 
AMIGONI, F.; GASPARINI, S.; GINI, M.. Building segment-based maps without pose information. Proceedings of IEEE, vol. 94 (7), p. 1340 - 1359, 2006.

AMIGONI, F.; GASPARINI, S.. Analysis of methods for reducing line segments in maps: Towards a general approach. 2008 IEEE/RSJ International Conference on Intelligent Robots and Systems, p. 2896 - 2901, 2008.

ANDERSON, L. A. A.; NYGARDS, J.. On multi-robot map fusion by inter-robot observations. In $\mathbf{1 2}^{\text {th }}$ International Conference on Information Fusion, p. 1712 - 1721, 2009.

ANDREASSON, H.; TREPTOW, A.; DUCKETT, T.. Self-localization in non-stationary environments using omni-directional vision. Robotics and Autonomous Systems, vol. 55, p. $541-551,2007$.

AVOTS, D.; LIM, E.; THIBAUX, R.; THRUN, S.. A probabilistic technique for simultaneous localization and door state estimation with mobile robots in dynamic environments. Proceedings of the Conference on Intelligent Robots and Systems. IROS, 2002.

BARNES, L.; ALVIS, W.; FIELDS, A.; VALANIS, K.; MORENO, W.. Swarm formation control with Potential Fields formed by bivariate normal functions. $14^{\text {th }}$ Mediterranean Conference on Control and Automation, p. 1 - 7, 2006.

BAXES, G. A.. Digital Image Processing. John Wiley \& Sons, 1994.

BIRK, A.; CARPIN, S. Merging occupancy grid maps from multiple robots.. In Proceedings of the IEEE, vol. 94 (7), p. 1384 - 1397, 2006.

BISWAS, R.; LIMKETKAI, B.; SANNER, S.; THRUN, S.. Towards object mapping in dynamic environments with mobile robots. Proceedings of the Conference on Intelligent Robots and System. IROS, 2002.

\footnotetext{
${ }^{1}$ De acordo com a Associação Brasileira de Normas Técnicas. NBR 6023.
} 
BLANCO, J. L.; FERNÁNDEZ-MADRIGAL, J. -A.; GONZÁLEZ, J.. Toward a unified Bayesian approach to hybrid metric-topological SLAM. IEEE Transactions on Robotics, vol. 24 (2), p. $259-270,2008$.

BLANCO, J. L.; GONZÁLEZ, J.; FERNÁNDEZ-MADRIGAL, J.-A.. Subjective local maps for hybrid metric-topological SLAM. Robotics and Autonomous Systems, vol. 57, p. 64 74, 2009.

BLANCO, J. L.; GONZÁLEZ, J.; FERNÁNDEZ-MADRIGAL, J.-A.. A robust, multihypothesis approach to matching occupancy grid maps. Robotica, vol. 31(5), p. 687 - 701, 2013.

BLODOW, N.; GORON, L. C.; MARTON, Z.; PANGERCIC, D.; RÜHR, T.; TENORTH, M.; BEETZ, M.. Autonomous semantic mapping for robots performing everyday manipulation tasks in kitchen environments. Proceedings of the IEEE/RSJ International Conference on Intelligent Robots and Systems (IROS), p. 4263 - 4270, 2011.

BOADA, B. L.; BLANCO, D.; MORENO, L.. Symbolic place recognition in Voronoi-based maps by using Hidden Markov models. Journal of Intelligent and Robotic Systems, vol. 39, p. $173-197,2004$.

BORENSTEIN, J.; KOREN, Y.. The vector field histogram - fast obstacle avoidance for mobile robots. IEEE Journal of Robotics and Automation, vol. 7(3), p. 278 - 288, 1991.

BUHMANN, J.; BURGARD, W.; CREMERS, A. B.; FOX, D.; HOFMANN, T.; SCHNEIDER, J.; STRIKOS, J.; THRUN, S.. The mobile robot Rhino. AI Magazine, vol. 16, n. $1,1995$.

BURGARD, W.; FOX, D.; HENNIG, D.; SCHMIDT, T.. Estimating the absolute position of a mobile robot using position probability grids, 1996.

BURGARD, W.; MOORS, M.; STACHNISS, C.; SCHNEIDER, F.. Coordinated multi-robot exploration. IEEE Transactions on Robotics, vol. 21 (3), p. 376 - 386, 2005.

CALVO, R.. Sistemas bio-inspirados para coordenação de múltiplos robôs móveis. Tese de doutorado, Universidade de São Paulo, 2012.

CALVO, R; OLIVEIRA, J. R.; FIGUEIREDO, M.; ROMERO, R. A. F.. A distributed, bioinspired coordination strategy for multiple agent systems applied to surveillance tasks in 
unknown environments. International Joint Conference on Neural Networks, p. 3248 3255, 2011a.

CALVO, R; OLIVEIRA, J. R.; FIGUEIREDO, M.; ROMERO, R. A. F.. Inverse ACO applied for unknown environment exploration. The Third International Conference on Advanced Cognitive Technologies and Applications, p. 142 - 147, 2011 b.

CALVO, R; OLIVEIRA, J. R.; FIGUEIREDO, M.; ROMERO, R. A. F.. Bio-inspired coordination for multiple robots systems and stigmergy mechanims to cooperative exploration and surveillance tasks. IEEE International Conference on Cybernetics and Intelligent Systems and on Robotics, Automation and Mechatronics, p. 223 - 228, 2011c.

CALVO, R; OLIVEIRA, J. R.; FIGUEIREDO, M.; ROMERO, R. A. F.. A bioinspired coordination strategy for controlling of multiple robots in surveillance tasks. International Journal on Advances in Software, vol. 5, p. 146 - 165, 2012.

CASTELLANOS, J. A.; MARTINEZ-CANTIN, R.; TARDÓS, J. D.; NEIRA, J.. Robocentric map joining: Improving the consistency of EKF-SLAM. Robotics and Autonomous Systems, vol. 55, p. $21-29,2007$.

CASTELlanOS, J. A.; TARDÓS, J. D.. Mobile robot localization and map building: A multisensor fusion approach. Kluwer Academic Publishers, Boston, MA, 2000.

CHANG, H. J.; LEE, C. S. G.; HU, Y. C.; LU, Y.. Multi-robot SLAM with topological/metric maps. In Proceedings of the 2007 IEEE/RSJ International Conference on Intelligent Robots and Systems, p. 1467 - 1472, 2007.

CHATILA, R.; LAUMOND, J. P.. Position referencing and consistent world modeling for mobile robots. Proceedings of the 1985 IEEE International Conference on Robotics and Automation, 1985.

CHOSET, H.; NAGATANI, K.. Topological simultaneous localization and mapping (SLAM): Toward exact localization without explicit localization. IEEE Transactions on Robotics and Automation, vol. 17 (2), p. 125 - 137, 2001.

CHU, H.; GLAD, A.; SIMONIN O.; SEMP, F.; DROGOUL, A.; CHARPILLET, F.. Swarm approaches for the patrolling problem, information propagation vs. pheromone evaporation. Proceedings of the $19^{\text {th }}$ IEEE International Conference on Tools with Artificial Intelligence, p. $442-449,2007$. 
COBANO, J. A.; ESTREMERA, J.; GONZALEZ DE SANTOS, P.. Location of legged robots in outdoor environments. Robotics and Autonomous Systems, vol. 56, p. 751 - 761, 2008.

DE BERG, M.; CHEONG, O.; VAN KREVELD, M.; OVERMARS, M.. Computational Geometry: Algorithms and Applications. Springer-Verlag, $3^{\text {rd }}$ edition, 2008.

DELLAERT, F.; SEITZ, S. M.; THORPE, C.; THRUN, S.. EM, MCMC, and chain flipping for structure from motion with unknown correspondence. Machine Learning, 2000.

DISSANAYAKE, G.; NEWMAN, P.; CLARK, S.; DURRANT-WHYTE, H. F.; CSORBA, M.. A solution to the simultaneous localization and map building (SLAM) problem. IEEE Transactions of Robotics and Automation, 2001.

DORIGO, M.. Optimization, learning and natural algorithms. $\mathrm{PhD}$ thesis, Dipartimento di Eletronica, Politecnico di Milano, 1992.

DUDEK, G.; JENKIN, M.; MILIOS, E.; WILKES, D.. A taxonomy for multi-agent robotics. Autonomous Robots, vol. 3, p. 375 - 397, 1996.

ELFES, A.. Occupancy Grids: A probabilistic framework for robot perception and navigation. $\mathrm{PhD}$ thesis, Carnegie Mellon University, 1989a.

ELFES, A.. Using occupancy grid for mobile robot perception and navigation. IEEE Computer Magazine, vol. 22(6), p. 46 - 57, 1989 b.

ELFES, A.. A tessalated probabilistic representation for spatial robot perception. Proc. 1989 NASA Conf. on Space Telerobotics, NASA/Jet Propulsion Laboratory, California Institute of Technology, 1989c.

FERRI, G.; JAKUBA, M. V.; MONDINI, A.; MATOLLI, V.; MAZZOLAI, B.; YOERGER, D. R.; DARIO, P.. Mapping multiple gas/odor sources in an uncontrolled indoor environment using a Bayesian occupancy grid mapping based method. Robotics and Autonomous Systems, vol. 59(11), p. 988 - 1000, 2011.

FREEMAN, R. A.; YANG, P.; LYNCH, K. M.. Distributed estimation and control of swarm formation statistics. American Control Conference, vol. 7, p. 749 - 755, 2006.

FUJII, M.; INAMURA, W.; MURAKAMI, H.; TANAKA, K.; KOSUGE, K.. Cooperative control of multiple mobile robots transporting a single object with loose handling. Robotics and Biomimetics, p. $816-822,2007$. 
GAGE, D. W.. Command control for many-robot systems. Naval Command Control and Ocean Surveillance Center RDT and DIV, Sao Diego/CA., 1992.

GALINDO, C.; FERNÁNDEZ-MADRIGAL, J. A.; GONZÁLEZ, J.; SAFFIOTTI, A.. Robot task planning using semantic maps. Robotics and Autonomous System, vol. 56(11), p. 955 966, 2008.

GIFFORD, C. M.; WEBB, R.; BLEY, J.; LEUNG, D.; CALNON, M.; MAKAREWICZ, J.; BANZ, B.; AGAH, A.. Low-cost multi-robot exploration and mapping. IEEE International Conference on Technologies for Practical Robot Applications, p. 74 - 79, 2008.

GOERKE, N.; BRAUN, SVEN.. Building semantic maps by mobile robots. Proceedings of TAROS 2009: Towards Autonomous Robotic Systems, p. 149 - 156, 2009.

GRISETTI, G.; TIPALDI, G. D.; STACHNISS, C.; BURGARD, W.; NARDI, D.. Fast and accurate SLAM with Rao-Blackwellized particle filters. Robotics and Autonomous Systems, vol. 55, p. $30-38,2007$.

GUIBAS, L.; STOLFI, J.. Primitives for the manipulation of general subdivisions and the computation of Voronoi. ACM Trans. Graph., vol. 4(2), p. 74 - 123, 1985.

HOWARD, A.. Multi-robot simultaneous localization and mapping using particle filters. Robotics: Science and Systems, p. 201 - 208, 2005.

JIANG, Q.. An improves algorithm for coordination control of multi-agent system based on rlimited voronoi partitions. IEEE International Conference on Automation Science and Engineering, p. $667-671,2006$.

KALLMANN, M.; BIEIRI, H.; THALMANN, D.; TRIANGULATIONS, D.; POPULAR, C. D. T. A.. Fully dynamic constrained Delaunay triangulations. 2003.

KALRA, N.; FERGUSON, D.; STENTZ, A.. Incremental reconstruction of generalized Voronoi diagrams on grids. Robotics and Autonomous Systems, vol. 57, p. 123-128, 2009.

KIM, C.; SAKTHIVEL, R.; CHUNG, W. K.. Unscented FastSLAM: A robust and efficient solution to the SLAM problem. IEEE Transactions on Robotics, vol. 24 (4), p. 808 - 820, 2008. 
KO, B. Y.; SONG, J. B.; LEE, S.. Real-time building of thinning-based topological map with metric Features. In Proceedings of International Conference on Intelligent Robots and Systems, p. $1524-1529,2004$.

KOBAYASHI, F.; TOMITA, N.; KOJIMA, F.. Re-formation of mobile robots using genetic algorithm and reinforcement learning. SICE 2003 Annual Conference, vol. 3, p. 2902 2907, 2003.

KOOTSTRA, G.; BOER, B.. Tackling the premature convergence problem in Monte-Carlo localization. Robotics and Autonomous Systems, vol. 57, p. 1107 - 1118, 2009.

KORTENKAMP, D.; WEYMOUTH, T.. Topological mapping for mobile robots using a combination of sonar and vision sensing. In Proceedings of the Twelfth National Conference on Artificial Intelligence. AAAI - IAAI / MIT Press, p. 979 - 984, 1994.

KÖSE, H.; AKIN, H. L.. The Reverse Monte Carlo localization algorithm. Robotics and Autonomous Systems, vol. 55, p. 480 - 489, 2007.

KWON, T.; YANG, J.; SONG, J.; CHUNG, W.. Efficiency improvement in Monte Carlo localization through topological information. In 2006 IEEE/RSJ IROS - International Conference on Intelligent Robots and Systems, p. 424 - 429, 2006.

LEE, D.; CHUNG, W.. Discrete-status-based localization for indoor service robots. IEEE Transactions on Industrial Electronics, vol. 53(5), p. 1737 - 1746, 2006.

LEE, M.; TAROKH, M.; CROSS, M.. Fuzzy logic decision making for multi-robot security systems. Artificial Intelligence Review, vol. 34, p. 177 - 194, 2010.

LI, P.; HUANG, X.; WANG, M.; ZENG, X.. Multiple mobile robots map building based on DSmT. Robotics, Automation and Mechatronics, p. 509 - 514, 2008.

LILIENTHAL, A.; DUCKETT, T.. Building gas concentration gridmaps with a mobile robot. Robotics and Autonomous Systems, vol. 48, p. 3 - 16, 2004.

LIU, C.; MA, Y.. Cooperative multi-robot map-building under unknown environment. In 2009 International Conference on Artificial Intelligence and Computational Intelligence, p. $392-396,2009$. 
LIU, Y.; EMERY, R.; CHAKRABERTI, D.; BURGARD, W.; THRUN, S.. Using EM to learn 3D models with mobile robots. Proceedings of the International Conference on Machine Learning, 2001.

MATARIĆ, M. J.. Interaction and intelligent behavior. Technical Report AI-TR-1495, Massachusetts Institute of Technology, Artificial Intelligence Laboratory, Cambridge, MA, 1994.

MENEGATTI, E.; PRETTO, A.; SCARPA, A.; PAGELLO., E. Omnidirectional vision scan matching for robot localization in dynamic environments. IEEE Transactions on Robotics, vol. 22 (3), p. $523-535,2006$.

MORAVEC, H. P.. Sensor fusion in certainty grids for mobile robots. AI Magazine, p. 61 $74,1988$.

MULLANE, J.; ADAMS, M. D.; WIJESOMA, W. S.. Robotic mapping using measurement likelihood filtering. The International Journal of Robotics Research, vol. 28, p. 172 - 190, 2009.

MURPHY, R. R.. Introduction to AI robotics. MIT Press, 2000.

NAGLA, K. S.; UDDIN, M.; SINGH, D.. Improved occupancy grid mapping in specular environment. Robotics and Autonomous Systems, vol. 60(10), p. 1245 - 1252, 2012.

NEWMAN, P.. On the structure and solution of the simultaneous localization and map building problem. PhD thesis, Australian Centre for Field Robotics, University of Sydney, Australia, 2000.

NOYKOV, S.; ROUMENIN, C.. Occupancy grids building by sonar and mobile robot. Robotics and Autonomous Systems, vol. 55, p. 162 - 175, 2007.

OLIVEIRA, J. R.; ROMERO, R. A. F.. Image skeletonization method applied to generation of topological maps. In Proceedings of Latin American Robotics Symposium, Valparaiso/Chile, 2009.

OLIVEIRA, J. R.; FILHO, E. A. S.; ROMERO, R. A. F.. Mathematical morphology filters applied to an image sketonization method to generation of topological maps. In Proceedings of International Conference on Computer Sciences and Converge Information Technology, Seoul/Korea, 2009. 
OLSON, C. F. Probabilistic self-localization for mobile robots.. IEEE Transactions On Robotics And Automation, vol. 16(1), p. 55 - 66, 2000.

PARTRIDGE, B. L.. The structure and function of fish schools. Scientific American, vol. 246, n. 6, p. $114-123,1982$.

POTA, H.; EATON, R.;; KATUPITIYA, J.; PATHIRANA, S.. Agricultural robotics: A streamlined approach to realization of autonomous farming. Industrial and Information Systems, p. $85-90,2007$.

RAWLINSON, D.; JARVIS, R.. Topologically-directed navigation. Robotica, vol. 26, p. 189 $-203,2008 \mathrm{a}$.

RAWLINSON, D.; JARVIS, R.. Ways to tell robots where to go - Directing autonomous robots using topological instructions. IEEE Robotics \& Automation Magazine, p. 27 - 36, 2008 b.

RIZZINI, D. L.; CASELLI, S.. Metric-topological maps from laser scans adjusted with incremental tree network optimizer. Robotics and Autonomous Systems, vol. 57, p. 1036 1041, 2009.

RODRÍGUEZ, A. B.; RAMIREZ, A. R. G.; DE PIERI, E. R.; LOPEZ, A. L.; ALBORNOZ, A. D. C.. An approach for robot-based odor navigation. Journal of Medical and Biological Engineering, vol. 32(6), p. $453-456,2012$.

ROQUE, W. L.; DOERING, D.. Trajectory planning for lab robots based on global vision and Voronoi roadmaps. Robotica, vol. 23, p. 467 - 477, 2005.

SANTANA, A. M.; AIRES, K. R. T.; VERAS, R. M. S.; MEDEIROS, A. A. D.. An approach for 2D visual occupancy grid map using monocular vision. Eletronic Notes in Theoretical Computer Science, vol. 281, p. 175 - 191, 2011.

SHATKAY, H.; KAELBLING, L.. Learning topological maps with weak local odometric information. Proceedings of IJCAI 97, 1997.

SHEWCHUCK, J. R.. Delaunay refinement mesh generation. Master's thesis, School of Computer Science, Computer Science Department, Carnegie Mellon University, 1997. 
SIMMONS, R.; KOENIG, S.. Probabilistic robot navigation in partially observable environments. Proceedings of the International Joint Conference on Artificial Intelligence (IJCAI-95), Montreal/Canada, p. 1080 - 1087, 1995.

SMITHERS, T.. Autonomy in robots and others agents. Brain and Cognition, vol. 34, p. 88 $-106,1997$.

SPACEK, L.; BURBRIDGE, C.. Instantaneous robot self-localization and motion estimation with omnidirectional vision. Robotics and Autonomous Systems, vol. 55, p. 667 - 674, 2007.

TAN, J.; XI, N.; SHENG, W.; XIAO, J.. Modeling multiple robot systems for area coverage and cooperation. Proceedings of the 2004 IEEE International Conference on Robotics and Automation, p. 2568 - 2573, 2004.

THRUN, S.. Learning metric-topological maps for indoor mobile robot navigation. Artificial Intelligence, vol. 99, p. $21-71,1998$.

THRUN, S.. A probabilistic online mapping algorithm for teams of mobile robots. International Journal of Robotics Research, vol. 20, n. 5, p. 335 - 363, 2001.

THRUN, S.. Robotic mapping: A survey. Carnegie Mellon University, CMU-CS-02-111, 2002.

THRUN, S.; BÜCKEN, A.. Integrating grid-based and topological maps for mobile robot navigation. In Proceedings of the Thirteenth National Conference on Artificial Intelligence, 1996.

THRUN, S.; BEETZ, M.; BENNEWITZ, M.; BURGARD, W.; CREMERS, A. B.; DELlAERT, F.; FOX, D.; HAHNEL, D.; ROSENBERG, C.; ROY, N.; SCHULTE, J.; SCHULZ, D.. Probabilistic algorithms and the interactive museum tour-guide robot Minerva. International Journal of Robotics Research, vol. 19, n. 11; p. 972 - 999, 2000a.

THRUN, S.; FOX, D.; BURGARD, W.. Probabilistic robotics. Early Draft, 2000b.

THRUN, S.; FOX, D.; BURGARD, W.; DELLAERT, F.. Robust Monte Carlo Localization for mobile robots. Artificial Intelligence, vol. 128, p. 99 - 141, 2001. 
TONG, T.; YALOU, H.; JING, Y.; FENGCHI, S.. Multi-robot cooperative map building in unknown environment considering estimation uncertainy. In Control and Decision Conference, p. 2896 - 2901, 2008.

TOPAL, S.; ERKMEN, I.; ERKMEN, A. M.. A novel multirobot map fusion strategy for occupancy grid maps. Turkish Journal of Electrical Engineering and Computer Sciences, vol. 21, p. $107-119,2013$.

TOVAR, B.; MUÑOZ-GÓMEZ, L.; MURRIETA-CID, R.; ALENCASTRE-MIRANDA, M.; MONROY, R.; HUTCHINSON, S.. Planning exploration strategies for simultaneous localization and mapping. Robotics and Autonomous Systems, vol. 54, p. 314 - 331, 2006.

VIDAL-CALLEJA, T.; BERGER, C.; LACROIX, S.. Even-driven loop closure in multi-robot mapping. IEEE International Conference on Intelligent Robots and Systems, p. 1535 $1540,2009$.

VINCENT, R.; FOX, D.; KO, J.; KONOLIGE, K.; LIMKETKAI, B.; MORISSET, B.; ORTIZ, C.; SCHULZ, D.; STEWART, B.. Distributed multirobot exploration, mapping, and task allocation. Annals of Mathematics and Artificial Intelligence, vol. 52, p. 229 - 255, 2008.

ZADEH, L. A.. Fuzzy sets. Journal of Information and Control, vol. 8, p. 338 - 353, 1965.

ZHANG, Y.; XIAO, Y.. Digital pheromone based patrolling algorithm in Wireless sensor and actuator networks. The $\mathbf{1 0}^{\text {th }}$ Annual IEEE Consumer Communications and Networking Conference, p. $496-501,2013$.

ZHOU, X. S.; ROUMELIOTIS, S. I.. Multi-robot SLAM with unknown initial correspondence: The robot rendezvous case. In Proceedings of the 2006 IEEE/RSJ International Conference on Intelligent Robots and Systems, p. 1785 - 1792, 2006.

WAGNER, I. A.; LINDENBAUM, M.; BRUCKSTEIN, A. M.. Distributed covering by antrobots using evaporating traces. IEEE Transactions on Robotics and Automation, vol. 15, n. 5, p. $918-933,1999$.

WEI, Z.; HUANG, G.; WANG, P.. The research on multi-robot simultaneous localization mapping algorithm. Proceedings of the IEEE International Conference on Automation and Logistics, p. 1241 - 1247, 2007. 
WEIXING, F.; KEJUN, W.; XIUFEN, Y.; SHUXIANG, G.. Novel algorithms for coordination of underwater swarm robotics. Proceedings of IEEE Int. Conf. on Mechatronics and Automation, p. 654 - 659, 2006.

WOLF, J.; BURGARD, W.; BURKHARDT, H.. Robust vision-based localization by combining an image-retrieval system with Monte Carlo Localization. IEEE Transactions on Robotics, vol. 21(2), p. $208-216,2005$.

WU, M.; KONNO, A.; UCHIYAMA, M.. Cooperative object transportation by multiple humanoid robots. IEEE/SICE International Symposium on System Integration, p. 779 784, 2011.

YAMAUCHI, B.; LANGLEY, P.. Place recognition in dynamic environments. Journal of Robotic System, vol. 14, n. 2, p. 107 - 120, 1997.

YU, Y.; WANG, N.; LIANG, A.; GUAN, H.; LIU, L.. Integrating line segment based maps in multi-robots exploration. In Second International Conference on Future Information Technology and Management Engineering, p. 230 - 233, 2009.

YUN, X.; YI-MIN, Y.; YI-MIN, X.. Cooperative map building of multi-robot based on grey fusion. IEEE International Conference on Industrial Technology, p. 353 - 358, 2005. 
Referências Bibliográficas 